CRISTINA GIOVANNETTI DEL CONTE ZARDETTO

\title{
PREVALÊNCIA DE CÁRIE DENTÁRIA EM ADOLESCENTES RESIDENTES NO MUNICÍPIO DE SÃO PAULO: INDICADORES DE RISCO E GRAVIDADE
}


Cristina Giovannetti Del Conte Zardetto

Prevalência de cárie dentária em adolescentes residentes no Município de São Paulo: indicadores de risco e gravidade

Tese apresentada à Faculdade de Odontologia da Universidade de São Paulo, para obter o título de Doutor pelo Programa de Pós-Graduação em Odontologia.

Área de Concentração: Odontopediatria

Orientadora: Profa. Dra. Célia Regina Delgado Rodrigues

Co-orientador: Prof. Dr. Domingos Palma

São Paulo 


\section{FOLHA DE APROVAÇÃO}

Zardetto CGDC. Prevalência de cárie dentária em adolescentes residentes no município de São Paulo: indicadores de risco e gravidade [Tese de Doutorado]. São

Paulo: Faculdade de Odontologia da USP; 2004.

São Paulo, 14/12/2004

\section{Banca Examinadora}

1) $\operatorname{Prof}(a) \cdot \operatorname{Dr}(a)$.

Titulação:

Julgamento:

Assinatura:

2) $\operatorname{Prof}(a) . \operatorname{Dr}(a)$.

Titulação:

Julgamento:

Assinatura:

3) $\operatorname{Prof}(a) . \operatorname{Dr}(a)$.

Titulação:

Julgamento:

Assinatura:

4) $\operatorname{Prof}(a) . \operatorname{Dr}(a)$.

Titulação:

Julgamento:

Assinatura:

5) $\operatorname{Prof}(a) . \operatorname{Dr}(a)$.

Titulação:

Julgamento:

Assinatura: 


\title{
DFD I CA I'ÓRIA
}

A MARCO Y RAFAEL, mis angelitos, ustedes son mi grande tesoro y mi vida! ...

\begin{abstract}
AO RUY, meu grande amor, amigo, companheiro, quem sempre me apoiou, incentivou e ajudou; pela enorme felicidade de estar ao teu lado...
\end{abstract}

A PAPI y MAMI, que siempre me apoyaron, entusiasmaron, incentivaron, y sobre todo, amaron....

A TODOS VOCÊS, por existirem em minha vida e formarmos uma família.... 


\section{AGRADECIMENTOS ESPECIAIS}

Á Deus, pela vida.

Á Mami, Nélida, por ser extremamente solícita e sempre disposta a ajudar; pelo estimulante apoio; por acreditar em mim; e por ter cuidado com extremo carinho e dedicação do Marco e Rafael nos meus períodos de ausência.

À Papi, Franco, pelo apoio, estímulo e "torcida àdistância".

Ao Ruy, meu querido marido, por estar sempre ao meu lado e pelo constante apoio, estímulo, ajuda e "socorros".

Às minhas irmãs, Alessandra (Shani) e Adriana (Picho), ao meu cunhado, Tyler, a minha tia-mãe, Liliana (Tuca), a minha avó, Nonna, ao meus sogros-pais, Jurema e Francisco, pela força, carinho e estímulo.

À Denise Fernandes, por ter me ensinado a olhar para mim mesma e a vida de uma maneira mágica e fantástica. 


\section{Na USP}

À Profa. Dra. Célia Regina Martins Delgado Rodrigues, orientadora e amiga, exemplo de pesquisadora, pela confiança deposita em mim, estímulo contínuo e por sempre estar disposta a ajudar. Obrigada pelo carinho e pela força!

À Daniela Forlin, por estar sempre disposta a ajudar e pela imensa colaboração na coleta dos dados e correção final.

Ao Prof. Dr. Antônio Guedes Pinto, pela confiança deposita em mim e pelas oportunidades oferecidas.

À Profa. Dra. Marcia Pinto Alves Mayer, por Ter me despertado paro o fascínio da carreira acadêmica.

Aos colegas do curso de Doutorado, pelos bons momentos que convivemos juntos.

Ao Prof. Dr. Marcelo José Bönecker, pela revisão e sugestões deste trabalho e pelo estímulo .

Aos Professores da Odontopediatria, pelo empenho e dedicação no curso de Pós-graduação.

À Profa. Dra. Márcia Wanderley, por estar sempre disposta a ajudar e ouvir; pelo estímulo contagiante e pela ajuda na correção final.

À Vânia Martins Bueno de O. Funaro, bibliotecária, pela revisão e correção.

À Cidininha, pela ajuda na formatação e impressão.

À Marize Morais Paiva, pelos "socorros" imediatos. 


\section{Na Disciplina de Nutrologia do Departamento de Pediatria da UNIFESP-Escola Paulista de Medicina}

Ao Prof. Dr. Domingos Palma, pelo apoio, co-orientação e acompanhamento na realização deste trabalho.

Ao Prof. Dr. José Augusto de Aguiar CarrazedoTaddei, por ter me acolhido na Disciplina de Nutrologia, por permitir a minha participação no Projeto ECCCHOS e pela colaboração na elaboração da analise estatística.

À mestre Karol Felcar, pela elaboração da análise estatística deste estudo e por estar sempre disposta a ajudar e acudir minhas dúvidas e solicitações.

À mestre Fernanda Cobayashi, pela amizade e imensa colaboração durante toda a execução do Projeto ECCCHOS e elaboração da tese.

À mestre Daniela Silveira, pela ajuda durante a realização do Projeto ECCCHOS.

A todos da equipe do Projeto ECCCHOS.

Aos funcionários da Disciplina de Nutrologia, Bruno César Rocha dos Santos, Elivânia Dias dos Santos e Ivone da Conceição Gomes de Souza, sempre dispostos a ajudar.

Aos adolescentes, que participaram do Projeto ECCCHOS. 
Zardetto CGDC. Prevalência de cárie dentária em adolescentes residentes no município de São Paulo: indicadores de risco e gravidade [Tese de Doutorado]. São

Paulo: Faculdade de Odontologia da USP; 2004.

\section{RESUMO}

Este estudo foi resultado da parceira entre as Disciplinas de Odontopediatria da FOUSP e de Nutrologia do Departamento de Pediatria da UNIFESP - Escola Paulista de Medicina -, fazendo parte do Projeto ECCCHOS (Estudos Clínicos sobre Crescimento, Comportamento, Hipertensão Arterial, Obesidade e Saúde Bucal). O objetivo do estudo foi investigar os indicadores de risco para cárie dentária em adolescentes residentes no município de São Paulo. Participaram deste estudo 230 adolescentes entre 15 e 19 anos de idade de uma escola pública do bairro da Vila Mariana. Primeiramente, foi realizado um questionário com os pais e adolescentes, obtendo informações do contexto familiar, dos hábitos alimentares e de comportamento. Para a classificação nutricional dos adolescentes, foi realizada avaliação antropométrica por nutricionistas da Disciplina de Nutrologia da UNIFESP. A avaliação odontológica foi executada por duas cirurgiãs-dentistas, previamente padronizadas, segundo as recomendações da OMS (1999). A análise quantitativa da dieta foi realizada pelas nutricionistas com base no registro alimentar de 3 dias, preenchidos pelos adolescentes, avaliando a ingestão de carboidratos, calorias totais e lipídeos, por meio do software "Programa de Apoio à Nutrição - NUTWIN 2002, versão 1.5 DIS - UNIFESP/EPM. A partir desse mesmo registro alimentar, foram calculados pela pesquisadora o número médio de refeições consumidas, a média de refeições contendo sacarose e o consumo médio de salgadinhos e refrigerantes normais e light/diet. Realizaram-se também exames laboratoriais de sangue para as dosagens de triglicérides, e colesterol total e frações. Os resultados 
foram tabulados e dicotomizados na mediana ou valor de risco. O CPO-D foi dicotomizado em baixo $\leqslant 5$ ) e alto (>5). Cerca de $29,57 \%$ dos adolescentes apresentavam-se sem lesões de cárie. O CPO-D médio encontrado foi 5,86 . Os resultados foram analisados primeiramente por meio do teste de Qui-quadrado de Pearson ou teste exato de Fisher e da regressão logística, obtendo odds ratio e intervalos de confiança. A seguir foi realizada a análise dos indicadores de risco através da regressão logística múltipla com o procedimento "backward stepwise". Conclui-se que os indicadores de risco de alto índice CPO-D entre os adolescentes pesquisados foram: o nível de escolaridade da mãe até fundamental incompleto $\left(\mathrm{OR}=3,05\left[\mathrm{IC} \mathrm{95}_{95}(\mathrm{OR})=1,15-8,07\right]\right)$; idade do adolescente igual ou superior a 17 anos $\left(\mathrm{OR}=2,19\left[\mathrm{IC}_{95 \%}(\mathrm{OR})=1,24-3,87\right]\right) ;$ e o fato de ser sobrepeso $\left(\mathrm{OR}=2,23\left[\mathrm{IC} \mathrm{C}_{95 \%}(\mathrm{OR})=1,04-4,75\right]\right)$. Os adolescentes que escovavam os dentes duas ou três vezes ao dia, apresentaram menor chance de terem alto índice CPO-D quando comparados com aqueles que higienizam uma vez ou menos ao dia $(\mathrm{OR}=0,30[\mathrm{IC} 95 \%(\mathrm{OR})=0,13-0,68]$ e $(\mathrm{OR}=0,32[\mathrm{IC} 95 \%(\mathrm{OR})=0,15-0,68]$ respectivamente); e, aqueles que foram ao cirurgião-dentista há mais de um ano, apresentaram menor chance de terem lesão de cárie quando comparados com aqueles que durante o último ano (OR =0,62 [IC 95\% (OR) =0,35-1,09]).

Palavras-Chave: cárie dentária; prevalência; fatores de risco; adolescência 
Zardetto CGDC. Dental caries prevalence in adolescents living in São Paulo city: risk indicators and severity [Tese Doutorado]. São Paulo: Faculdade de Odontologia da USP; 2004.

\section{ABSTRACT}

This study is the result of a partnership between the Pediatrics Department of the University of São Paulo and the Nutrology Department at the Federal University of São Paulo,UNIFESP-EPM. It is part of a larger study called ECCCHCOS (Clinical study on growth, behavior, hypertension, obesity, and oral health). The aim of this study was to examine the risk indicators for dental caries among adolescents living in the city of São Paulo, Brazil. 230 adolescents between 15 and 19 years of age from a public school located in the neighborhood of Vila Mariana participated in this study. First, a questionnaire was administered to parents and adolescents, gathering information on the family's socioeconomic background, and on adolescents' behavior and eating habits. Nutritionists from the Department of Nutrology at UNIFESP-EPM, weighed and measured the adolescents and performed the nutritional classification of participants. Dental examination was performed by two trained dentists, in accordance with WHO guidelines (1999). The quantitative, dietary evaluation of adolescents was carried out by the nutritionists, who assessed total intake of carbohydrates, lipids and calories, by examining the three-day diet/food records that adolescents kept, with the help of the NUTWIN 2002 software (Version 1.5, UNIFESP-EPM). The dental researcher also analyzed these records in order to evaluate the mean number of meals consumed, the mean number of meals containing sugar, and the mean consumption of chips and regular and diet softdrinks. Blood examination looking at the level of triglycerides and total cholesterol and its fractions was also performed. Results were tabulated and dichotomized, using 
median values or risk factors as cut-off points. The DMF-T was categorized into high $(>5)$ and low $(\leq 5)$ values. $29.57 \%$ of the adolescents were caries-free. The mean DMF-T was 5.86. The results were first analyzed using Pearson's Chi-square or Fisher's Exact tests and multiple regressions, to obtain odds-ratios and confidence intervals. Analysis of the risk factors were next obtained through logistic multiple regression and backward stepwise analysis. Results indicate that risk factors for dental caries among study participants were: mother's low level of education $\left(\mathrm{OR}=3.05\left[\mathrm{Cl}{ }_{95 \%}(\mathrm{OR})=1.15-8.07\right]\right)$; adolescent's age being 17 years or higher $(\mathrm{OR}=2.19 \quad[\mathrm{Cl} 95 \% \quad(\mathrm{OR})=1.24 \quad-3.87]) ;$ and being overweight $(\mathrm{OR}=2.23[\mathrm{Cl} 95 \%(\mathrm{OR})=1.04-4.75])$. Adolescents who reported brushing their teeth two or three times a day were less likely to have high DMF-T scores as compared to those who brushed their teeth only once a day (OR $=0.30[\mathrm{Cl} 95 \%(\mathrm{OR})$ $=0.13-0.68]$ and $(\mathrm{OR}=0.32[\mathrm{Cl} 95 \%(\mathrm{OR})=0.15-0.68]$ respectively $)$; and, those who most recently visited the dentists more than one year ago showed higher probability of being caries-free when compared to those who visited the dentist within the last twelve months $(\mathrm{OR}=0,62[\mathrm{Cl} 95 \%(\mathrm{OR})=0,35-1,09])$.

Key words: dental caries; prevalence; epidemiology; risk factors; adolescence 


\section{SUMÁRIO}

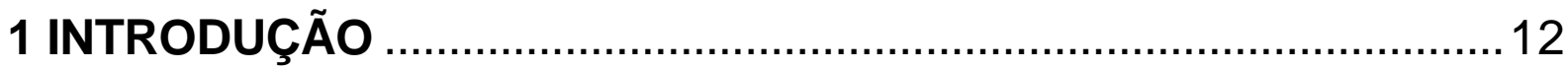

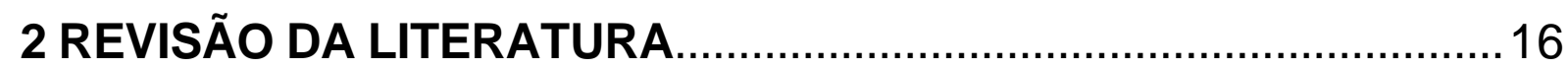

2.1 Epidemiologia da cárie dentária …………………....................... 16

2.2 Fatores relacionados à cárie dentária .........................................22

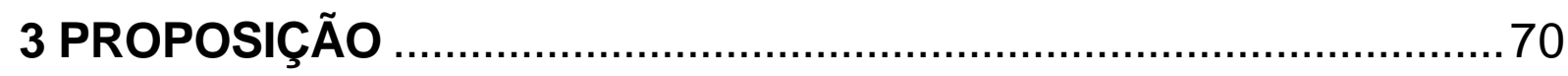

4 CASUÍSTICA - MATERIAL E MÉTODOS ………………..................72

5 RESULTADOS

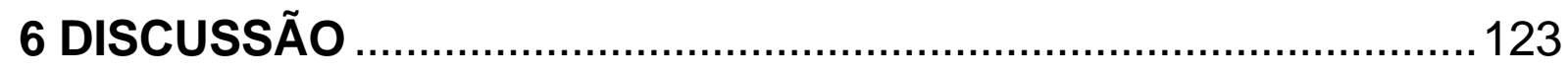

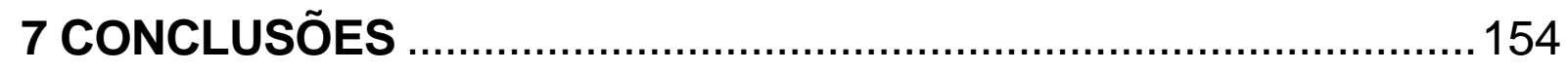

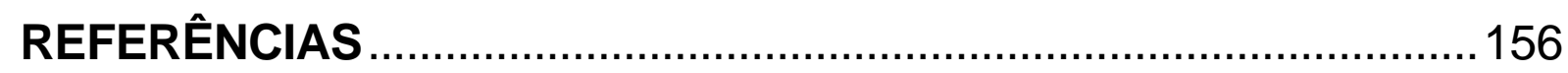

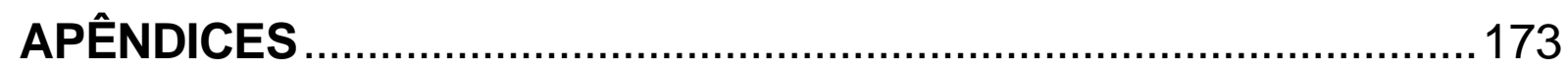

ANEXOS 
1 INTRODUÇÃO 


\section{INTRODUÇÃO}

A adolescência é uma fase peculiar do desenvolvimento do ser humano caracterizada por inúmeras e rápidas mudanças sociais, emocionais, físicas, biológicas e psicológicas. A nutrição apresenta aspectos singulares e muito importantes nesta época, visto que o indivíduo adquire $25 \%$ da estatura e $50 \%$ de seu peso definitivo (PINKHAM, 1999; SAITO; ABREU, 1991). Esse período é marcado também por um rápido crescimento com grande necessidade calórica, que ocorre simultaneamente a uma maior liberdade de escolha de alimentos.

A vida social do adolescente fora de casa é mais freqüente devido æ̀ atividades esportivas, recreativas e de trabalho, permitindo que eles realizem, esporádica ou freqüentemente, refeições fora de casa (SAITO; ABREU, 1991). Além disso, eles normalmente demonstram hábitos alimentares particulares como o consumo irregular das refeições principais, consumo freqüente de lanches e alimentos contendo açúcar e uma diminuição da ingestão de alimentos saudáveis (MAJEWSKI, 2001).

A cárie dentária atinge seu pico máximo na adolescência e tem sido descrita como um mal típico do processo de industrialização, cuja gravidade e velocidade de expansão estão fortemente condicionadas por fatores extra biológicos (Pinto, 1992) como o nível socioeconômico, o comportamento, a idade e o cuidado com a cavidade bucal (AXELSSON, 2000b; MOBLEY, 2003; NAVIA 1996).

Foi verificado que a doença cárie e o índice de massa corpórea (IMC) podem indicar adolescentes com fatores de riscos para doenças cardiovasculares, em níveis desfavoráveis. Os índices de lesões de cárie aumentaram paralelamente 
aos da obesidade. Portanto, é de fundamental importância identificar adolescentes com alta prevalência de cárie dentária e obesidade para iniciar precocemente um aconselhamento dietético e a conscientização dos riscos aos quais estão expostos (LARSSON et al., 1995).

Todos esse fatores já mencionados são preocupantes, pois os fatores que mais contribuem para o início e a progressão da doença cárie nos adolescentes são o alto consumo de alimentos que contêm açúcar, especialmente refrigerantes e deficiência na higiene bucal (MAJESWKI, 2001).

Atualmente tem sido utilizado o conceito de risco para diversas doenças, assim como risco em comum entre doenças.

Sarue et al. (1984) definiram risco como uma maior possibilidade que uma pessoa ou grupo de pessoas tem de sofrer dano em sua saúde no futuro e fatores de risco como as circunstâncias ou características pessoais, ambientais ou sociais do indivíduo ou grupo associados com um aumento dessa possibilidade.

Os fatores de risco são determinados após a realização de estudos longitudinais bem controlados. A terminologia indicadores de risco é utilizada quando os fatores de risco foram identificados em estudo transversal (Axelsson, 2000b).

O paciente adolescente vive um momento ímpar em sua vida. Ocorrem rápidas mudanças em diversos aspectos de sua vida pessoal e social que podem afetar seu comportamento e seus hábitos alimentares e de higiene bucal. Conhecer os indicadores de risco para doença cárie nesses pacientes facilitaria a compreensão desse período e a elaboração de um plano preventivo e curativo mais adequado as suas necessidades especiais. 
Assim, procuramos investigar os indicadores de risco fisiológicos, dietéticos, de hábitos alimentares, comportamentais e sócio demográficos, para cárie dentária em adolescentes. 
2 REVISÃO DA LITERATURA 


\section{REVISÃO DA LITERATURA}

\subsection{Epidemiologia da cárie dentária}

A doença cárie é infecciosa e multifatorial, envolvendo como fatores locais o biofilme dental, a saliva, os minerais e a alimentação, além daqueles dependentes do hospedeiro, como genética, comportamento, idade, nível de escolaridade e cuidado com a cavidade bucal. A interação de todos esses fatores determinará a presença ou não da doença e sua gravidade num processo dinâmico de desmineralização e remineralização (MOBLEY, 2003; NAVIA, 1996). O desenvolvimento dessa doença requer a presença de açúcar e microrganismos, mas é influenciado pela suscetibilidade do dente, o perfil desses microrganismos e a quantidade e qualidade da saliva (WHO, 2003).

A cárie dentária atinge seu pico máximo na adolescência e tem sido descrita como um mal típico do processo de industrialização nacional, cuja gravidade e velocidade de expansão estão fortemente condicionadas por fatores extra biológicos (PINTO, 1992).

Estudos de prevalência da doença cárie vêm sendo elaborados em vários locais, há algum tempo, e mostram o declínio da prevalência dessa doença em várias partes do mundo, enquanto em outras ela se mantém estável (ATTWOOD; BLINKHORN; MACKMILLAN, 1990; BOLIN; BOLIN; KOCH, 1996; BÖNECKER; CLEATON-JONES, 2003; BRASIL, 2004; ESTIOKO; WRIGHT, 1995; LARSON et al., 1995; MIYAZAKl; MORIMOTO, 1996; MOREIRA; PEREIRA; OLIVEIRA, 1996; 
NARVAI; CASTELLANOS; FRAZÃO, 2000; PETERSSON; BRATTHALL, 1996; POULSEN, 1996; SÃO PAULO, 1999; SPLIETH; MEYER, 1996; SUNDBERG, 1996), especialmente nos países desenvolvidos (WHO, 2003). Entretanto, em alguns países, a prevalência da cárie dentária ainda permanece alta entre os adolescentes (BJARNASON, 1998; WHO, 2003) e, ainda em outros, houve aumento na prevalência da cárie dentária por causa do aumento do consumo de açúcar e da falta de fluoreto em quantidade adequada (WHO, 2003) (Quadro 2.1). Ao final da revista da literatura estão apresentados os Quadros 2.1 e 2.2, contendo alguns trabalhos apresentados neste estudo, de maneira sucinta.

Diversos autores têm mostrado que a diminuição da prevalência de cárie dentária se deve ao uso de fluoretos em suas diversas formas, especialmente nos dentifrícios (BRATTHALL, 1996; BRATHALL, HÄNSEL-PETERSSON; SUNDBERG, 1996; GIBBONS, 1996; HELÖE; HAUGEJORDEN, 1981; NADAVOSKY; SHEIHAM, 1995; NARVAI; CASTELLANOS; FRAZÃO, 2000; PETERSSON; SPLIETH; MEYER, 1996; TREASURE; DEVER, 1994) e à fluoretaçao da água de abastecimento (BALDANI; NARVAI; ANTUNES, 2002; NARVAI; CASTELLANOS; FRAZÃO, 2000; PERTERSSON; BRATTHALL, 1996), além de outros fatores como o aumento da consciência para saúde bucal, diminuição do consumo de açúcar, programas de educação em saúde bucal, profilaxia e aplicação de selantes, tratamento odontológico mais preventivo, alteração nos critérios de diagnósticos e outros fatores ainda desconhecidos (PERTERSSON; BRATTHALL, 1996). Há evidências bem claras de que a exposição ao flúor, em ótimos níveis, por um longo período, diminui o índice de cárie dentária em crianças, adolescentes e adultos (GIBBONS, 1996; HELÖE; HAUGEJORDEN, 1981; PETERSEN, 2003). O uso de antibióticos para tratamento de outras infecções também é apontada por alguns pesquisadores como 
um outro fator associado à redução da cárie dentária (GIBBONS, 1996; PERTERSSON; BRATTHALL, 1996).

Contudo, a cárie dentária ainda é a doença infecciosa que mais atinge crianças, adolescentes e adultos (AMERICAN ACADEMY OF PEDIATRIC DENTISTRY, 2000; PETERSEN, 2003; PINKHAM 1999) sendo que os adolescentes podem apresentar maior atividade e risco à cárie dentária (NOWAK; CRALL, 1999; PINKHAM, 1999; MAJEWSKI, 2001).

O primeiro mapa do mundo contendo dados sobre o índice CPO-D (número de dentes cariados, perdidos e obturados) aos 12 anos de idade foi elaborado em 1969 e mostrava alta prevalência de cárie dentária nos países industrializados e relativamente baixos nos países em desenvolvimento. A diminuição da prevalência de cárie dentária nos países desenvolvidos, que vem ocorrendo desde então, se deve às medidas públicas em saúde aliado æ̀s mudanças no estilo de vida, à condição de vida e à melhoria do autocuidado (PETERSEN, 2003).

A Organização Mundial da Saúde (OMS) utiliza o índice CPO (Cariado Perdido ou Obturado) aos 12 anos de idade como indicador básico de comparação para o estado de saúde bucal entre populações diversas, e definiu o valor 3,0 como satisfatório e como meta para o ano $2000\left(\mathrm{OMS}^{1}\right.$, 1985 apud PINTO, 1992). A OMS também estabeleceu uma escala de gravidade do índice CPO-D para a idade de 12 anos (MOLLER ${ }^{2}, 1980$ apud PINTO, 1992) 0,1 a 1,1 prevalência muito baixa; 1,2 a 2,6 prevalência baixa; 2,7 a 4,4 prevalência moderada; 4,5 a 6,5 prevalência alta; e 6,6 ou superior prevalência muito alta.

\footnotetext{
1 OMS. Oral dental health global indicators for 2000:DMFT 3 at 12 years; dental caries levels at 12 years. Geneva:WHO. 1985.

2 Moller IJ. Oral health in Portugal: reports on 4 visits. Copenhagen. WHO/EURO.1980.
} 
O índice CPO-D em adolescentes varia muito, de acordo com a população e o período avaliado (ATTWOOD; BLINKHORN; MACKMILLAN, 1990; BJARNASON, 1998; BOLIN; BOLIN; KOCH, 1996; BÖNECKER; CLEATON-JONES, 2003; BRASIL, 2004; ESTIOKO; WRIGHT, 1995; LARSSON et al., 1995; MIYAZAK! MORIMOTO, 1996; MOREIRA; PEREIRA; OLIVEIRA, 1996; NARVAl; CASTELLANOS; FRAZÃO, 2000; PAIXÃO, 2002; SÃO PAULO, 1999; SPLIETH; MEYER, 1996; SUNDBERG, 1996) (Quadro 2.1).

Poulsen (1996) analisou os dados obtidos pelo Serviço de Saúde Bucal Municipal da Dinamarca, entre 1988 e 1994, em adolescentes entre 12 e 15 anos de idade e verificou que aquele constante decréscimo na prevalência de cárie dentária em crianças e adolescentes, observado entre 1970 e 1980, não foi observado a partir de 1990 (Quadro 2.2).

Em 1986, o Ministério da Saúde do Brasil executou o primeiro levantamento epidemiológico de âmbito nacional de Saúde Bucal na zona urbana de 16 das cinco regiões brasileiras com crianças, adolescentes e idosos. O segundo levantamento epidemiológico foi realizado em 1996, em 27 capitais, em crianças de 6 e 12 anos de idade (BRASIL, 2004).

Narvai, Castellanos e Frazão (2000) estudaram a evolução da prevalência da cárie dentária em crianças e adolescentes entre 5 e 12 anos de idade, das redes pública e privada de ensino, do Município de São Paulo entre 1970 e 1996. Constataram que houve declínio expressivo na prevalência de cárie dentária nesse período. No levantamento realizado em 1996, não observaram diferença estatística em relação ao índice CPO-D entre estudantes de rede pública de ensino e da particular. Contudo, destacaram que havia diferenças ao analisar os componentes 
desse índice, sendo que a mais alta porcentagem de dentes cariados encontrava-se nas escolas públicas, e o inverso ocorria para os dentes restaurados.

Em 1998, foi realizado no Estado de São Paulo um levantamento epidemiológico em saúde bucal em diversas faixas etárias através de convênio firmado com o Núcleo de Estudo e Pesquisas de Sistemas da Faculdade de Saúde Publica da Universidade de São Paulo e a Secretaria de Estado da Saúde de São Paulo (SES - SP). Foram examinados estudantes entre 5 e 12 anos de idade, adolescentes aos 18 anos de idade, adultos entre 35 e 44 anos de idade e idosos entre 65 e 74 anos de idade. A maioria dos estudantes pertencia àrede pública de ensino. A média de CPO-D encontrada aos 12 e aos 18 anos de idade para o Estado de São Paulo foi 3,72 e 8,64 respectivamente (SÃO PAULO, 1999) (Quadro 2.1). Estas faixa etárias são determinadas pela Organização Mundial da Saúde (OMS) para o estabelecimento de metas, sendo através do índice ceo-d e CPO-D respectivamente aos 5 e 12 anos. Aos 18 anos, a meta da OMS para o ano 2000 era que $85 \%$ dessa população tivesse todos os dentes (WHO, 2004).

No período de 2002 à 2003, foi realizado o Projeto SB Brasil 2003: condições de saúde bucal da população brasileira 2002-2003, pelo Ministério da Saúde. Foi avaliado o índice CPO-D em indivíduos de 250 municípios das 5 macroregiões do Brasil: Norte, Nordeste, Sudeste, Sul e Centro-Oeste e cujas médias estão apresentadas na Tabela 2.1 (BRASIL, 2004). 


\section{Tabela 2.1 - Média de CPO-D para as regiões Norte, Nordeste, Sul, Sudeste e Centro-Oeste do Brasil aos 12 anos e entre 15 e 19 anos de idade no Projeto SB Brasil 2003. Brasil, 2002}

\begin{tabular}{ccc}
\hline Idade & Região & Média CPO-D \\
\hline 12 anos & Norte & 3,13 \\
& Nordeste & 3,19 \\
Sudeste & 2,30 \\
Sul & 2,31 \\
Centro-Oeste & 3,16 \\
$15-19$ anos & BRASIL & 2,78 \\
& Norte & 6,14 \\
& Nordeste & 6,34 \\
& Sudeste & 5,94 \\
& Sul & 5,77 \\
& Centro-Oeste & 6,97 \\
& BRASIL & 6,17 \\
\hline
\end{tabular}

Splieth e Meyer (1996) verificaram a prevalência de cárie dentária em adolescentes entre 13 e 14 anos de idade das Alemanhas Oriental e Ocidental com dados coletados entre 1990 e 1992. Após a Segunda Guerra Mundial, houve aumento no consumo de açúcar, tanto na Alemanha Oriental como na Ocidental, o que resultou em aumento também na prevalência de cárie dentária até 1970. Com a introdução de dentifrícios fluoretados após 1973 na Alemanha Ocidental, houve diminuição da prevalência de cárie dentária. Essa redução não foi devida à diminuição do consumo de sacarose nem a melhoria da remoção do biofilme, mas sim ao uso de dentifrícios fluoretados entre 1970 e 1980 na Alemanha Ocidental, e em 1990, na Oriental. A prevenção de grupo que incluía programas de aplicação de 
verniz fluoretado e prevenção sem custo para crianças entre 6 e 19 anos de idade em cirurgiões-dentistas particulares desde 1983 (instrução de higiene bucal, aplicação tópica de flúor e selantes), parece ser responsável pela diminuição da incidência cárie dentária nas duas Alemanhas.

\subsection{Fatores relacionados à cárie dentária}

A dieta, o nível socioeconômico e o comportamento são fatores externos relacionados àcárie dentária (AXELSSON, 2000b).

A predição de qualquer doença com causa multifatorial é difícil especialmente se a doença apresentar fatores que dependem do estilo de vida, como é a doença cárie (RUSSEL et al., 1991). Os modelos preditores de cárie dentária que utilizam diversos fatores são mais sensíveis, pois a cárie dentária é uma doença que envolve o indivíduo (hospedeiro), o agente (microrganismo) e o substrato (dieta) (POWELL, 1998; STECKSÉN-BLICKS; GUSTAFSSON, 1986).

Alterações na prevalência de doenças multifatoriais são difíceis de serem explicadas. Em relação à cárie dentária, essa mudança que vem sendo observada desde a década de 70 coincide com aumento do consumo de açúcar refinado em alguns países em desenvolvimento e com o aumento do uso de fluoretos em países industrializados e já desenvolvidos (HELÖE; HAUGEJORDEN, 1981).

A história pregressa de cárie dentária é o fator de risco mais evidente para

o desenvolvimento de novas lesões de cárie (BJARNASON; KÖLHER, 1997; HAUSEN, 1997; HELFENSTEIN; STEINER; MARTHALER, 1991; POWELL, 1998; 
RAITIO; PIENIHÄKKINEN; SCHEININ, 1996; RUSSELL et al., 1991). Segundo Helfenstein, Steiner e Marthaler (1991), é possível predizer o aparecimento de novas lesões de cárie utilizando-se de informações clínicas detalhadas, sem a necessidade de exame microbiológico, capacidade-tampão da saliva ou avaliação do nível socioeconômico.

Fatores sociais, demográficos e comportamentais foram importantes fatores de risco para cárie dentária em crianças com pouca idade e idosos. Nos adolescentes, um dos fatores de risco evidente para novas lesões de cárie foi a presença da lesão de cárie inicial em esmalte (POWELL, 1998). Segundo Hunter (1988), os fatores de risco gerais incluem idade, etnia, sexo, local de moradia e classe social. O ambiente sociocultural no qual a pessoa está inserida pode influenciar no desenvolvimento da cárie dentária.

A análise da microbiota bucal também pode ser utilizada para prever o aparecimento de novas lesões de cárie (BJARNASON; KÖHLER, 1997; KINGMAN et al., 1988; POWELL, 1998; RUSSELL et al., 1991; STECKSÉN-BLICKS; GUSTAFSSON 1986).

Tuomi (1989) avaliou o valor preditivo da obesidade para cárie dentária em 516 crianças e adolescentes na Finlândia. Através de registros médicos e dentais, verificaram quais crianças foram obesas entre o nascimento e os dois anos de idade e esse dado foi utilizado para verificar a possibilidade de prever alto risco de cárie dentária aos cinco anos de idade. O poder preditivo da obesidade e a história passada da cárie dentária foi medido calculando-se sensibilidade, especificidade e acurácia. Quando foi feita a combinação entre obesidade nos dois primeiros anos de vida com experiência passada de cárie dentária, houve um aumento importante na sensibilidade, especificidade e acurácia. O autor constatou 
que a obesidade isoladamente não foi um grande fator preditivo da cárie dentária; porém, quando combinada com a historia passada de cárie dentária, 67 a 70\% do grupo de risco foram identificados. O pesquisador também salientou que uma dieta incorreta pode prever cárie dentária e obesidade, porém a obesidade se desenvolve mais rápido que a cárie dentária.

Raitio, Pienihäkkinen e Scheinin (1996) estudaram os fatores de risco para cárie dentária em 181 adolescentes finlandeses e os relacionaram com o incremento de cárie dentária após 11 meses. Após exames clínico e salivar, observaram que lesões de cárie incipientes, experiência passada de cárie dentária, número de lactobacilos e cândida sp. e nível de sucrase na saliva estavam associados ao aumento da prevalência de cárie dentária, enquanto a presença de biofilme visível, gengivite, fluxo salivar, capacidade-tampão e nível de $S$. mutans não foram associados ao aumento no CPO-S desses indivíduos.

Em adolescentes suecos, Bjarnason e Köhler (1997) verificaram que a história pregressa de cárie dentária e níveis salivares bacterianos apresentaram uma correlação significante com o aumento no índice CPO-S, durante os 3 anos do estudo. A melhor associação encontrada com o aumento na prevalência de CPO-S foi o número de lesões de cárie incipientes.

Em estudo longitudinal realizado na Suécia, Swedberg, Fredén e Norén (1997) estudaram adolescentes sem cárie dentária e outros com muitas lesões de cárie entre 15 e 19 anos de idade, quando eles sairiam do serviço público odontológico. Foram examinados 4380 adolescentes sendo considerados no grupo sem cárie dentária, aqueles que não apresentavam lesão de cárie em dentina e não tinham nenhuma restauração. O CPO-D médio aos 19 anos de idade variou entre 1,08 e 0,79 para os adolescentes nascidos em 1971 e 1972 respectivamente. Dos 
adolescentes sem cárie dentária aos 15 anos de idade, 60 a 70\% permaneceram assim até os 19 anos de idade. Os adolescentes que apresentaram muitas lesões de cárie aos 15 anos de idade tinham média de CPO-D mais alta aos 19 anos de idade.

Segundo Kingman et al. (1988), a prevalência de cárie dentária foi maior nos adolescentes com alto nível de $S$ mutans do que naqueles com baixo nível desse microrganismo, que moravam em uma cidade de Michigan, onde a água de abastecimento apresentava baixo teor de flúor (inferior a 0,2 ppm).

\subsection{1 dieta e fatores relacionados}

A alimentação exerce um papel fundamental no crescimento e desenvolvimento da criança e do adolescente. Tanto o excesso como o baixo consumo de alimentos podem causar diversos problemas àsaúde geral do indivíduo (KOCH et al., 1995). A dieta refere-se a tudo o que é ingerido, costumeiramente no dia-a-dia do indivíduo, independentemente do valor nutricional, enquanto a nutrição refere-se a assimilação e absorção dos alimentos e ao seu efeito no processo metabólico no organismo. A nutrição afeta o organismo apenas por via sistêmica (BEZERRA; TOLEDO, 1997; JENSEN, 1999; JOHANSSON; BIRKHED, 2001; NEWBRUN, 1989). A relação entre nutrição e dieta no processo da cárie dentária envolve efeitos locais e sistêmicos. O efeito sistêmico afeta a formação dos dentes e a composição salivar. A dieta exerce efeito local, pela reação com a superfície do esmalte, servindo de substrato para os microrganismos do biofilme dental (NEWBRUN, 1989; RUGG-GUNN, 1989; LEBER; CORRÊA, 1998). Além disso, há 
uma relação sinérgica entre a nutrição e a integridade da cavidade bucal. Essa relação apresenta grande significância e foi abordada nos Estados Unidos como um dos objetivos para o anos 2010 para uma população saudável (Public Health Service's Healthy People 2010 Objective for the Nation) , sendo que a integração entre saúde bucal e nutrição podem melhorar a condição bucal, nutricional e sistêmica dos pacientes (TOUGER-DECKER, 2004).

A associação da cárie dentária com a alimentação não é recente. Ao se observar a própria história e evolução da humanidade, percebe-se que uma mudança no padrão alimentar dos indivíduos levou a uma maior prevalência de cárie dentária nessas populações. Na Idade da Pedra (entre 12.000 e 10.000 anos a.c.), o homem começou a cultivar a terra e criar animais. Iniciaram-se então, o processamento dos alimentos com o seu cozimento e o uso do pão em forma primitiva. Através dos estudos antropológicos com crânios daquela época, observouse que entre 6 e 7\% desses apresentavam lesões de cárie. Na Idade do Ferro, este percentual aumentou para 10 a 12\%. Na Grã-Bretanha, a partir século XVII, houve a intensificação do mercado do milho e da indústria da cana-de-açúcar, levando a um rápido e alto consumo de xarope e diversos doces. Porém, só a partir do século XIX esses alimentos ficaram ao alcance de todos os segmentos da população, e observou-se, então, aumento dramático na incidência de lesões de cárie em superfícies oclusais e proximais (BEZERRA; TOLEDO, 1997).

A dieta assume grande importância na etiologia da doença cárie dentária pois, além de fornecer a principal fonte de substrato, influencia na produção de ácidos, no tipo e na quantidade de biofilme dental, na composição de microrganismos e na qualidade e quantidade de secreção salivar (KRAMER, 1997). Existe uma interação complexa entre a dieta e os fatores necessários para o 
desenvolvimento da cárie dentária que podem deixar o indivíduo mais suscetível ou menos à doença (JENSEN, 1999).

Dados epidemiológicos, estudos em humanos e animais de laboratório, observações clínicas e estudos in vitro têm demostrado o papel importante da dieta, especialmente os carboidratos refinados, no desenvolvimento da doença cárie. Esses estudos salientaram a existência de uma relação causa/efeito entre o consumo de carboidratos fermentáveis e o desenvolvimento da cárie dentária. Porém, sendo a cárie dentária uma doença multifatorial, há diversos fatores que podem aumentar ou diminuir seu desenvolvimento, existindo portanto uma variação individual (BEZERRA; TOLEDO, 1997; JOHANSSON; BIRKHED, 2001).

Estudos de intervenção em humanos como os de Vipeholm (GUSTAFFSON et al., 1954) e de Turku (SCHEININ et al., 1975) e Hopewood House (HARRIS et al., 1963) demonstraram claramente a relação dos açúcares com a cárie dentária.

O estudo de Vipeholm foi realizado na Suécia entre 1945 e 1954 num hospital de pacientes adultos com problemas mentais, e foi um dos primeiros a mostrar a importância da consistência dos alimentos e freqüência do consumo de alimentos contendo açúcar, especialmente entre as refeições. O flúor da água de abastecimento que esses pacientes utilizavam era muito baixa $(0,4 \mathrm{ppm})$ e menos de 20\% deles apresentavam higiene bucal freqüente (GUSTAFFSON et al., 1954).

O potencial cariogênico dos alimentos está relacionado, dentre outros fatores, ao conteúdo de vários açúcares como glicose, frutose, sacarose, maltose e lacatose, além do amido. Todos eles podem servir de substrato para os microrganismos do biofilme dental, sendo então metabolizados e induzindo uma redução do $\mathrm{pH}$ na interface dente-biofilme, além de influenciar na quantidade e 
qualidade desses microrganismos (BEZERRA; TOLEDO, 1997; JOHANSSON; BIRKHED, 2001). Contudo, para analisar a cariogenicidade dos alimentos, outros fatores além da sua composição química devem ser estudados, como por exemplo, suas propriedades físicas e organolépticas, incluindo a adesão à estrutura dental, textura, sabor, solubilidade, $\mathrm{pH}$ e tamanho das partículas. Em termos de cariogenicidade, o período que os carboidratos permanecem na cavidade bucal durante e após a refeição é fundamental (EDGAR, 1985; EDMONDSON, 1990; JOHANSSON; BIRKHED, 2001).

Os açúcares da dieta difundem-se rapidamente no biofilme dental e são metabolisados por microrganismos ali presentes. Dentre os açúcares da dieta, a sacarose refinada foi considerada como o dissacarídeo mais cariogênico. (AXELSSON, 2000b; BEZERRA; TOLEDO, 1997; FREIRE; CANNON; SHEIHAM, 1994; JOHANSSON; BIRKHED, 2001). A sacarose é o principal açúcar da dieta e o único que favorece a colonização de microrganismos orais e aumenta a viscosidade do biofilme dental, permitindo sua aderência aos dentes em quantidades maiores (AXELSSON, 2000b; JOHANSSON; BIRKHED, 2001; NEWBRUN, 1989). Segundo a análise sobre as recomendações sobre o consumo de açúcar publicadas entre 1961 e 1991 realizada por Freire, Cannon e Sheiham (1984), o açúcar é um dos fatores da dieta mais importante para o desenvolvimento da doença cárie.

Rocha et al. (1998) utilizaram o método preconizado por Fanning e Smith (1991) para classificar a cariogenicidade dos alimentos consumidos por crianças entre 5 e 7 anos de idade. Desta maneira, foram estipulados "escores" aos alimentos contendo sacarose, da seguinte maneira: para os alimentos líquidos ou não retentivos que continham sacarose, atribuiu-se peso 1; para aqueles pegajosos peso 3. O momento de consumo desses alimentos também foi considerado; o peso 
referente ao alimento era multiplicado por 1 , se consumido durante as refeições e por três quando a ingestão era entre as refeições. Os autores encontraram que a média do índice de cárie dentária aumentava à medida que os valores de cariogenicidade dos diários alimentares se elevavam.

Uma outra maneira de estudar o consumo de sacarose é estimar a quantidade de exposições aos alimentos açucarados que a pessoa teve por dia e multiplicar esse número por 20, que representa o tempo médio em minutos que o pH do biofilme dental permanece crítico naquele dia. Obtém-se, portanto, uma média diária de quanto tempo a pessoa ficou exposta `a diminuição do $\mathrm{pH}$ na interface dente/biofilme dental (KATZ, 1981).

Katz (1981) elaborou uma "Escala de Perigo" dos alimentos cariogênicos para ser utilizada em programas de orientação dietética. Considerou a consistência dos alimentos contendo sacarose e o momento de consumo desses alimentos. Os "grupos" alimentares foram categorizados em ordem decrescente de cariogenicidade e, portanto, de "perigo" cariogênico, da seguinte maneira:

- alimentos consistentes contendo sacarose e consumidos freqüentemente entre as refeições;

- alimentos consistentes contendo sacarose e consumidos durante as refeições;

- líquidos contendo sacarose consumidos freqüentemente entre as refeições;

- líquidos contendo sacarose consumidos durante as refeições.

Os alimentos não devem ser considerados apenas quanto ao seu potencial cariogênico, pois muitos também possuem potencial anticariogênico. Alguns componentes são denominados protetores, como o flúor, o fosfato e a gordura (BEZERRA; TOLEDO, 1997; JOHANSSON; BIRKHED, 2001; RUGGGUNN, 1993). Segundo Schachtele (1982), os alimentos com baixo potencial 
cariogênico possuem as seguintes características: alto conteúdo de proteína, conteúdo moderado de gordura para facilitar sua remoção da cavidade bucal; alta capacidade-tampão; alto conteúdo de mineral, especialmente cálcio e fósforo, concentração mínima de carboidratos fermentáveis, $\mathrm{pH}$ maior que 6,0 e habilidade de estimular o fluxo salivar.

O queijo é um dos alimentos com propriedades anticariogênicas pois estimula a mastigação, aumentando a secreção salivar e, portanto, facilitando a autolimpeza e efeito-tampão, aumenta a concentração de cálcio no biofilme dental, além de absorver proteínas como a caseína na superfície do esmalte, reduzindo sua solubilidade (HEROD, 1991; RUGG-GUNN, 1993).

O xilitol é um tipo de substituto calórico do açúcar, encontrado em frutas e vegetais, e comercialmente é obtido da casca de algumas árvores, da semente do algodão e das casca do coco (RUGG-GUNN, 1993). Uma das vantagens do xilitol é não ser metabolizado pelos microrganismos da cavidade bucal (JOHANSSON; BIRKHED, 2001; RUGG-GUNN, 1993). É considerado por alguns pesquisadores como anticariogênico por apresentar efeito antimicrobiano (BEZERRA; TOLEDO, 1997; JOHANSSON; BIRKHED, 2001; SCHEININ et al., 1975).

Dentre os principais temas polêmicos encontrados no estudo da alimentação do ser humano, um dos mais controversos é o consumo de refrigerante por crianças e adolescentes (FISBERG; AMÂNCIO; LOTTENBERG, 2002).

No final do século $\mathrm{XIX}$ e princípio do século $X X$, foram registrados os primeiros relatos de distribuição maciça de bebidas à base em extratos de noz de cola adicionadas de água e adoçantes. A partir de então, observou-se a difusão de diferentes bebidas gaseificadas artificialmente e o uso universalizado desses 
refrigerantes, que chegaram a remotas regiões do planeta, com aceitação globalizada (FISBERG; AMÂNCIO; LOTTENBERG, 2002).

Segundo Fisberg, Amâncio e Lottenberg (2002), os resultados dos estudos que relacionaram o consumo de refrigerantes ao aumento de peso, da incidência de cárie dentária e a baixo consumo de alimentos fonte de cálcio ainda são controversos.

Os principais períodos de risco associados ao incremento agudo de consumo de lanches, alimentos gordurosos e refrigerantes são a infância, especialmente os estudantes e a adolescência (FISBERG; AMÂNCIO; LOTTENBERG, 2002).

A associação entre consumo de refrigerantes e risco de desenvolver cárie dentária foi encontrada em diversos estudos, utilizando metodologias distintas (BIRKHED, 1984; BRIMACOMBE, 2001; ERICKSON; ALEVIZOS; RINDELAUB, 2001; HELLER, BURT; EKLUND, 2001; ISMAIL; BURT; EKLUND, 1984; JONES et al., 1999; MAJEWSKI, 2001).

Alguns fatores específicos encontrados na adolescência favorecem o início e a progressão da doença cárie; um dele é o alto consumo de açúcar, especialmente dos refrigerantes (MAJEWSKI, 2001).

Ismail, Burt e Eklund (1984) verificaram que o aumento na prevalência de cárie era maior naqueles que consumiam refrigerantes com mais freqüência entre as refeições, quando comparado ao consumo total de refrigerantes.

Os refrigerantes apresentam $\mathrm{pH}$ muito baixo, que varia entre 2,5 e 4,0, especialmente aqueles do tipo cola (BIRKHED, 1984; ERICKSON; ALEVIZOS; RINDELAUB, 2001) . Jones et al. (1999) não encontraram diferença no CPO-D dos 
adolescente com 14 anos de idade que consumiam refrigerantes normais com aqueles que consumiam refrigerantes diet/light.

Os consumidores mais ávidos de refrigerantes são os adolescentes, especialmente os meninos entre 12 e 19 anos de idade, que podem chegar a consumir entre 8 e 12 latas por dia (BRIMACOMBE, 2001; ERICKSON; ALEVIZOS; RINDELAUB, 2001). Isso ocorre porque os adolescentes têm dinheiro e facilidade, pois há máquinas que vendem refrigerantes nas escolas e locais onde eles se reúnem (BRIMACOMBE, 2001). Contudo, há grande diferença na freqüência de consumo dessas bebidas em diferentes países, sendo muito comum em alguns lugares e pouco freqüente em outros (KUUSELA et al., 1999).

No primeiro estudo sobre nutrição e saúde, NHANES I (National Health And Nutrition Examination Survery), realizado em âmbito nacional entre os anos de 1971 e 1974 nos Estados Unidos, foi verificado que a freqüência de consumo de alimentos cariogênicos entre as refeições esteve associado a um alto índice CPO-D nos indivíduos entre 9 e 29 anos de idade (ISMAIL, 1986).

Sheiham (1991) salientou que muitos estudos se preocuparam apenas em associar a freqüência de consumo de alimentos cariogênicos com a cárie dentária e não mencionaram a importância da quantidade total ingerida, e que outros estudos demostraram claramente a associação que existe entre a freqüência de consumo desse tipo de alimento e a quantidade total. Esse autor sugere que o consumo anual de açúcar deve ser em torno de 15 quilos por pessoa em locais onde fluoretos estão amplamente disponíveis, pois foi constatado que as pessoas que consumiam 10 quilos de açúcar por ano apresentaram baixa prevalência de cárie dentária quando comparadas com aquelas que consumiam mais quantidade. 
Após estudar os hábitos alimentares em adolescentes do norte da Suécia e compará-los com aqueles que apresentavam alta e baixa prevalências de cárie dentária, Larsson; Johansson e Ericson (1992) verificaram que não houve diferença significante entre o consumo diário de açúcar e o número de refeições realizadas por dia entre esses dois grupos. Porém, constataram que aqueles que apresentavam nove ou mais superfícies cariadas ou restauradas tinham hábitos alimentares piores que aqueles de baixa prevalência, sendo que consumiam mais gordura, menos quantidade de carboidratos complexos e menos quantidade de ferro.

Larsson et al. (1995) verificaram que a alta prevalência de cárie dentária na adolescência podia ser fator de risco para doenças cardiovasculares. Participaram desse estudo longitudinal de 3 anos 181 adolescentes com 15 anos de idade, do norte da Suécia. Entre os 7 e 13 anos de idade, todos haviam feito bochecho com solução fluoretada a $0,2 \%$ e participaram de programa preventivo entre os 9 e 15 anos de idade. A pressão arterial desses adolescentes foi aferida e foram coletadas amostras de sangue para colesterol total, HDL colesterol e triglicérides. Cerca de $65 \%$ de todos os pacientes não tinham nenhum fator de risco para doença cardiovascular. Foi encontrada correlação entre o Índice de massa corpórea e o CPO-S $(r=0,23)$, nível de triglicérides $(r=0,29)$, pressão sistólica $(r=0,32)$ e diastólica $(r=0,23)$. Por outro lado, o índice CPO-S não apresentou correlação com o colesterol total $(r=0,10)$, triglicérides $(r=0,08)$, HDL colesterol $(r=-0,05)$ ou pressão arterial sistólica $(r=0,16)$ e diastólica $(r=0,11)$. A regressão logística stepwise apresentou uma correlação moderada entre o CPO-S e o índice de massa corpórea (IMC) $(p=0,002)$. Os adolescentes com índice de cárie dentária CPO-S maior ou igual a 9, considerado como alto, apresentaram IMC e pressão arterial estatisticamente mais altos que aqueles sem cárie dentária. O número de 
pacientes sem cárie, que tinham algum fator de risco para doença cardio-vascular, era estatisticamente menor que aqueles com alto índice de cárie dentária. Pacientes com um ou dois fatores de risco para doença cardiovascular também tinham CPO-S mais alto que aqueles sem fator de risco. Os autores mencionaram que os adolescentes com o alto índice de cárie dentária coincidam com aqueles que apresentam fatores de risco para doença cardiovascular.

Kuusela, Honkala e Rimpelä (1997) estudaram o consumo de diferentes alimentos contendo açúcar entre adolescentes Finlandeses com 12, 14 e 16 anos de idade e a associação do padrão de consumo com a prevalência de cárie dentária dental aos 18 anos de idade. Os resultados encontrados destacaram que os diferentes alimentos contendo açúcar e o fato de adicionar açúcar ao chá ou café se comportam de maneira diferente em relação à cárie dentária. Entre os rapazes, o fator de risco mais comum foi o consumo diário de açúcar e entre as meninas, não foi encontrado um fator de risco em comum.

Na Islândia, Arnadóttir et al. (1998) verificaram que a freqüência de consumo de alimentos cariogênicos entre as refeições foi fator de risco de cárie dentária entre adolescentes com 14 anos de idade.

Campain et al. (2003) realizaram um estudo longitudinal em Melbourne, Austrália, com adolescentes entre 12 e 13 anos de idade para verificar fatores de risco da dieta nesse grupo de baixo risco de cárie dentária. Os resultados demonstraram que a interação de açúcar e amido em diversos alimentos pode ser fator de risco de cárie dentária. Eles destacaram o fato que, nos adolescentes pesquisados, o consumo de alimentos pobres em sacarose, porém ricos em amido como pães, bolachas salgadas, salgadinhos e salgados foi fator preditivo para cárie dentária. 
Peres, Bastos e Latorre (2000) estudaram os fatores de risco para a maior gravidade da cárie dentária em crianças com 12 anos de idade, da cidade de Florianópolis, de escolas públicas e privadas, e verificaram que as crianças que consumiam produtos cariogênicos duas a três vezes por dia, todos os dias, apresentavam 4,41 vezes mais chances de ter alta prevalência de cárie dentária quando comparadas aquelas que consumiam esses alimentos no máximo uma vez ao dia.

Um novo modelo denominado de "janela de risco" foi proposto por van Loveren (2001) para explicar e guiar a prevenção da cárie dentária. Nele, são considerados fatores locais como o uso de fluoretos, higiene bucal, a proteção da saliva e o consumo de alimentos cariogênicos. O risco dos alimentos cariogênicos depende mais da freqüência de consumo que a quantidade total ingerida, porém esses dois aspectos podem ser diretamente relacionados com a cárie dentária. Utilizando esse modelo, naqueles casos onde não há uso de fluoretos e a higiene bucal é negligenciada, ao diminuir o consumo de alimentos cariogênicos, a "janela de risco" fica menor. Por outro lado, caso o indivíduo tenha acesso a fluoretos e higiene bucal porém estes são deficientes, não seria possível diminuir o círculo correspondente ao alimento cariogênico de tal maneira que ele desaparecesse.

Em estudo de revisão sistemática, Burt e Pai (2001) concluíram que a relação entre o consumo de açúcar e a cárie dentária é muito menor nos tempos atuais, de diversas formas de exposição aos fluoretos, do que era anteriormente. Contudo, o controle do consumo de açúcar continua a ser um método justificável para a prevenção da cárie dentária. Em outro estudo sistemático da literatura, Anderson e Curzon (2003) observaram que não houve clara associação entre a quantidade de consumo de açúcar e cárie dentária, mas houve uma associação 
fraca entre freqüência de consumo de alimentos contendo açúcar e cárie dentária. Segundo Duggal e van Loveren (2001), estudos epidemiológicos têm demonstrado, que para muitas populações, o consumo de açúcar e a prevalência de cárie dentária são fatores independentes.

Stecksén-Blicks e Gustafsson (1986) constataram que os adolescentes de 13 anos de idade da cidade de Umeå Suécia, que tiveram pouco aumento na prevalência de cárie dentária após um ano de estudo, apresentavam também baixa freqüência de número de refeições e consumo diário de sacarose.

Kleenmola-Kujala e Räsänen (1982) encontraram pouca associação entre o consumo total de açúcar e a cárie dentária, e Larsson, Johansson e Ericson (1992) e Walker et al. $^{3}$ (2000, apud WHO, 2003) não encontraram associação entre o consumo diário de açúcar e a cárie dentária. Por outro lado, Rugg-Gunn et al. (1984) observaram que aqueles que consumiam mais quantidade de açúcar em gramas por dia tiveram maior número de novas lesões de cárie após 2 anos de estudo que aqueles que consumiam menor quantidade. Em outro estudo longitudinal, Szpunar, Eklund e Burt (1995) também encontraram que o consumo total de açúcar no dia estava associado ao aumento na incidência de lesões de cáries nos adolescentes entre 11 e 15 anos de idade de cidades rurais do estado de Michigan, Estados Unidos, onde não havia água de abastecimento fluoretada.

Aleksejuniene, Arneberg e Eriksen (1996) não encontraram associação entre a freqüência de consumo de alimentos contendo açúcar com a prevalência de cárie dentária.

Beighton, Adamson e Rugg-Gunn (1996), na Inglaterra, e Peres, Bastos e Latorre (2000), no Brasil, constataram que a alta freqüência de consumo de

\footnotetext{
${ }^{3}$ Walker et al. National diet and nutrition survey: young people aged 4 to 18 years. Vol. 2. Report of the oral health survey. London: The Stationary Office, 2000.
} 
alimentos cariogênicos estava associada \{a cárie dentária. Por outro lado, Moreira, Severo e Rosenblatt (2002) constataram que aqueles que consumiam alimentos cariogênicos até 2 vezes por dia apresentavam prevalência de cárie dentária maior $(77,3 \%)$ que aqueles que consumiam 4 ou mais vezes $(70,7 \%)$, porém a diferença não foi estatisticamente significante.

Aqueles países ou populações mais pobres que vivem de maneira tradicional e tem baixo consumo de açúcar, apresentam baixa prevalência de cárie dentária. Contudo, à medida que o nível econômico deles aumenta, há também aumento no consumo de açúcar e outros carboidratos fermentáveis, marcando um incremento significante da cárie dentária (WHO, 2003).

Ao indagar "experts" de vários países sobre os motivos do declínio da incidência de cárie dentária nos últimos 30 anos, Brathall, Hänsel-Petersson e Sundberg (1996) verificaram que houve grande variação de como esses profissionais graduaram o impacto de vários fatores na prevalência da cárie dentária. Em relação à diminuição do consumo de açúcar, 38\% não deram importância alguma, 37\% assinalaram pouca importância e, em relação àredução da freqüência do consumo de açúcar, 17\% mencionaram não estar associada ao declínio da incidência de cárie dentária, 35\% descreveram pouca importância e 4\% apenas como muito importante.

Estudando os hábitos alimentares em relação ao consumo de açúcar e a experiência de cárie dentária em adolescentes entre 12 e 13 anos de idade da Islândia, Bjarnason, Finnbogason e Norén (1989) constataram que a maior incidência de cárie dentária foi associada ao freqüente consumo de guloseimas, pães doces e bolos durante as refeições. 
Russell et al. (1991) verificaram fatores de risco para cárie dentária em adolescentes escoceses durante 2 anos, e constataram que o padrão de dieta não foi um bom fator preditivo da cárie dentária e que houve melhor valor preditivo quando foram associadas variáveis clínicas e microbiológicas.

Ismail, Burt e Eklund (1984) observaram que o aumento na prevalência de CPO-D era maior naqueles que consumiam refrigerantes com mais freqüência entre as refeições quando comparado ao consumo total de refrigerantes.

Os adolescentes demonstram hábitos alimentares particulares. Geralmente, têm padrão de consumo irregular das refeições principais, consumo freqüente de lanches e alimentos contendo açúcar e diminuição da ingestão de alimentos saudáveis (MAJEWSKI, 2001).

Priore (1998) pesquisou os hábitos alimentares de 320 adolescentes entre 12 e 18 anos de idade matriculados em escolas públicas da cidade de São Paulo. Na anamnese alimentar, foi utilizado o inquérito-recordatório de 24 horas, e obteve informações sobre consumo, preferências e recusas de alimentos. A maioria $(60,8 \%)$ dos adolescentes relatou preferência por refrigerantes, seguida pelas massas $(37,1 \%)$. Mais da metade $(59,9 \%)$ mencionou que ingeria refrigerante pelo menos uma vez ao dia e doces em geral (81,2\%). O consumo diário de sanduíches também foi relatado por grande parte dos entrevistados $(67,4 \%)$. Foram observados déficit na ingestão de calorias, cálcio e ferro que, segundo a pesquisadora, podem expor o adolescente a riscos nutricionais de diferentes magnitudes; portanto, é importante corrigir as distorções no hábito alimentar.

Gama (1999) estudou os hábitos alimentares e o estado nutricional de 724 adolescentes entre 10 e 19 anos de idade matriculados em escolas públicas e privadas da cidade de São Paulo. O hábito alimentar foi pesquisado utilizando o 
inquérito do dia alimentar habitual e a freqüência do consumo de alimentos. Houve diferença entre os grupo etários, os sexos e o tipo de escola quanto ao consumo habitual de refrigerante. O consumo habitual de refrigerante foi referido, praticamente, por metade dos adolescentes. Contudo, foi maior no sexo masculino que no feminino, independentemente do tipo de escola freqüentada, para praticamente todas as faixas etárias. Comparando os adolescentes que freqüentavam escolas particulares com aquelas de escolas estaduais, foi verificado que o consumo diário dessa bebida foi maior entre aqueles que freqüentavam as escolas estaduais, independentemente do sexo. Quanto ao consumo de junk food, não houve diferença significante entre os grupos etários, sexo e escolas. A porcentagem geral de consumo habitual desse tipo de alimento foi 64,2 . Observouse também consumo inadequado de leite e laticínios, frutas, hortaliças, cálcio e vitaminas $\mathrm{A}$ e $\mathrm{C}$.

Alguns autores realizaram algumas diretrizes para orientação da dieta:

- Segundo a OMS (WHO, 2003) é importante estabelecer um limite máximo para o consumo de açúcar. As evidências têm mostrado que em países onde o consumo de açúcar é baixo, 15 a 20 quilos por pessoa por ano, a prevalência da cárie dentária também é baixa. Deve-se recomendar que o consumo de alimentos e líquidos açucarados seja de no máximo 4 vezes ao dia, e diminuir o consumo de refrigerantes e sucos também para diminuir a ocorrência de erosão dental.

- Como a cárie dentária continua sendo um problema para alguns pacientes, Jensen (1999) recomendou que lanches altamente acidogênicos sejam consumidos durante as refeições para reduzir o risco de cárie dentária e que entre as refeições os lanches devem ser de alimentos não-acidogênicos ou 
pouco acidogênicos, e Mobley (2003) orientou para que líquidos açucarados fossem consumidos durante as refeições ou nos "lanches" combinados com alimentos cariostáticos.

- Segundo Duggal e van Loveren (2001), nas crianças com alto risco de cárie dentária, o aconselhamento dietético deve ser realista e positivo; os doces devem ser consumidos durante a refeição como sobremesa em vez de consumido entre as refeições, assim como os refrigerantes.

- Restringir a freqüência de consumo de alimentos ricos em açúcar (BEIGHTON; ADAMSON; RUGG-GUNN, 1996)

A obesidade e a cárie dentária têm no hábito alimentar um importante componente etiológico comum e podem se instalar precocemente. A introdução precoce de alimentos sólidos na alimentação infantil pode contribuir para a instalação de um hábito alimentar desfavorável, propiciando o desenvolvimento destas doenças (TRAEBERT et al., 2004).

A nutrição assume grande importância na adolescência, pois é um período em que o indivíduo ganha $25 \%$ da altura e 50\% do peso corpóreo final. Além disso, essa é uma fase de crescimento rápido e transformações corporais intensas, que necessita de aporte adequado de calorias e nutrientes. O adolescente é facilmente influenciado pelo relacionamento grupal e desconhece o valor nutritivo real dos alimentos e portanto está sujeito a hábitos alimentares impróprios, que podem vir a comprometer seu crescimento adequado (VITALLE, 2003).

Atualmente, o mundo se depara com dois tipos de má nutrição, aquela associada àfome e deficiência nutricional e outra associada ao excesso de consumo alimentar. A urbanização e o desenvolvimento econômico resultam em rápidas mudanças na dieta e no estilo de vida. A globalização apresenta um pacto marcante 
no consumo excessivo de alimentos, que leva a doenças crônicas como a obesidade, diabetes, doenças cardiovasculares, câncer, osteoporose e doenças orais (PETERSEN, 2003).

Segundo o relatório da OMS denominado Dieta, Nutrição e prevenção de doenças crônicas de 2003 (WHO, 2003), a prevenção da obesidade em crianças e adolescentes deve ser considerada de alta prioridade e sugere algumas estratégias preventivas, tais como a promoção do aleitamento materno exclusivo, limitar o tempo de assistir televisão, promover o consumo de frutas e vegetais e restringir o consumo de refrigerantes e alimentos ricos em calorias e pobres em micronutrientes, como os salgadinhos.

A obesidade é uma doença crônica, complexa e com etiologia multifatorial, definida como um distúrbio do metabolismo energético. Geralmente, ocorre pela associação de fatores genéticos, ambientais e comportamentais (ESCRIVÃO et al., 2003). Outros autores definem a obesidade como uma síndrome de alterações fisiológicas, bioquímicas, metabólicas, anatômicas, psicológicas e sociais, caracterizada pelo aumento do tecido adiposo, com conseqüente acréscimo do peso corpóreo (ARTEGA; SANTOS; OLIVEIRA, 1982 ).

A obesidade ocorre basicamente quando a quantidade de energia ingerida excede o gasto energético por um tempo considerável (LIVINGSTONE, 2000; MAFFEIS, 2000; OGDEN et al., 2002; SCHLICKER; BORRA; REGAN, 1994; WABITSCH, 2000b; WHO ${ }^{4}, 1998$ apud WHO, 2003). A interação entre diversos e complexos fatores pode colaborar para a manutenção do balanço energético positivo (WHO5, 1998 apud WHO, 2003; WABITSCH, 2000b). A obesidade está relacionada ao consumo alimentar e à atividade física, sendo que esses são influenciados pela

\footnotetext{
${ }^{4}$ WHO (World Health Organization), 1998. Obesity: Preventing and managing the global epidemic. Report of the WHO Consultation on Obesity. Geneva: WHO/NUT/NCD.
} 
sociedade, economia e ambiente no qual a criança vive (OGDEN et al., 2002). Evidências recentes sugerem que a obesidade seja decorrente da interação múltipla entre o meio ambiente e a genética (MAFFEIS, 2000; SCHLICKER; BORRA; REGAN, 1994; WABITSCH, 2000a), porém o motivo desse desequilíbrio na infância ainda não está bem claro (OGDEN et al., 2002). Dentre os fatores ambientais, pode-se citar o nível de atividade física, prática de assistir televisão por várias horas (SCHLINCKER; BORRA; REGAN, 1994; TADDEI, 1998) e difusão dos jogos eletrônicos (TADDEI, 1998). Além desses fatores, devem ser considerados também a diminuição do aleitamento infantil, o consumo de alimentos formulados na alimentação infantil, a substituição dos alimentos processados em casa pelos alimentos industrializados, os quais são acompanhados de forte campanha de estímulo ao consumo (TADDEI, 1998).

Segundo Wabitsch (2000a), o aumento dramático da prevalência da obesidade infantil no mundo ocidental estaria mais associado às alterações no meio ambiente que ao fator genético. Isso pode ser explicado pelo fato de que, nas últimas décadas, não ocorreram alterações substanciais nas características genéticas da população, enquanto as alterações nos hábitos alimentares foram enormes (TADDEI, 1998).

Há dois momentos críticos para o estabelecimento da obesidade: os dois primeiros anos da vida e o início da adolescência. Muitas vezes, a obesidade na adolescência é originaria nos primeiros anos de vida, época em que o peso é extremamente valorizado e considerado como sinônimo de saúde (SAITO; ABREU, 1991).

A obesidade é uma das mais complexas doenças no que diz respeito à sua etiologia e fisiopatologia. Fatores culturais tais como gênero, etnia, 
características socioeconômicas e familiares são determinantes do peso corpóreo à medida que ditam conotações morais e sociais e definem atitudes para o comportamento alimentar e de atividade física (RIBEIRO, 2001). Os diversos fatores sociais associados à obesidade na infância provavelmente não interagem de maneira igual em populações diferentes (LIVINGSTONE, 2000).

Em praticamente todos os países do mundo, tanto aqueles de baixa como naqueles de alta renda, está havendo uma epidemia de obesidade. A prevalência está presente não só nos adultos, mas também em jovens e crianças e associado a níveis socioeconômicos mais baixos (WHO, 2003). Em países em desenvolvimento, que estão em fase de transição econômica, a obesidade coexiste junto com a desnutrição crônica na mesma população e, às vezes, até na mesma família $\left(\mathrm{WHO}^{5}, 2002\right.$ apud WHO, 2003). No Brasil, em 1989, a obesidade infantil foi mais freqüente nas regiões mais desenvolvidas, como o Sudeste e Sul, onde estava mais adiantado o processo de modernização industrial e, portanto, as mudanças de hábitos que o acompanhava (TADDEI, 1998).

Estudos epidemiológicos realizados em países europeus têm demonstrado que crianças e adolescentes deste continente estão ficando mais altos e pesados. Foi verificado, também, que a prevalência da obesidade infantil apresenta grande variabilidade de um país para outro e dentro do próprio país. As razões para essa grande variabilidade ainda não estão bem definidas, mas sugerem que, independentemente dos fatores genéticos, as variáveis ambientais são importantes preditores da obesidade e funcionam de maneira muito complexa (LIVINGSTONE, 2000).

\footnotetext{
${ }^{5}$ WHO. The World Health report 2002: reducing risks, promoting healthy life. Geneva: WHO. 2002.
} 
Nos Estados Unidos, a obesidade é considerada um problema de saúde pública (ERNST; OBARZANEK, 1994). A prevalência da obesidade infantil aumentou muito, especialmente em meados dos anos 70 (LINVINSTONE, 2000; OGDEN et al., 2002). Segundo levantamento realizado pela National Health and Nutrition Examination Survey (NHANES), entre 1999 e 2000, 15,3\% das crianças entre 6 e 11 anos de idade e $15,5 \%$ dos adolescentes entre 12 e 19 anos eram obesos. No mesmo levantamento realizado entre 1963 e 1965, as prevalências eram de 4,2 e 4, 6, respectivamente para as idades de 6 a 11 anos e 12 a 19 anos (OGDEN et al., 2002; AMERICAN HEART ASSOCIATION, 2004).

Em estudo realizado por Ribeiro (2001) com 2519 estudantes entre 7 e 10 anos de idade de escolas públicas da Vila Mariana, 10,5\% foram diagnosticados como obesos. Esse mesmo estudo encontrou alguns fatores de risco da criança desenvolver obesidade, tais como peso ao nascer maior ou igual a $3500 \mathrm{~g}$, IMC (índice de massa corpórea) dos pais superior a $30 \mathrm{~kg} / \mathrm{m}^{2}$, o fato de assistir televisão por mais de 4 horas e nível de escolaridade materna superior a 4 anos de estudo. Analisando isoladamente os dados, o consumo de lanche inadequado na escola, o alto consumo de gordura saturada e o fato de assistir televisão nos momentos de lazer estiveram associados àobesidade.

Se o ambiente for favorável, ou seja, se houver bons hábitos alimentares e prática regular de atividade física, a obesidade dificilmente será desenvolvida, mesmo havendo predisposição genética (CTENAS, 1999).

Existe uma clara associação entre a obesidade $\mathrm{e}$ as doenças cardiovasculares, sendo que essas ocupam atualmente o primeiro lugar em causas de morte no país. Estima-se que a prevenção do excesso de peso reduziria a incidência dessas doenças em no mínimo 30\% (BRASIL, 1999). 
São várias as repercussões metabólicas e sociais da obesidade instalada na infância e adolescência. Os distúrbios psicossociais são provocados pelo estigma da obesidade e apresentam grande relevância na fase de estruturação da personalidade. Uma das alterações metabólicas comumente encontrada é a hiperinsulinemia, correlacionando-se significativamente com a porcentagem de gordura corporal. Outra repercussão metabólica de destaque está relacionada aos adversos níveis de lipídeos (ESCRIVÃO et al., 2003). Vários estudo demonstraram a associação entre a obesidade e o aumento dos níveis de colesterol total, LDL colesterol e triglicérides com maior risco para o desenvolvimento de doença aterosclerótica e baixo níveis de HDL colesterol, aumentando ainda mais esse risco em crianças e adolescentes (ERNST; OBARZANEK, 1994; ESCRIVÃO et al., 2003; GIDDING et al., 1995; GUTIN et al., 1997). A aterosclerose pode iniciar-se na infância, e só altos níveis de colesterol nessa fase têm um papel importante no estabelecimento da aterosclerose do adulto (FREEDMAN et al., 1999). Contudo, as alterações metabólicas são dependentes da duração da obesidade e de sua gravidade (ESCRIVÃO; LOPEZ, 1998). Além dessas alterações, a obesidade em crianças pode provocar algumas alterações a curto prazo, tais como a síndrome de Pickwic (apneia obstrutiva), cardiomiopatias, pancreatite, problemas ortopédicos, respiratórios, psicossociais, dislipidemias, esteatose hepática, hipertensão e hiperinsulinimia, levando lentamente ao aparecimento de diabetes e doença arterial coronariana na idade adulta (MUST, 1996; WABITSCH, 2000a), dermatológicas (infecções de pele, acne, estrias, problemas na cicatrização de feridas) e imunológicas (WABITSCH, 2000a).

Existe uma tendência dos estudos a mostrar que crianças e adolescentes obesos, quando comparados com os não-obesos, têm maior risco de serem adultos 
obesos (ERNST; OBARZANEK, 1994; ESCRIVÃO et al., 2003; JEBB; LAMBERT, 2000; LIVINGSTONE, 2000; MAFFEIS, 2000; MUST, 1996); e esse risco aumenta acentuadamente com a idade, na própria infância. Portanto, quanto mais idade tem a criança obesa, maior probabilidade terá de ser um adulto obeso (LIVINGSTONE, 2000; ESCRIVÃO et al., 2003) e se não for devidamente controlada, leva a um aumento da morbimortalidade e diminuição da expectativa de vida (MUST, 1996; JEBB; LAMBERT, 2000).

Hernández et al. (1999) pesquisaram a associação entre a atividade física e o fato de assistir televisão com prevalência de obesidade em 712 crianças entre 9 e 16 anos de idade da Cidade do México. Crianças que assistiam mais de 3 horas por dia de televisão apresentavam uma razão de chance de 1,87 de serem obesas. A prevalência de crianças obesas era menor naquelas que praticavam mais que 2 horas e meia por dia de atividade física do que aquelas que praticamente menos de uma hora diária.

Segundo a OMS, no seu relatório sobre dieta, nutrição e prevenção de doenças crônicas, a prevenção da obesidade em crianças deve ser considerada de alta prioridade para diminuir essa epidemia e as doenças associadas a ela. Algumas medidas preventivas mencionadas para crianças e adolescentes foram as seguintes: limitar o tempo que a criança assiste televisão, promover uma vida mais ativa, aumentar o consumo de frutas e vegetais, restringir o consumo de refrigerantes e alimentos ricos em energia e pobres em micronutrientes, como por exemplo os salgadinhos (WHO, 2003).

Os adolescentes estão sofrendo não só maturação física, mas também cognitiva e psicossocial. Eles estão em busca de sua identidade, lutam por independência e aceitação e estão preocupados com a aparência. Os padrões de 
refeição dos adolescentes são freqüentemente caóticos, pois omitem um número crescente de refeições em casa ou substituindo essa refeição (SAITO; ABREU, 1991; SPEAR, 2002). O consumo de fast food para refeições ou lanches é especialmente popular entre os adolescentes ocupados (SPEAR, 2002). Além disso, a alimentação pode ser vista por elas como uma maneira de contentar autoridade, com quebra de padrões entre os quais o hábito alimentar da família, da necessidade de rever seus próprios comportamentos, o que leva o adolescente a mudanças, muitas vezes, danosas (SAITO; ABREU, 1991).

O estilo de vida atual dos adolescentes, onde há aumento da permanência fora do lar, devido às atividade esportivas e recreativas, faz com que os jovens realizem esporádica ou freqüentemente refeições fora do lar. Assim, a expansão dos horizontes sociais advinda da adolescência faz com que o indivíduo passe a sofrer modificações em sua rotina de vida, incorporando novas praticas alimentares àsua nutrição (SAITO; ABREU, 1991).

Silveira (2004) estudando os fatores de risco de excesso de peso em adolescentes da cidade de São Paulo, encontrou que os hábitos alimentares, freqüência de consumo de alimentos obesogênicos e outros indicadores de atividade física não apresentaram associação significante com o excesso de peso. Porém, o fato de ter pais obesos e o adolescente ter sido obeso durante alguma fase da infância apresentaram razão de chance de 2,23 e 3,60 respectivamente. Outros fatores concomitantes foram o hábito de dormir durante àtarde e já ter feito algum tratamento para obesidade. 


\subsection{2 fatores sociodemográficos}

Diversos estudos foram realizados para comparar a prevalência da cárie dentária em adolescentes pertencentes a grupos socioculturais e sociodemográficos diferentes.

Para comparar classes sociais ou nível socioeconômico, alguns trabalhos compararam o tipo de escola na qual o adolescente estava matriculado, particular ou pública, enquanto outros utilizavam informações sobre renda familiar e nível educacional dos pais para categorizar o nível socioeconômico.

Os estudos realizados por Hausen, Heinonen e Paunio (1981), Dummer et al. (1987), Attwood, Blinkhorn e MacMillan (1990), em Glasglow, Inglaterra, Treasure e Dever (1994), na Nova Zelandia, du Plessis (1997) em Port Elizabeth e Despatch, África do Sul, Bolin, Bolin e Kock (1996) em vários países da Europa: Bélgica, Alemanha, Grécia, Irlanda, Itália, Escócia, Espanha e Suécia), Kinirons e Stewart (1998) em Blefaste, Irlanda do Norte, e no Brasil por Peres, Bastos e Latorre (2000) em Florianópolis, Freire, Sheiham e Hardy (2001) em Goiânia, e Nicolau et al. (2003) em Cianorte, constataram que adolescentes de nível socioeconômico mais baixo (renda familiar) apresentavam índice CPO maior que aqueles de níveis mais altos. Em contrapartida, Estioko e Wright(1995), na Austrália, e Taani(1996), na Jordânia, não encontraram diferença significante entre CPO-D e nível socioeconômico (Quadro 2.1).

O nível de educação formal dos pais não foi relacionado àalta prevalência de cárie dentária nos adolescentes da cidade de Cianorte, Paraná, Brasil (NICOLAU et al., 2003). Em Florianópolis, Peres, Bastos e Latorre (2000) constataram que o 
alto grau de escolaridade paterna estava associada aos adolescentes com baixo índice CPO-D, igual ou menor a 1, porém o nível de escolaridade materna não apresentou associação. Nadanovsky e Sheiham (1995) observaram que quanto maior a educação formal da mãe, menor o CPO-D dos adolescentes em 18 países industrializados (Itália, Espanha, Portugal, Grécia, Alemanha Ocidental, França, Irlanda, Austrália, Nova Zelândia, Bélgica, Suíça, Estados Unidos, Reino Unido, Suécia, Holanda, Normandia, Finlândia e Dinamarca); a mesma tendência foi verificada em Goiânia, por Freire, Sheiham e Hardy (2001).

Em estudantes com 12 anos de idade da rede pública de ensino da zona urbana do interior de Goiás, Freire et al. (1999) constataram que apenas 4,4\% não apresentavam lesões de, 20\% apresentavam CPO-D superior a 8 , e 47,3\% entre 4 e 7, sendo que esses resultados foram considerados preocupantes pelos pesquisadores.

No levantamento epidemiológico realizado no Estado de São Paulo, em 1998, através do convênio firmado entre a Faculdade de Saúde Pública da Universidade de São Paulo e a Secretaria de Estado da Saúde de São Paulo, foi constatado que os alunos com 12 e 18 anos de escolas públicas apresentaram um CPO-D (3,83 e 8,84) maior que aqueles matriculados em escolas particulares $(1,72$ e 6,15$)$ respectivamente (SÃO PAULO, 1999). Essa tendência de prevalência de cárie dentária maior naqueles adolescentes matriculados em escolas da rede pública de ensino também foi encontrada na cidade do México (IRIGOYEN; MAUPOMÉ; MEJÍA, 1999) e em Porto Alegre, Rio Grande do Sul (MALTZ; SILVA, 2001). No estudo de Irigoyen, Maupomé e Mejia (1999), 28,6\% dos adolescentes das escolas particulares não apresentaram cárie dentária contra 9,5\% daqueles de escolas públicas (Quadro 2.1). 
Na cidade de Salvador, não houve diferença estatisticamente significante entre o CPO-D dos adolescentes das escolas públicas, comparados com aqueles de escolas particulares (CANGUSSU et al., 2002) o mesmo ocorrendo na Jordânia (TAANI, 2002) (Quadro 2.1).

Källestæ (1991) comparou os índices CPO-D e CPO-S em adolescentes do norte da Suécia de uma cidade urbana e outra rural. Esses índices foram estatisticamente menores naqueles residentes na zona rural, quando comparados com os da cidade da região urbana (Quadros 2.1 e 2.2).

Para verificar a associação entre fatores biológicos, comportamentais, socioeconômicos e condição psicológica da criança nos primeiros anos de vida com cárie dentária aos 13 anos de idade, Nicolau et al. (2003) avaliaram 330 famílias de adolescentes de escolas públicas e privadas da cidade Cianorte, Brasil. Foi constatado que os fatores de risco relacionados aos primeiros anos de vida para o alto índice de cárie dentária aos 13 anos de idade foram os seguintes: baixo peso ao nascimento, não ser o primogênito da família, casa não feita com tijolos e renda familiar inferior a 5 salários mínimos. O nível de escolaridade formal dos pais, consumo de açúcar, quantidade de biofilme dental e higiene bucal aos 13 anos de idade não foram relacionados à alta prevalência de cárie dentária. Assim, esse estudo mostrou que houve uma associação entre fatores socioeconômicos e biológicos na primeira infância com a prevalência de cárie dentária em adolescentes.

Em relação à idade do adolescente, vários estudos mostraram que a prevalência de cárie dentária aumentou com a idade (ALEKSEJUNIENE; ARNEBERG; ERIKSEN, 1996; ATTWOOD; BLINKHORN; MACMILLAN, 1990; CANGUSSU et al., 2002; DU PLESSIS, 1997; ESTIOKO; WRIGHT, 1995; FREIRE et al., 1999; IRIGOYEN; MAUPOMÉ; MEJÍA, 1999; KÄLESTÅL, 1991; KINGMAN et 
al., 1988; MIYASAKI; MORIMOTO, 1996; MOREIRA, 2003; MOREIRA; PEREIRA; OLIVEIRA, 1996; POULSEN, 1996; SÃO PAULO, 1999; SUNDBERG, 1996; TOLEDO et al., 1989).

O sexo do adolescente apresentou associação diferente nos estudos pesquisados, em alguns houve maior prevalência de cárie dentária no sexo masculino (KULAK-OZHAN et al., 2001; ÖGAARD; RÖSLER, 1991) em outros no sexo feminino (ALEKSEJUNIENE; ARNEBERG; ERIKSEN, 1996; KÄLESTÅL, 1991; MOREIRA, 2003) e ainda em alguns não foi encontrada diferença (DUMMER et al., 1987; ESTIOKO; WRIGHT, 1995; JONES et al., 1999; KÄLESTÅL, 1991; LARSSON; JOHANSSON; ERICSON, 1992; MOREIRA; SEVERO; ROSENBLATT, 2002; RAITIO; PIENIHÄKKINEN; SCHEININ, 1996).

No estudo de Kälestæ̊ (1991), foi encontrada diferença entre a prevalência de cárie dentária e o sexo do adolescente, apenas na faixa etária dos 18 anos, na qual as meninas apresentavam prevalência mais alta que os meninos. Dummer et al. (1987) também só verificaram diferença na prevalência de cárie dentária entre os adolescentes com nível socioeconômico mais alto, sendo que as meninas apresentaram um CPO-S maior que o dos meninos.

Jones et al. (1999) verificaram que não houve associação entre o sexo e - CPO-D; porém, ao separar os componentes deste índice, observaram que a prevalência de dentes cariados era maior no sexo masculino, enquanto no sexo feminino, a prevalência de dentes restaurados era maior.

Bolin et al. (1997) não encontraram associação entre a idade do pai ou da mãe dos adolescentes com 12 anos de idade, de 8 países da Europa, com a prevalência de cárie dentária desses adolescentes. 
2.2.3 fatores comportamentais (higiene bucal, ida ao cirurgião-dentista e assistir televisão)

Axelsson (2000a) afirmou que a cárie dentária não se desenvolve em dentes limpos, mesmo com consumo freqüente de açúcar e sem a presença do flúor.

Estudando os fatores do comportamento relacionado à higiene bucal em adolescentes entre 14 e17 anos de idade de escolas pública e privada da cidade de Belo Horizonte, Minas Gerais, Silva, Paixão e Pordeus (1997) encontraram que a escovação dental apresentou comportamento complexo, pois diversos fatores influenciaram sua prática. Observaram, também, que praticamente a metade dos adolescentes relatou que escovavam seus dentes para evitar a cárie dentária, e que a mãe foi a principal responsável pelo ensino da escovação.

Segundo Duggal e van Loveren (2001), crianças com alto risco de cárie dentária devem realizar a higiene bucal duas vezes ao dia, com dentifrício fluoretado, além de obter aconselhamento alimentar.

Beighton, Adamson e Rugg-Gunn (1996) encontraram que uma higiene bucal ineficiente em adolescentes que não apresentavam nenhuma restrição alimentar influenciou os níveis salivares de $S$. mutans e lactobacilos, independentemente da freqüência ou quantidade de açúcar consumido.

Kleemola-Kujala e Räsänen (1982) encontraram associação significante entre a quantidade de biofilme dental e a cárie dentária em grupo de crianças e adolescentes de região com baixo nível de flúor na água de abastecimento $(0,10$ 0,46 ppm) independentemente da quantidade de alimentos açucarados consumidos. 
Portanto, os resultados desse estudo sugerem que uma higiene bucal ineficiente pode promover a cárie dentária, mesmo quando o consumo de sacarose é baixo.

A freqüência de escovação dental foi estatisticamente associada à baixa atividade de cárie dentária, sendo que os resultados desse estudo apontaram para a importância da boa higiene bucal e uso freqüentes de fluoretos como reguladores do incremento da cárie dentária (STECKSÉN-BLICKS; GUSTAFFSON, 1986).

Em adolescentes lituanos, Aleksejuniene, Arneberg e Eriksen (1996) encontraram uma correlação fraca entre nível de higiene bucal e cárie dentária. No Brasil, Nicolau et al. (2003) não encontraram associação significativa entre o índice CPO-D e quantidade de biofilme dental ou vezes de higienizaçao da cavidade oral nos adolescentes de Cianorte.

Dummer et al. (1987) verificaram que a quantidade de biofilme dental e freqüência de higienização da cavidade oral estavam associados ao nível socioeconômico dos adolescentes, sendo que aqueles de nível mais baixo, apresentavam índices de biofilme mais altos que aqueles de alto nível, assim como também menos freqüência de escovação dental. No estudo realizado por Kälestæ̊ (1991), o número dos adolescentes residentes na zona rural da Suécia que usavam o fio dental mais de três vezes por semana foi bem maior quando comparado com os da zona urbana.

Em Istambul, Kulak-Özkan et al. (2001), ao avaliar 150 adolescentes entre 15 e 18 anos de idade, verificaram que $75 \%$ deles escovavam os dentes uma vez ao dia ou menos, e $27 \%$ utilizavam o fio dental.

No estudo de Brathall, Hänsel-Petersson e Sundberg (1996) com 30 "experts" mundiais da cariologia, e como esses profissionais graduaram o impacto de vários fatores na prevalência da cárie dentária, verificaram que apenas o uso do 
dentifrício fluoretado foi apontado pela maioria e associado ao seu efeito preventivo., sendo que $65 \%$ assinalaram como muito importante e $33 \%$ como importante. Em relação à higiene bucal, redução do biofilme dental, 29\% e 10\% descreveram como sendo importante ou muito importante, respectivamente, contra $35 \%$ que mencionaram ser pouco importante.

Em relação à visita ao dentista, Kinirons e Stewart (1998) constataram que os adolescentes que foram há mais tempo ao dentista, apresentaram um CPO-D maior do que aqueles que foram há menos tempo.

Segundo o estudo realizado por Hawley, Holloway e Davies (1997), os adolescentes que procuram assistência odontológica sem apresentarem sintomas sofrem menos exodontias e têm mais dentes selados que aqueles que procuram atendimento quando o sintoma já está instalado.

Moreira, Severo e Rosenblatt (2002) verificaram que a prevalência de cárie dentária foi maior naqueles que faziam visitas periódicas ao dentista em relação àqueles que não costumavam fazê-la (73,6\% versus $65,7 \%)$, porém não foi significante. 


\begin{tabular}{|c|c|c|c|c|c|}
\hline Autores (ano do trabalho) & $\frac{\text { ano }}{\text { CPO-D }}$ & $\frac{\text { ano }}{\text { CPO-D }}$ & $\frac{\text { ano }}{\text { CPO-D }}$ & $\frac{\text { ano }}{C P O-D}$ & Informações adicionais \\
\hline $\begin{array}{l}\text { Dummer et al. (1987) } \\
\text { - socioeconômico alto } \\
\text { - socioeconômico baixo }\end{array}$ & $\underline{1981}$ & $-\cdots--\cdot$ & ----- & ------ & $\begin{array}{l}\text { - Local do estudo: South Whales, Grã-Bretanha } \\
\text { - Data de realização: } 1981 \\
\text { - Tipo de estudo: transversal } \\
\text { - Total da amostra: } 1015 \text { adolescentes entre } 11 \text { e } 12 \text { anos de } \\
\text { idade } \\
\text { - Metodologia: levantamento do CPO-D } \\
\text { - Observações importantes: além do exame clínico, foram } \\
\text { realizadas radiografias interproximais }\end{array}$ \\
\hline Toledo et al. (1989) & $\underline{1989}$ & ----- & ----- & ------ & $\begin{array}{l}\text { - Local do estudo: Distrito Federal, Brasil } \\
\text { - } \text { Data de realização: ---- } \\
\text { - Tipo de estudo: transversal } \\
\text { - Total da amostra: } 201 \text { estudantes entre } 6 \text { e } 13 \text { anos de } \\
\text { idade } \\
\text { - Metodologia: levantamento do CPO-D, avaliação da dieta } \\
\text { por_inquérito nutricional de } 24 \text { horas } \\
\text { Observações importantes: ---- }\end{array}$ \\
\hline $\begin{array}{l}\text { Attwood,Blinkhorn } \\
\text { MacMillan(1990) } \\
12 \text { anos de idade } \\
15 \text { anos de idade } \\
\text { - } 12 \text { anos de idade } \\
\text { socioeconômico alto } \\
\text { socioeconômico baixo } \\
\text { - } 15 \text { anos de idade } \\
\text { socioeconômico baixo } \\
\text { socioeconômico alto }\end{array}$ & $\begin{array}{l}\frac{1984}{4,71} \\
7,97 \\
4,34 \\
5,18\end{array}$ & $\begin{array}{l}\frac{1987}{2,91} \\
5,56 \\
2,14 \\
3,79 \\
7,40 \\
4,09\end{array}$ & ----- & ------ & $\begin{array}{l}\text { - Local do estudo: Glasglow, Reino Unido } \\
\text { - } \frac{\text { Data de realização: } 1984 \text { e } 1987}{\text { - Tipo de estudo: comparativo }} \\
\text { - } \frac{\text { Total da amostra: --- }}{\text { - Metodologia: levantamento de CPO-D }} \\
\text { - } \text { Observações importantes: ---- }\end{array}$ \\
\hline
\end{tabular}

Quadro 2.1 - Resumo sucinto dos trabalhos que utilizaram o índice CPO-D 


\begin{tabular}{|c|c|c|c|c|c|}
\hline Autores (ano do trabalho) & $\frac{\text { ano }}{\text { CPO-D }}$ & $\frac{\text { ano }}{\text { CPO-D }}$ & $\frac{\text { ano }}{\text { CPO-D }}$ & $\frac{\text { ano }}{\text { CPO -D }}$ & Informações adicionais \\
\hline $\begin{array}{l}\text { Kalestal (1991) } \\
\text { - } \quad 16 \text { anos de idade } \\
\text { cidade } \\
\text { campo } \\
\text { - } \quad 18 \text { anos de idade } \\
\text { cidade } \\
\text { campo }\end{array}$ & $\begin{array}{l}5,6 \\
4,2 \\
7,1 \\
5,6\end{array}$ & ----- & ------ & ------- & $\begin{array}{l}\text { - Local do estudo: Vasterbotten, Suécia } \\
\text { - } \frac{\text { Data de realização: } 1987}{\text { Tipo de estudo: transversal }} \\
\text { - } \frac{\text { Total da amostra: } 570 \text { de } 16 \text { e } 18 \text { anos de idade }}{\text { - }} \text { Metodologia: levantamento de CPO-D e CPO-S } \\
\text { Observações importantes: participaram de programa } \\
\text { preventivo com orientação de dieta e higiene bucal, aplicação } \\
\text { tópica de flúor desde a dentição decídua e bochechos com } \\
\text { solução fluoretadas semanais a partir dos } 13 \text { anos de idade }\end{array}$ \\
\hline $\begin{array}{l}\text { Treasure e Dever (1994) } \\
\text { - Água fluoretada } \\
\text { - Descontinuidade de água } \\
\text { fluoretada } \\
\text { - Sem água fluoretada }\end{array}$ & $\begin{array}{l}\frac{1994}{2,4} \\
2,8 \\
4,37\end{array}$ & ----- & $---\cdot$ & ----- & $\begin{array}{l}\text { - Local do estudo: Nova Zelândia } \\
\text { - } \text { Data de realização: -- } \\
\text { - Tipo de estudo: transversal } \\
\text { - } \quad \text { Total da amostra: } 413 \\
\text { - Método: levantamento de CPO-D e CPO-S } \\
\text { - } \text { Observações importantes: -- }\end{array}$ \\
\hline $\begin{array}{l}\text { Estioko e Wright (1995) } \\
\text { - } 11-13 \text { anos de idade } \\
\text { - } 14-16 \text { anos de idade }\end{array}$ & $\begin{array}{l}3,22 \\
6,26\end{array}$ & $\begin{array}{l}1,50 \\
1,91\end{array}$ & ---- & ---- & $\begin{array}{l}\text { - Local do estudo: Heidelberg (Victoria), Austrália } \\
\text { - Data de realização: } 1991 \\
\text { - Tipo de estudo: transversal comparativo } \\
\text { - Total da amostra: } 403 \\
\text { - Metodologia: levantamento de CPO-D } \\
\text { - Observações importantes: água fluoretada desde } 1977\end{array}$ \\
\hline
\end{tabular}




\begin{tabular}{|c|c|c|c|c|c|}
\hline Autores (ano do trabalho) & $\stackrel{\text { ano }}{\text { CPO-D }}$ & $\stackrel{\text { ano }}{\text { CPO-D }}$ & $\stackrel{\text { ano }}{\text { CPO-D }}$ & $\stackrel{\text { ano }}{\text { CPO -D }}$ & Informações adicionais \\
\hline Nadanovsky e Sheiham (1995) & 1960-1978 & $\underline{1975-1985}$ & & & \\
\hline Itália & $\frac{1962}{0,6}$ & $\frac{1983}{4,1}$ & & & $\begin{array}{l}\text { - Local do estudo: vários países } \\
\text { - } \quad \text { Data de realização: entre } 1970 \text { e } 1980 \\
\text { - } \quad \text { Tipo de estudo: comparativo }\end{array}$ \\
\hline Espanha & $\frac{1968}{1,9}$ & $\frac{1983}{3,7}$ & & & $\begin{array}{l}\text { - Total da amostra: adolescentes com } 12 \text { anos de idade } \\
\text { - Metodologia: comparar índice CPO-D, }\end{array}$ \\
\hline Portugal & $\frac{1960}{2,3}$ & $\frac{1979}{4,6}$ & & & - Observações importantes: ---- \\
\hline Grécia & $\frac{1963}{3,2}$ & $\begin{array}{c}1978 \\
5,0\end{array}$ & & & \\
\hline Alemanha Ocidental & $\frac{1973}{5,5}$ & $\frac{1983}{5,7}$ & & & \\
\hline França & $\frac{1975}{3,5}$ & $\frac{1982}{3,4}$ & & & \\
\hline Irlanda & $\frac{1961}{4,7}$ & $\frac{1984}{2,9}$ & & & \\
\hline Austrália & $\frac{1960}{6,9}$ & $\frac{1975}{4,8}$ & & & \\
\hline Nova Zelândia & $\frac{1973}{6,0}$ & $\frac{1978}{5,3}$ & & & \\
\hline Bélgica & $\frac{1967}{7,4}$ & $\frac{1983}{3,9}$ & & & \\
\hline Suíça & $\frac{1969}{5,4}$ & $\frac{1979}{3,4}$ & & & \\
\hline Estados Unidos & $\frac{1972}{3,8}$ & $\frac{1979}{2,6}$ & & & \\
\hline
\end{tabular}


Continuação

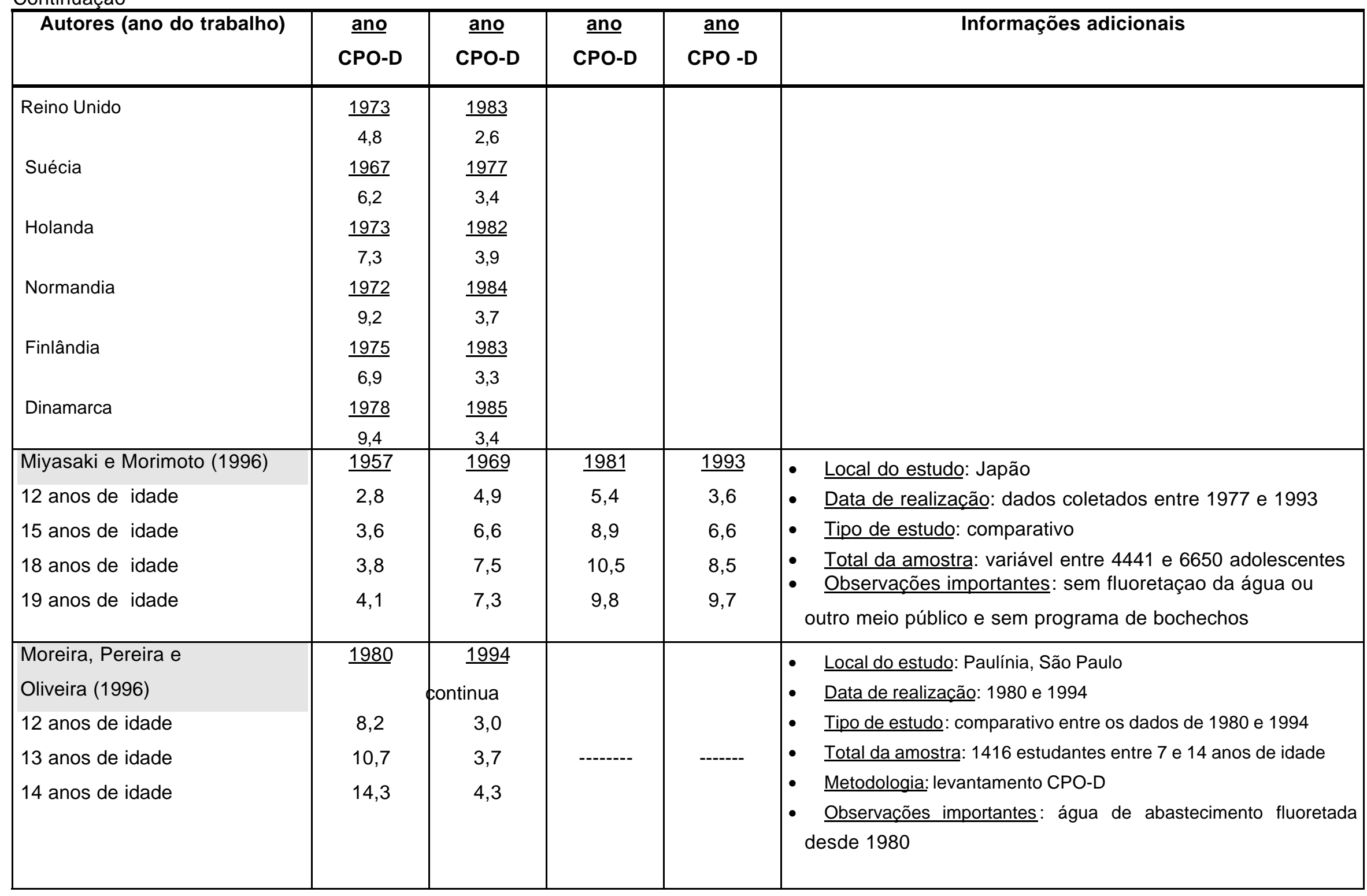




\begin{tabular}{|c|c|c|c|c|c|}
\hline Autores (ano do trabalho) & $\frac{\text { ano }}{\text { CPO-D }}$ & $\begin{array}{l}\text { ano } \\
\text { CPO-D }\end{array}$ & $\frac{\text { ano }}{\text { CPO-D }}$ & $\begin{array}{l}\frac{\text { ano }}{\text { CPO -D }} \\
\text {. }\end{array}$ & Informações adicionais \\
\hline $\begin{array}{l}12 \text { anos de idade } \\
19 \text { anos de idade }\end{array}$ & $\begin{array}{l}2,8 \\
8,5\end{array}$ & $\begin{array}{l}2,6 \\
----\end{array}$ & $\begin{array}{l}1,4 \\
5,2\end{array}$ & ---- & $\begin{array}{l}\text { - Local do estudo: Suécia } \\
\text { - } \text { Data de realização: } 1985 \text { e } 1994 \\
\text { - } \frac{\text { Tipo de estudo: comparativo entre registros de } 10 \text { anos }}{\text { - }} \text { Total da amostra: ----- } \\
\text { - Metodologia: avaliação dos registros odontológicos dos } \\
\text { pacientes em atendimento público nacional } \\
\text { - Observações importantes: não houve calibração entre } \\
\text { examinadores, porém houve explicação em relação æ̀s } \\
\text { informações a serem coletadas }\end{array}$ \\
\hline $\begin{array}{l}\text { Aleksejuniene, Arneberg e } \\
\text { Eriksen (1996) } \\
7 \text { anos de idade } \\
12 \text { anos de idade } \\
15 \text { anos de idade }\end{array}$ & $\begin{array}{l}1,3 \\
4,9 \\
7,0\end{array}$ & & & & $\begin{array}{l}\text { - Local do estudo: Lituânia } \\
\text { - } \text { Data de realização: } 1993-1994 \\
\text { - } \frac{\text { Tipo de estudo: transversal }}{\text { - }} \text { Total da amostra: } 551 \text { aos } 7 \text { anos de idade; } 735 \text { aos } 12 \\
\text { anos e } 515 \text { aos } 15 \text { anos } \\
\text { - Metodologia: levantamento de CPO-D e índice de higiene } \\
\text { bucal } \\
\text { - Observações importantes: ----- }\end{array}$ \\
\hline $\begin{array}{l}\text { Hawley, Holloway e } \text { Davies } \\
\text { (1997) }\end{array}$ & $\underline{1996}$ & dontinua & ----- & ------ & 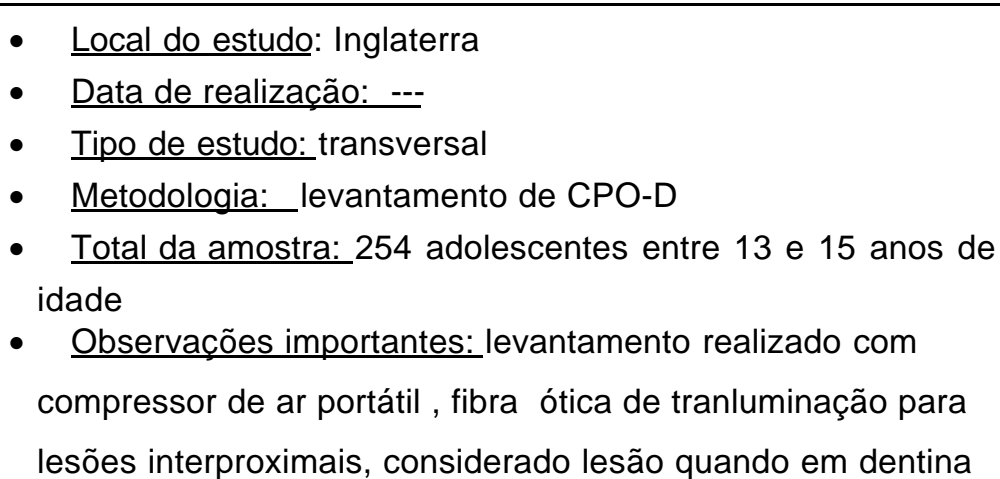 \\
\hline
\end{tabular}




\begin{tabular}{|c|c|c|c|c|c|}
\hline Autores (ano do trabalho) & $\frac{\text { ano }}{\text { CPO-D }}$ & $\frac{\text { ano }}{\text { CPO-D }}$ & $\frac{\text { ano }}{\text { CPO-D }}$ & $\frac{\text { ano }}{C P O-D}$ & Informações adicionais \\
\hline $\begin{array}{l}\text { Bolin, Bolin e Koch (1996) } \\
12 \text { anos de idade } \\
\text { Bélgica } \\
\text { Alemanha } \\
\text { Grécia } \\
\text { Irlanda } \\
\text { Itália } \\
\text { Escócia } \\
\text { Espanha } \\
\text { Suécia }\end{array}$ & $\begin{array}{l}1,93 \\
2,58 \\
2,35 \\
1,85 \\
2,24 \\
1,82 \\
1,75 \\
1,94\end{array}$ & ------- & ------ & ------- & $\begin{array}{l}\text { - Local do estudo: } 8 \text { países da Europa } \\
\text { - Data de realização: } 1993-1994 \\
\text { - Tipo de estudo: comparativo } \\
\text { - Metodologia: levantamento CPO-D } \\
\text { - Total da amostra: } 3200 \text { crianças entre } 5 \text { e } 12 \text { anos de idade } \\
\text { - } \text { Observações importantes: ---- }\end{array}$ \\
\hline $\begin{array}{l}\text { Taani (1996) } \\
\text { Média do grupo } \\
\text { - socioeconômico muito baixo } \\
\text { - socioeconômico baixo } \\
\text { - socioeconômico moderado } \\
\text { - socioeconômico alto }\end{array}$ & $\begin{array}{l}\frac{1996}{4,7} \\
4,6 \\
4,5 \\
4,9 \\
5,0\end{array}$ & ------- & ------ & ------- & $\begin{array}{l}\text { - Local do estudo: Jordânia } \\
\text { - } \text { Data de realização: -- } \\
\text { - Tipo de estudo: transversal } \\
\text { - } \frac{\text { Total da amostra: } 1375 \text { adolescentes entre } 13-14 \text { anos de }}{\text { idade }} \\
\text { - Metodologia: levantamento CPO-D e CPO-S } \\
\text { - Observações importantes:--- }\end{array}$ \\
\hline $\begin{array}{l}\text { du Plessis (1997) } \\
\text { Baixo nível de água } \\
\text { fluoretada } \\
12 \text { anos de idade } \\
\text { - socioeconômico baixo } \\
\text { - socioeconômico médio } \\
\text { - socioeconômico alto }\end{array}$ & $\begin{array}{l}1,7 \\
1,5 \\
1,3\end{array}$ & & & & $\begin{array}{l}\text { - Local do estudo: Port Elizabeth e Despatch, África do Sul } \\
\text { - } \text { Data de realização: --- } \\
\text { - Tipo de estudo: transversal } \\
\text { - Total da amostra: } 1688 \text { com 6,12 e } 15 \text { anos de idade } \\
\text { - Metodologia: levantamento de CPO-D } \\
\text { - } \text { Observações importantes: --- }\end{array}$ \\
\hline
\end{tabular}


Continuação

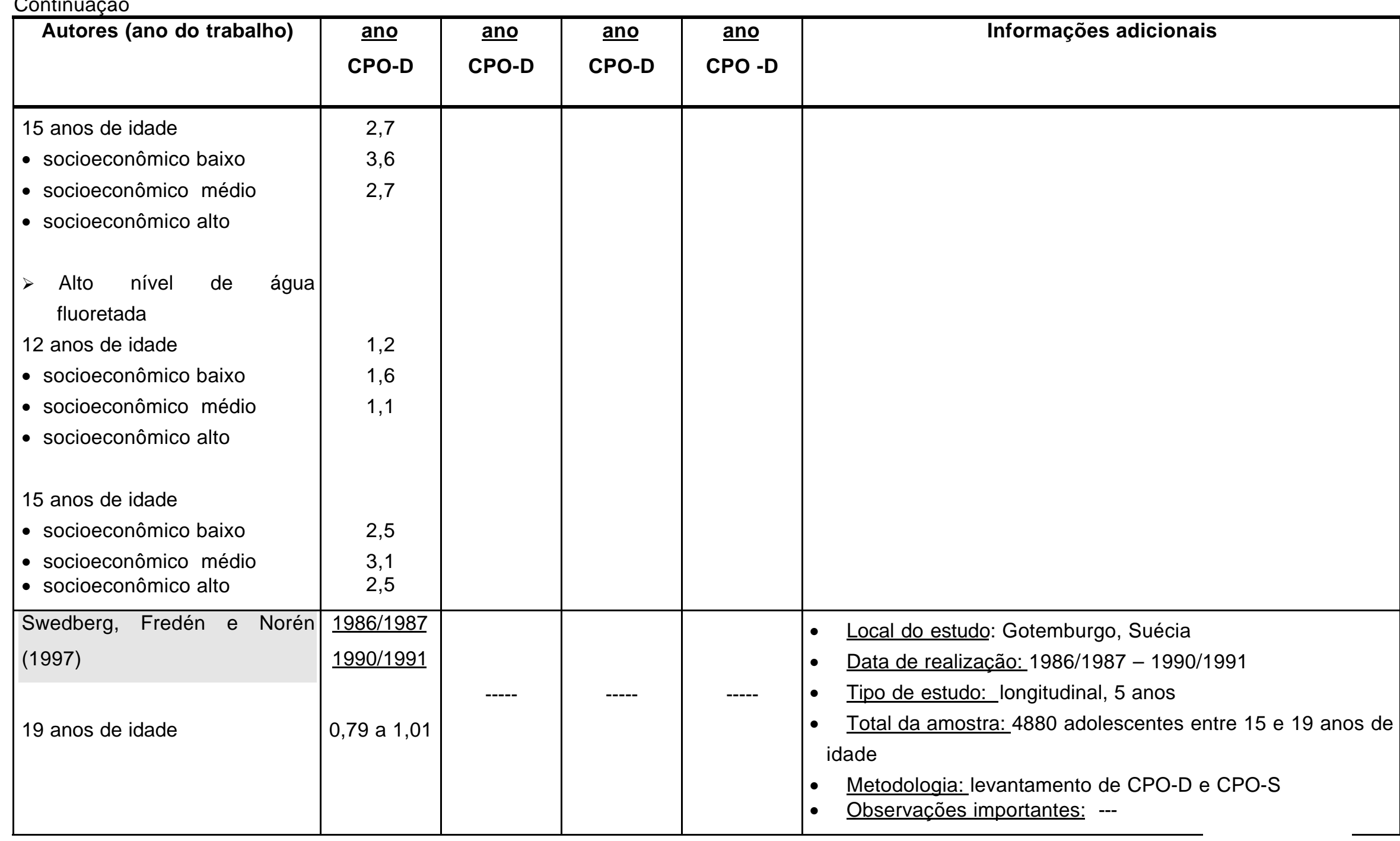




\begin{tabular}{|c|c|c|c|c|c|}
\hline Autores (ano do trabalho) & $\frac{\text { ano }}{\text { CPO-D }}$ & $\frac{\text { ano }}{\text { CPO-D }}$ & $\frac{\text { ano }}{\text { CPO-D }}$ & $\frac{\text { ano }}{\text { CPO -D }}$ & Informações adicionais \\
\hline $\begin{array}{l}\text { Irigoyen, Maupomé e Mejía } \\
\text { (1999) } \\
\text { - } 6 \text { anos de idade } \\
\text { escola pública } \\
\text { escola particular } \\
\text { - } 8 \text { anos de idade } \\
\text { escola pública } \\
\text { escola particular } \\
\text { - } 10 \text { anos de idade } \\
\text { escola pública } \\
\text { escola particular } \\
\text { - } 12 \text { anos de idade } \\
\text { escola pública } \\
\text { escola particular }\end{array}$ & $\begin{array}{l}1998 \\
\\
0,54 \\
0,26 \\
1,94 \\
1,41 \\
3,06 \\
2,01 \\
4,64 \\
2,78 \\
\end{array}$ & & & & $\begin{array}{l}\text { - Local do estudo: Cidade do México, México } \\
\text { - Data de realização: } 1988 \\
\text { - Tipo de estudo: transversal } \\
\text { - } \frac{\text { Total da amostra: } 4048 \text { (546 escola particular e } 3502 \text { de }}{\text { escolas públicas) }} \\
\text { - Metodologia: levantamento CPO-D } \\
\text { - Observaç̃os importantes: sem água fluoretada ou outro } \\
\text { meio de fluoretação pública }\end{array}$ \\
\hline $\begin{array}{l}\text { São Paulo (1999) } \\
12 \text { anos de idade } \\
18 \text { anos de idade } \\
12 \text { anos de idade } \\
\text { escola pública } \\
\text { escola particular } \\
18 \text { anos de idade } \\
\text { escola pública } \\
\text { escola particular }\end{array}$ & $\begin{array}{l}\frac{1998}{3,72} \\
8,64 \\
3,83 \\
1,73\end{array}$ & ----- & ----- & ------ & $\begin{array}{l}\text { - Local do estudo: Estado de São Paulo } \\
\text { - } \text { Data de realização: } 1998 \\
\text { - Tipo de estudo: transversal } \\
\text { - Total da amostra: } 9323 \text { adolescentes com } 12 \text { anos e } \\
\text { - } 5195 \text { com } 18 \text { anos de idade } \\
\text { - Metodologia: levantamento CPO-D e CPO-S } \\
\text { Observações importantes: } 93 \% \text { eram de escolas públicas }\end{array}$ \\
\hline
\end{tabular}




\begin{tabular}{|c|c|c|c|c|c|}
\hline Autores (ano do trabalho) & $\stackrel{\text { ano }}{\text { CPO-D }}$ & $\frac{\text { ano }}{\text { CPO-D }}$ & $\stackrel{\text { ano }}{\text { CPO-D }}$ & $\frac{\text { ano }}{\text { CPO -D }}$ & Informações adicionais \\
\hline Freire et al. (1999) & $\underline{1994}$ & ------ & ----- & ------ & $\begin{array}{l}\text { - Local do estudo: Estado de Goiás } \\
\text { - Data de realização: } 1994 \\
\text { - Tipo de estudo: transversal } \\
\text { - Total da amostra: } 1419 \text { crianças entre } 6 \text { e } 12 \text { anos de idade } \\
\text { - } \text { Metodologia: levantamento de CPO-D e CPO-S } \\
\text { Observações importantes: crianças de escolas públicas; } \\
\text { alguns municípios com água fluoretada desde 1990-1993 }\end{array}$ \\
\hline $\begin{array}{l}\text { Moreira, Severo e Rosenblatt } \\
\text { (2002) } \\
\text { Desnutrido } \\
\text { Eutrófico } \\
\text { Sobrepeso } \\
\text { obesos }\end{array}$ & $\begin{array}{l}3,96 \\
4,33 \\
3,70 \\
5,29\end{array}$ & & & & $\begin{array}{l}\text { - Local do estudo: João Pessoa, Paraíba, Brasil } \\
\text { - } \text { Data de realização: } 2002 \\
\text { - Tipo de estudo: transversal } \\
\text { Total da amostra: } 100 \text { adolescentes entre } 12 \text { e } 15 \text { anos de } \\
\text { idade } \\
\text { Metodologia: levantamento de CPO-D, questionário } \\
\text { recordatório de } 24 \text { horas; avaliação do numero de refeições } \\
\text { cariogênicas por dia } \\
\text { - Observacões importantes: --- }\end{array}$ \\
\hline $\begin{array}{l}\text { Cangussu et al, (2002) } \\
12 \text { anos de idade } \\
\text { escola pública } \\
\text { escola particular } \\
15 \text { anos de idade } \\
\text { escola pública } \\
\text { escola particular } \\
\end{array}$ & $\begin{array}{l}2,38 \\
2,69\end{array}$ & ------ & ----- & ----- & $\begin{array}{l}\text { - Local do estudo: Salvador (Bahia), Brasil } \\
\text { - } \quad \text { Data de realização: -- } \\
\text { - } \frac{\text { Tipo de estudo: transversal }}{\text { - }} \text { Total da amostra: } 2808 \text { (1404 com } 12 \text { anos de idade e } \\
1404 \text { com } 15 \text { anos de idade) } \\
\text { - Metodologia : levantamento de CPO-D } \\
\text { - } \text { Observações importantes: sem fluoretação na água de } \\
\text { abastecimento; serviço de saúde cirúrgico-restaurador }\end{array}$ \\
\hline
\end{tabular}




\begin{tabular}{|c|c|c|c|c|c|}
\hline Autores (ano do trabalho) & 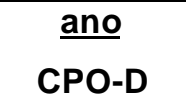 & $\begin{array}{l}\underline{\text { ano }} \\
\text { CPO-D }\end{array}$ & $\frac{\underline{\text { ano }}}{\text { CPO-D }}$ & $\frac{\text { ano }}{C P O-D}$ & Informações adicionais \\
\hline $\begin{array}{l}\text { Taani (2002) } \\
\text { Escola pública } \\
\text { Escola particular }\end{array}$ & $\begin{array}{l}\underline{2002} \\
2,9 \\
2,1\end{array}$ & & ---- & ----. & $\begin{array}{l}\text { - Local do estudo: Jordânia } \\
\text { - Data de realização: --- } \\
\text { - } \text { Tipo de estudo: transversal } \\
\text { - } \frac{\text { Total da amostra: } 1021 \text { adolescentes entre } 12 \text { e } 15 \text { anos de }}{\text { idade }} \\
\text { - Metodologia: levantamento de CPO-D e CPO-S } \\
\text { - } \text { Observações importantes: ---- }\end{array}$ \\
\hline Nicolau et al. (2003) & $\underline{1999}$ & ------ & ----- & ------- & $\begin{array}{l}\text { - Local do estudo: Cianorte, Brasil } \\
\text { - Data de realização: } 1999 \\
\text { - Tipo de estudo: transversal } \\
\text { - Total da amostra: } 330 \text { adolescentes com } 13 \text { anos de idade } \\
\text { - Metodologia: levantamento de CPO-D } \\
\text { - Observações importantes: ---- }\end{array}$ \\
\hline $\begin{array}{l}\text { Moreira (2003) } \\
\text { - } \text { Escola particular } \\
\text { - } 12 \text { anos de idade } \\
\text { - } 13 \text { anos de idade } \\
\text { - } 14 \text { anos de idade } \\
\text { - } 15 \text { anos de idade } \\
\text { - } \text { Escola pública } \\
\text { - } 12 \text { anos de idade } \\
\text { - } 13 \text { anos de idade } \\
\text { - } 14 \text { anos de idade } \\
\text { - } 15 \text { anos de idade }\end{array}$ & $\begin{array}{l}1,35 \\
1,62 \\
2,43 \\
2,88\end{array}$ & & 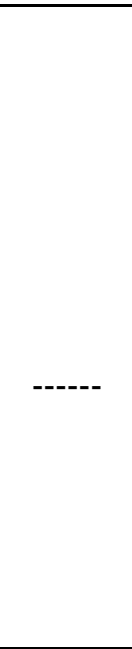 & ---י & $\begin{array}{l}\text { - Local do estudo: João Pessoa, Paraíba } \\
\text { - } \text { Data de realização: 2002-2003 } \\
\text { - Tipo de estudo: transversal } \\
\text { - } \text { Total da amostra: } 3330 \text { adolescentes entre } 12 \text { e } 15 \text { anos } \\
\text { - Metodologia: levantamento de CPO-D } \\
\text { - } \text { Observacõos importantes: }\end{array}$ \\
\hline
\end{tabular}



Continuação

\begin{tabular}{|c|c|c|c|c|c|}
\hline Autores (ano do trabalho) & $\frac{\text { ano }}{\text { CPO-S }}$ & $\frac{\text { ano }}{\text { CPO-S }}$ & $\frac{\text { ano }}{\text { CPO-S }}$ & $\frac{\text { ano }}{\text { CPO-S }}$ & Informações adicionais \\
\hline $\begin{array}{l}\text { Stecksén-Blicks e Gustafsson } \\
(1986)\end{array}$ & 1986 & ------- & ------ & ------- & $\begin{array}{l}\text { - } \text { Local do estudo: Umeå Suécia } \\
\text { - } \text { Data de realização: --- } \\
\text { - } \frac{\text { Tipo de estudo: longitudinal, } 1 \text { ano }}{\text { - }} \text { Metal da amostra: } 97 \text { adolescentes com } 13 \text { anos de idade } \\
\text { inclusão de lesão de carie inicial; histórico alimentar e consumo de } \\
\text { açúcar em gramas/dia; índice de sangramento gengival; coleta de } \underline{\text { S. }} \\
\text { mutans e lactobacilos } \\
\text { Observações importantes: bochecho semanal com NaF, profilaxia } \\
\text { profissional e aplicação de verniz fluoretado; crianças tinham } \\
\text { atendimento odontológico gratuito }\end{array}$ \\
\hline $\begin{array}{l}\text { Källestå (1991) } \\
16 \text { anos de idade } \\
\text { cidade } \\
\text { campo } \\
18 \text { anos de idade } \\
\text { cidade } \\
\text { campo }\end{array}$ & $\begin{array}{l}6,5 \\
4,9\end{array}$ & ------ & ------ & & 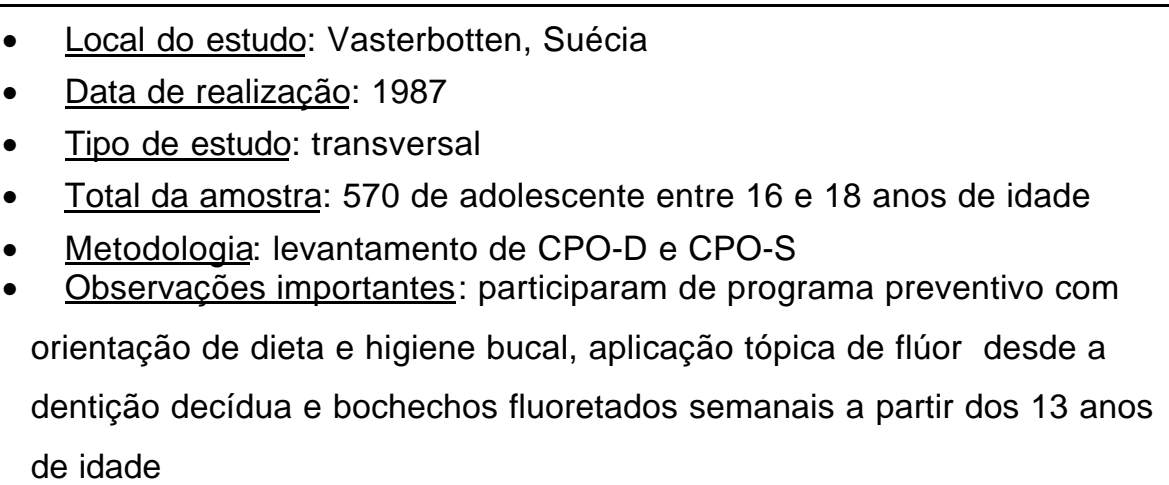 \\
\hline
\end{tabular}

Quadro 2.2 - Resumo sucinto dos trabalhos que utilizaram o índice CPO-S 
Continuação

\begin{tabular}{|c|c|c|c|c|c|}
\hline Autores (ano do trabalho) & $\frac{\text { ano }}{\text { CPO-S }}$ & $\frac{\text { ano }}{\text { CPO-S }}$ & $\frac{\text { ano }}{\text { CPO-S }}$ & $\frac{\text { ano }}{\text { CPO-S }}$ & Informações adicionais \\
\hline $\begin{array}{l}\text { Larsson, Johansson e Erickson } \\
\text { (1992) } \\
15 \text { anos de idade } \\
\text { * } 19 \% \text { sem restaurações ou } \\
\text { lesões de cárie }\end{array}$ & $\underline{1987-1989}$ & ------ & ----- & ------ & $\begin{array}{l}\text { - } \text { Local do estudo: Norsjö, Suécia } \\
\text { - } \text { Data de realização: } 1987 ; 1988,1989 \\
\text { - } \frac{\text { Tipo de estudo: transversal }}{\text { - }} \text { Total da amostra: } 199 \text { adolescentes de } 15 \text { anos de idade } \\
\text { - } \quad \text { Metodologia: levantamento CPO-S ; radiografias interproximais } \\
\text { - } \text { Observações importantes: baixo nível de fluoretação da água; } \\
\text { bochechos semanais com solução fluoretada a 0,2\%; consultas gratuitas } \\
\text { com aplicação tópica de flúor, orientação de dieta e higiene }\end{array}$ \\
\hline Larsson et al. (1995) & $\frac{1987}{4,4}$ & $\frac{1988}{3,7}$ & $\frac{1989}{3,3}$ & & $\begin{array}{l}\text { - } \text { Local do estudo: Suécia } \\
\text { - } \text { Data de realização: } 1987-1989 \\
\text { - } \frac{\text { Tipo de estudo: transversal }}{\text { - }} \text { Total da amostra: } 199 \text { adolescentes de } 15 \text { anos de idade } \\
\text { - } \frac{\text { Metodologia: levantamento de CPO-S ; radiografias interproximais }}{\text { - }} \text { Observações importantes: baixo nível de fluoretação da água; } \\
\text { bochechos semanais com solução fluoretada a 0,2\%; consultas gratuitas } \\
\text { com aplicação tópica de flúor, orientação de dieta e higiene. }\end{array}$ \\
\hline
\end{tabular}


Continuação

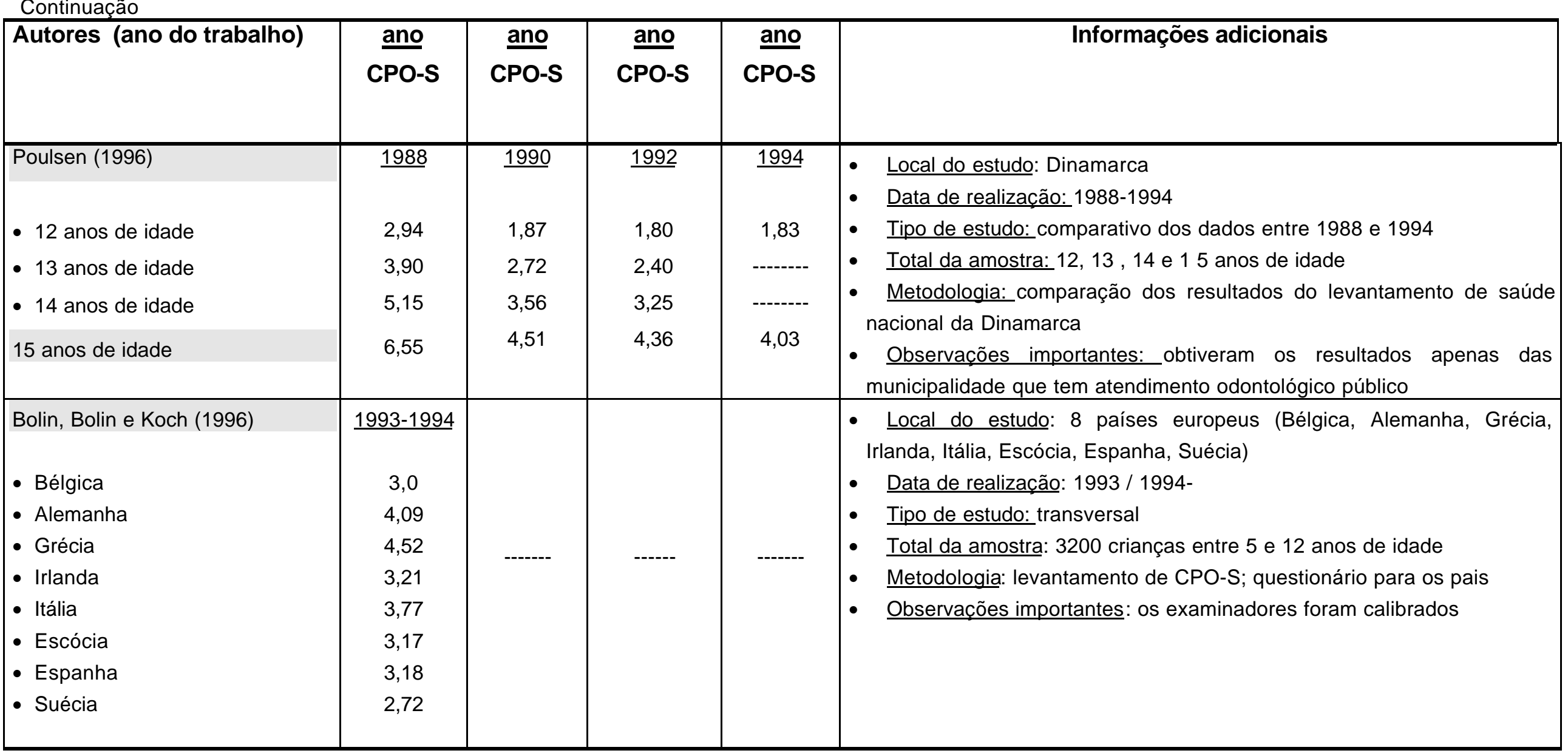


Continuação

\begin{tabular}{|c|c|c|c|c|c|}
\hline Autores (ano do trabalho) & $\frac{\text { ano }}{\text { CPO-S }}$ & $\frac{\text { ano }}{\text { CPO-S }}$ & $\frac{\text { ano }}{\text { CPO-S }}$ & $\frac{\text { ano }}{\text { CPO-S }}$ & Informações adicionais \\
\hline $\begin{array}{l}\text { Bolin et al. (1997) } \\
\text { - socioeconômico alto } \\
\text { socioeconômico baixo }\end{array}$ & $\underline{1993 / 1994}$ & & & & $\begin{array}{l}\text { - Local do estudo: } 8 \text { países europeus (Bélgica, Alemanha, Grécia, } \\
\text { Irlanda, Itália, Escócia, Espanha, Suécia) } \\
\text { - } \text { Data de realização: 1993/ 1994- } \\
\text { - } \frac{\text { Tipo de estudo: transversal }}{\text { - }} \text { Total da amostra: } 3200 \text { crianças entre } 5 \text { e } 12 \text { anos de idade } \\
\text { - } \text { Metodologia: levantamento CPO-S; questionário para os pais } \\
\text { - Observações importantes: examinadores forem calibrados }\end{array}$ \\
\hline $\begin{array}{l}\text { Kingman et al. (1988) } \\
\text { - } 10 \text { anos de idade } \\
\text { - } 12 \text { anos de idade } \\
\text { - } 14 \text { anos de idade } \\
\text { - } 15 \text { anos de idade }\end{array}$ & $\begin{array}{l}1,56 \\
4,07 \\
6,69 \\
7,86\end{array}$ & ------ & ------- & & $\begin{array}{l}\text { - Local do estudo: Coldwater, Michigan, Estado Unidos } \\
\text { - } \text { Data de realização: --- } \\
\text { - Tipo de estudo: longitudinal de } 3 \text { anos } \\
\text { - } \text { Total da amostra: } 541 \text { adolescentes entre } 10 \text { e } 15 \text { anos de idade } \\
\text { - Metodologia: levantamento de CPO-S; análise microbiológica da saliva } \\
\text { - } \text { Observações importantes: baixo nível de flúor em água de } \\
\text { abastecimento (menor que 0,2 ppm) }\end{array}$ \\
\hline $\begin{array}{l}\text { Maltz e Silva (2001) } \\
\text { - escola particular } \\
\text { - escola pública }\end{array}$ & 1998-1999 & ------ & ------ & -- & $\begin{array}{l}\text { - Local do estudo: Porto Alegre, Rio Grande do Sul } \\
\text { - } \text { Data de realização: } 1998 \text { e } 1999 \\
\text { - Tipo de estudo: transversal } \\
\text { - } \frac{\text { Total da amostra: } 1000 \text { estudantes com } 12 \text { anos de idade }}{\text { - Metodologia: levantamento de CPOS; escovação profissional prévia }} \\
\text { - Observações importantes: água de abastecimento público fluoretada } \\
\text { desde } 1975\end{array}$ \\
\hline
\end{tabular}


Continuação

\begin{tabular}{|c|c|c|c|c|c|}
\hline Autores (ano do trabalho) & $\frac{\text { ano }}{\text { CPO-S }}$ & $\frac{\text { ano }}{\text { CPO-S }}$ & $\frac{\text { ano }}{\text { CPO-S }}$ & $\frac{\text { ano }}{\text { CPO-S }}$ & Informações adicionais \\
\hline $\begin{array}{l}\text { Taani (2002) } \\
\text { escola pública } \\
\text { escola particular }\end{array}$ & $\begin{array}{l}2002 \\
3,86 \\
3,62\end{array}$ & ------ & ------- & ------- & $\begin{array}{l}\text { - } \text { Local do estudo: Jordânia } \\
\text { - } \text { Data de realização:--- } \\
\text { - } \frac{\text { Tipo de estudo: transversal }}{\text { - }} \text { Total da amostra: } 1021 \text { adolescentes entre } 12 \text { e } 15 \text { anos de idade } \\
\text { - } \text { Metodologia: levantamento de CPO-S e CPO-D, avaliação higiene } \\
\text { bucal e condição gengival } \\
\text { - Observações importantes: ----- }\end{array}$ \\
\hline
\end{tabular}


3 PROPOSIÇÃO 


\section{PROPOSIÇÃO}

O objetivo deste estudo foi estudar a cárie dentária em adolescentes residentes no município de São Paulo. Para tal, foram verificados:

- $\quad$ a prevalência de cárie dentária

- os indicadores de risco para a presença de cárie e gravidade do CPO-D considerando as seguintes variáveis:

- sociodemográficas: idade do adolescente, pai e mãe, nível de escolaridade materna e renda familiar;

- fisiológicas: estado nutricional, nível sérico de triglicérides e colesterol total e frações;

- dietéticas: consumo de sacarose, calorias totais, lipídeos e carboidratos; refeições que continham sacarose, consumo de salgadinhos, refrigerantes light/diet e normais por refeição; número de refeições;

- hábitos alimentares: freqüência de consumo semanal de salgados, salgadinhos, lanches, doces, queijo;

- comportamental: número de horas que assiste televisão, tempo transcorrido desde a última vez que foi ao cirurgiãodentista e número de vezes que higieniza os dentes. 
4 CASUÍSTICA - MATERIAL E MÉTODOS 


\section{CASUÍSTICA - MATERIAL E MÉTODOS}

Este estudo foi resultado da parceria entre as Disciplinas de Odontopediatria da Faculdade de Odontologia da Universidade de São Paulo e de Nutrologia do Departamento de Pediatria da Universidade Federal de São Paulo - Escola Paulista de Medicina (UNIFESP-EPM), e fez parte do Projeto ECCCHOS (Estudos Clínicos sobre Crescimento, Comportamento, Hipertensão Arterial, Obesidade e Saúde Bucal). O Projeto ECCCHOS reuniu profissionais de diferentes especialidades com o objetivo de atualizar conhecimentos sobre a saúde de adolescentes.

Antes de iniciar o estudo, foi obtida aprovação do Comitê de Ética em Pesquisa da Faculdade de Odontologia da Universidade de São Paulo (Parecer $n^{p}$ 205/02 Protocolo 213/03 (Anexo A) e da Universidade Federal de Medicina- Escola Paulista de Medicina (Anexo B).

\subsection{Projeto ECCCHOS - descrição}

Participaram desta pesquisa adolescentes de ambos os sexos, entre 15 e 19 anos de idade, de uma escola pública localizada no bairro de Vila Mariana na cidade de São Paulo. O trabalho de campo teve início no segundo semestre de 2002, após contato prévio com os coordenadores da Escola. 
Este estudo foi realizado em 5 fases:

- Pré-teste

- Fase I- Antropometria

- Fase II - Questionário Geral

- Fase III - Exames laboratoriais de sangue, ultra-sonografia de fígado e endotélio, terceira parte do questionário geral e registro alimentar

- Fase IV - Densitometria óssea, avaliação do registro alimentar de 4 dias e avaliação odontológica

\subsection{1 pré-teste}

Primeiramente, foi realizado um treinamento com a equipe do Projeto ECCCHOS com a finalidade de minimizar as variações intra e interpesquisadores. Esse processo incluiu a antropometria (medidas do peso e da estatura), aferição da pressão arterial e aplicação e modo de preenchimento do questionário geral.

Após esse treinamento, foi realizado estudo-piloto em escola estadual diferente daquela do projeto final, com o objetivo de avaliar e testar todos os instrumentos e exames a serem utilizados no protocolo definitivo. Trinta e dois adolescentes de 15 a 19 anos de idade do ensino médio completaram todas as fases do protocolo inicial. 


\subsection{2 fase I - antropometria}

Os adolescentes preencheram um formulário confirmando sua aceitação em participar voluntariamente do projeto. Foi realizada a antropometria dos 1420 alunos na própria escola por uma equipe composta por 7 profissionais de áreas diversas: 3 nutricionistas, 2 estagiárias de nutrição, 2 médicos pediatras e 1 psicóloga sob a responsabilidade das nutricionistas.

O peso corpóreo foi avaliado por meio de balanças digitais da marca Kratos ${ }^{\circledR}$, com capacidade de $150 \mathrm{~kg}$ e precisão de $50 \mathrm{~g}$, dispostas sobre superfície lisa. Os adolescentes foram orientados a permanecerem eretos, no centro da balança, com os braços esticados ao longo do corpo, vestindo apenas roupas leves e sem calçados.

A estatura foi medida com o estadiômetro portátil Alturexata ${ }^{\circledR}$, com escala em milímetros $(\mathrm{mm})$. Os adolescentes foram mantidos em posição vertical, eretos, com os ombros e nádegas encostados no antropômetro portátil. A medida foi realizada duas vezes, sendo que a diferença entre as duas leituras não poderia ser superior a $1 \mathrm{~cm}$, anotando-se a média como valor final.

Para a classificação do estado nutricional, foi utilizado o Índice de Massa Corpórea (IMC), obtido dividido o peso em quilos pela altura em metros ao quadrado $\left(\mathrm{kg} / \mathrm{m}^{2}\right)$. Como referência, utilizou-se a tabela distribuída em percentis $(P)$ de Must, Dallal e Dietz (1991), de acordo com o sexo e a idade, com a seguinte classificação:

$\begin{array}{ll}\text { Eutrofia } & >\text { P } 5 \text { e }<\text { P } 85 \\ \text { Sobrepeso } & \geq \text { P } 85 \text { e }<\text { P } 95 \\ \text { Obesidade } & \geq \text { P } 95\end{array}$




\subsection{3 seleção da amostra}

Do total de 1439 adolescentes regularmente matriculados no segundo semestre de 2002, 1420 participaram da fase de antropometria. Após terem sido pesados, medidos e classificados quanto ao estado nutricional, foram pareados por idade, sexo e estágio puberal. Dos 340 alunos elegíveis para o estudo, 77 se recusaram a participar. Dos 263 adolescentes que participaram das primeiras etapas do estudo, 4 foram excluídos por apresentarem hipotireoidismo, 3 se recusaram a fazer o exame odontológico e 26 não retornaram para a avaliação odontológica. Compuseram a amostra final odontológica 230 adolescentes, dos quais 39 com sobrepeso, 43 obesos e 148 eutróficos (Figura 4.1).

Foram excluídos aqueles com doenças graves ou condição genética desencadeante. Adolescentes que apresentaram alterações nos exames bioquímicos e que não atendiam os critérios da amostra foram excluídos e encaminhados para tratamento na Unidade Assistêncial da Disciplina de Nutrologia da UNIFESP/EPM. 


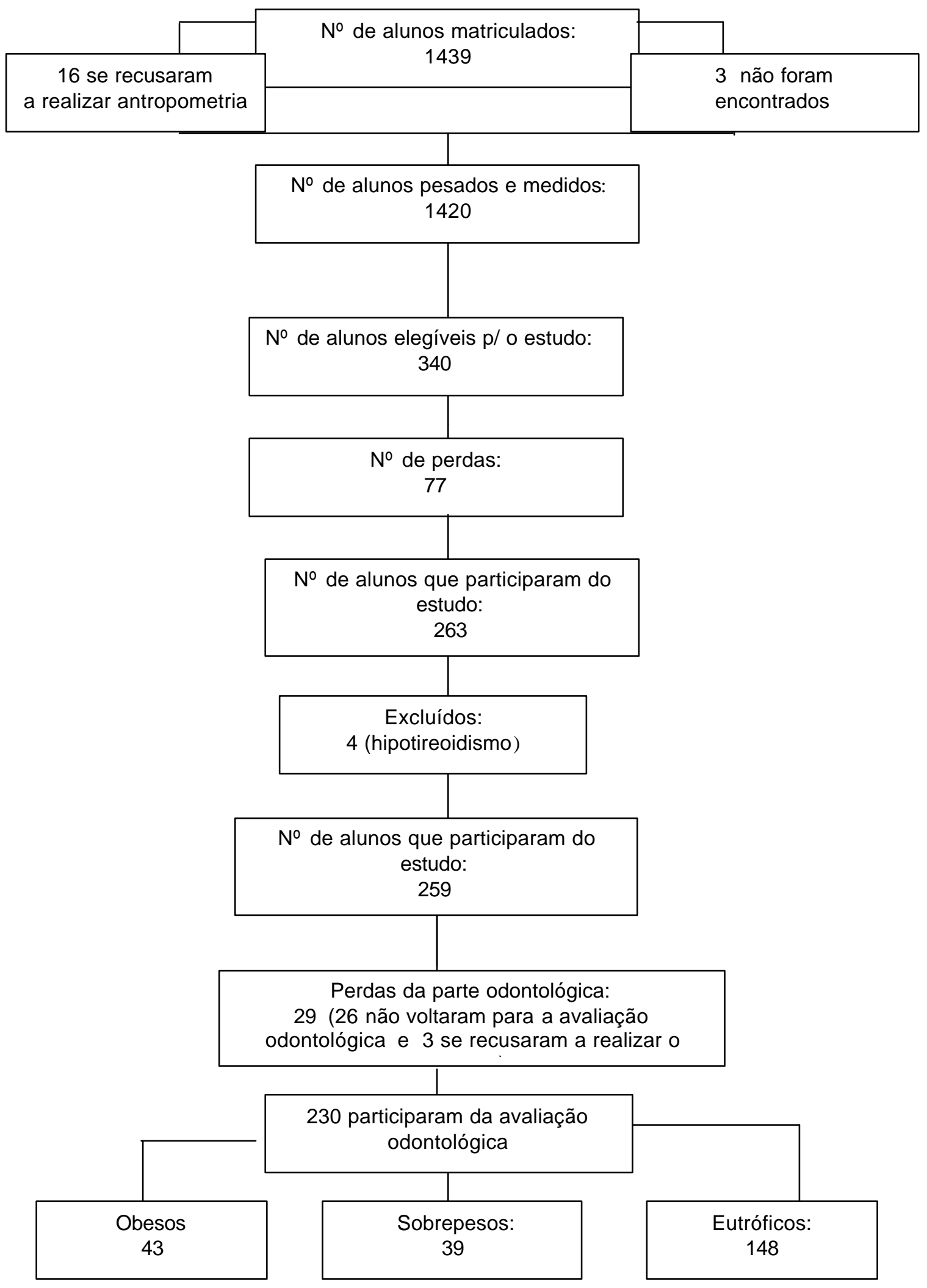

Figura 4.1 - Fluxograma da seleção da amostra 
Os adolescentes participantes tinham idade entre 15 e 19 anos (Tabela 4.1).

Tabela 4.1 - Distribuição dos adolescentes, segundo a idade

\begin{tabular}{c|rr}
\hline $\begin{array}{c}\text { Idade } \\
\text { (em anos completos) }\end{array}$ & $\mathbf{n}$ & $\%$ \\
\hline 15 & 32 & 13,9 \\
16 & 80 & 34,8 \\
17 & 75 & 32,6 \\
$18-19$ & 43 & 18,7 \\
Total & 230 & 100,0 \\
\hline
\end{tabular}

Ao aceitar a sua participação, o adolescente dirigia-se a uma sala onde se preenchia o cabeçalho do questionário geral e, a seguir, era realizada a aferição da pressão arterial.

A casuística definitiva foi selecionada após a fase da antropometria. Apenas os adolescentes selecionados seguiram nas fases seguintes, que constava de diferentes exames, tais como físico, aferição da pressão arterial, laboratoriais, de imagem e odontológico.

Os pais dos alunos selecionados foram convidados a comparecerem no final de semana na escola para serem esclarecidos sobre o estudo e assinarem o termo de consentimento livre e esclarecido (Apêndices A e B). 


\subsection{4 fase II - Questionário geral}

O Questionário Geral (Apêndice C ) foi desenvolvido por pediatras da equipe, e dividido em 3 blocos:

Bloco 1: Cabeçalho/ identificação do adolescente.

Bloco 2: História clínica e fatores socioeconômicos.

Bloco 3: Atividade física e comportamento (alimentar e social).

Os pais foram entrevistados pelos pediatras para o preenchimento do questionário geral e, na seqüência, foram realizadas a aferição da sua pressão arterial e antropometria. Ao final da entrevista, seus filhos eram agendados para a realização de exames laboratoriais na Unidade Assistencial da Disciplina de Nutrologia da UNIFESP-EPM e orientados a ficarem em jejum de 12 horas antes da realização desses exames.

4.1.5 fase III - Exames laboratoriais, terceira parte do questionário geral e registro alimentar de 4 dias

Um ônibus da UNIFESP/EPM buscava os adolescentes na escola e os transportava até a Unidade Assistencial da Disciplina de Nutrologia, sendo as atividades desta fase divididas em quatro etapas:

1. Coleta de amostras de sangue

2. Preenchimento do terceiro bloco do questionário geral 
3. Registro alimentar de 4 dias

4. Ultra-sonografia hepática e do endotélio

\subsubsection{1 primeira etapa - coleta de amostras de sangue}

Procedeu-se à coleta das amostras de sangue por punção periférica da veia do antebraço, com a retirada de $40 \mathrm{ml}$ de sangue, para as dosagens de glicemia, insulina, hemoglobina glicosilada, creatinina, ácido úrico, TGO/AST, TGP/ALT, ãGT, fosfatase alcalina, bilirrubina total, TSH, T4 livre, colesterol total e frações (LDLc, HDLc, VLDLc), triglicérides, apolipoproteínas, concentrações de vitamina B12 e folato, homocisteína e genotipagem. Essa coleta foi realizada por um enfermeiro especializado, com a supervisão de um pediatra. Todos os adolescentes recebiam lanche natural e nutricionalmente balanceado, após a realização dessa etapa.

4.1.5.2 segunda etapa- terceira parte do questionário geral

A entrevista com o adolescente era completada pelo pediatra responsável, tendo sido preenchido o terceiro bloco do questionário geral, que abordava questões de caráter pessoal e confidencial. 


\subsubsection{3 terceira etapa - registro alimentar}

Os adolescentes eram entrevistados por uma nutricionista devidamente treinada e entregava-se o registro alimentar de 4 dias (três dias da semana e um de final de semana) e explicava-se o seu preenchimento.

\subsubsection{4 quarta etapa - ultra-sonografia de fígado e endotélio}

Os exames de ultra-sonografia hepática e avaliação da função endotelial por meio da ultra-sonografia de alta resolução eram realizados em unidades especializadas do complexo médico-hospitalar da UNIFESP-EPM.

Retornando à Unidade Assistencial, sempre acompanhados por um membro da equipe, a data para a realização da densitometria óssea era marcada, e oferecido passe de ônibus para aqueles que solicitassem.

Ao final do período da manhã, todos eram transportados de volta à escola.

4.1.6 fase IV - densitometria óssea e avaliação odontológica

Nesse dia, o adolescente realizava a densitometria óssea, avaliação odontológica e entregava o registro alimentar de 4 dias já preenchido (Apêndice D). 
Uma nutricionista verificava o preenchimento deste registro. e acompanhava o mesmo até o local de exame de densitometria óssea. Os adolescentes submetiamse à avaliação odontológica com as cirurgiãs-dentistas da equipe, antes ou após a densitometria óssea e avaliação do registro alimentar, de maneira a não atrasar esses procedimentos.

\subsection{Avaliação odontológica}

O exame intrabucal foi realizado na Unidade Assistencial da Disciplina de Nutrologia da UNIFESP-EPM por duas cirurgiãs-dentistas, a própria pesquisadora e uma Especialista em Odontopediatria, previamente treinadas para o diagnóstico de cárie dentária adotando uma técnica sistemática para a avaliação. A concordância intra e entre examinadores foi determinado pelo teste Kappa (programa de computador GMC 2000), 0,913 e 0,909 respectivamente.

Foram utilizados espelhos clínicos planos número 5, sondas periodontais metálicas milimetradas, pinça, lanterna de mão e gaze. Os instrumentais e as gazes estavam em embalagens individuais próprias para uso em autoclave. A lanterna de mão era recoberta com filme plástico Magipak ${ }^{\circledR}$ e trocada a cada paciente. Todas as normas de biossegurança foram seguidas.

Para a avaliação, o paciente permaneceu sentado em cadeira convencional, com o tronco a noventa graus em relação ao solo e com a cabeça apoiada contra uma superfície plana. A compressa de gaze foi utilizada para secar a superfície dental e remover possíveis detritos das superfícies dentais. Com o auxílio 
de uma lanterna de mão, espelho clínico plano e sonda periodontal, foram avaliadas todas as superfícies dentais dos pacientes. As examinadoras realizaram suas observações estando posicionadas à frente do paciente. As anotações foram preenchidas em ficha desenvolvida especialmente para o estudo (Apêndice E).

A codificação do índice CPO-D utilizada foi a da OMS (OMS, 1999):

Código 0 - Coroa hígidas

Considerou-se coroa hígida quando ela não apresentava evidências de lesão de cárie clínica ou tratada. Os estágios da lesão de cárie que precedem a cavitação foram excluídos. Portanto, uma coroa com as seguintes alterações foi considerada hígida:

- manchas brancas ou porosas;

- manchas com alteração de coloração ou rugosidade que não sejam amolecidas ao toque por uma sonda periodontal metálica;

- fóssulas ou fissuras pigmentadas no esmalte sem sinais visíveis de esmalte socavado, ou amolecimento do assoalho ou paredes detectáveis com a sonda periodontal;

- áreas escuras, brilhantes, duras, pontilhadas de esmalte em um dente apresentando sinais de fluorose moderada a severa;

- lesões que, baseando-se em sua distribuição ou história clínica, ou ao exame visualtátil, parecem ser devidas àabrasão. 
Código 1 - Lesão de cárie presente na coroa dental

Foi considerada lesão de cárie em fóssula ou fissura, ou em uma superfície dental lisa, quando havia cavidade inconfundível, esmalte socavado, ou um assoalho ou parede detectavelmente amolecido. Nessa categoria, também foram incluídos os dentes com restauração provisória ou que estavam selados, mas com lesões de cárie. Em caso de dúvida, a lesão não era registrada.

Código 2 - Coroa restaurada, porém com lesão de cárie presente

Foi considerada uma coroa restaurada com lesão de cárie, quando uma ou mais restaurações estiverem presentes e havia lesões de cárie em uma ou mais áreas. Não foi feita distinção entre as lesões de cárie primárias e as secundárias.

Código 3 - Coroa restaurada, sem lesão de cárie

Uma coroa foi considerada restaurada, sem lesão de cárie, quando uma ou mais restaurações permanentes estavam presente e sem qualquer lesão de cárie em nenhuma das superfícies dentais. Dentes com coroa protética também foram classificadas com esse código.

Código 4 - Dente ausente como resultado de lesão de cárie

Esse código foi utilizado para designar os dentes extraídos devido a lesão de cárie.

Código 5 - Dente ausente por outro motivo que não a cárie dentária

Foram incluídos nesse código os dentes ausentes por motivos ortodônticos, periodontais ou congênitos. 
Código 6 - Selante de fissura

Nesse código, foram incluídos os dentes que apresentavam selante de fissura ou que tiveram suas fissuras alargadas para receber um compósito. O dente que apresentava selante e estavam cariado, foi codificado como cariado.

Código 7 -Apoio de ponte, coroa ou veneer

Esse código foi utilizado para designar o dente que fazia parte de uma prótese fixa, dentes com coroas colocadas por outras razões que não a cárie dentária, e dentes com Venners ou laminados que cobriam a superfície vestibular do dente.

Código 8 - Dentes não-erupcionados

Código T - Trauma

Dentes que tinham uma ou mais superfícies perdidas como resultado de trauma e sem evidência de cárie.

Código 9 - Não informado

Utilizou-se esse código para os dentes erupcionados que não podiam ser examinados por qualquer razão, como por exemplo, por terem bandas ortodônticas e hipoplasia severa.

Foram considerados dentes erupcionados aqueles presente na boca quando qualquer de suas partes era visível ou podia ser tocada com a sonda milimetrada. Se os dentes decíduo e permanente ocupassem o mesmo espaço, apenas o dente 
permanente foi anotado. Em caso de dúvida entre hígido e cariado, o dente foi considerado hígido; entre cariado e restaurado, o dente foi considerado restaurado; e entre cariado e extração indicada, o dente foi considerado cariado (Pinto, 1992).

Os adolescentes foram também questionados sobre seus hábitos de higiene bucal mediante três perguntas abertas e data da última consulta odontológica.

Seqüência da avaliação:

1. Preenchimento do cabeçalho da ficha clínica específica, anotando a identificação do adolescente.

2. Perguntas sobre os hábitos de higiene bucal e data da última consulta odontológica.

3. Anotação do índice CPO-D

O exame clínico para o levantamento do índice CPO-D foi realizado por quadrantes, iniciando-se pelo quadrante superior direito, seguido pelo superior esquerdo, inferior esquerdo e por último, o inferior direito.

\subsection{Avaliação quantitativa da dieta}

A dieta dos adolescentes foi avaliada por meio do registro alimentar de 4 dias, sendo três dias da semana e um de final de semana (Apêndice D) e freqüência de consumo de determinados alimentos durante a semana, obtida pelo questionário de freqüência alimentar do Questionário Geral (Apêndice C). 
A avaliação quantitativa da dieta para consumo total de calorias, carboidratos e lipídeos foi realizada pelas nutricionistas por meio do programa de computador Programa de Apoio à Nutrição - Nutwin 2002, versão 1.5 DIS - UNIFESP - EPM utilizando as informações do registro alimentar de 4 dias. Também foram verificados alguns fatores de risco de obesidade, como o consumo excessivo de lipídeos (consumo acima de $30 \%$ em relação às calorias totais), carboidratos (consumo acima de $60 \%$ em relação as calorias totais) e calorias totais (consumo acima de $100 \%$ das calorias recomendada pelo Food and Nutrition Board (NATIONAL RESEARCH COUNCIL, 1989).

Dados de alimentos industrializados, preparações e tamanho das medidas caseiras, que eventualmente não existiam no programa de computador, foram inseridos segundo a rotulagem dos produtos, ou ainda segundo informações obtidas diretamente dos endereços eletrônicos ("sites") dos fabricantes ou por meio de contato direto com as empresas alimentícias.

O diário alimentar também foi analisado pela pesquisadora, visando dados cariogênicos da dieta tais como porcentagens de refeições na qual a sacarose estava presente de alguma forma, seja ela líquida, sólida ou pastosa e consumo de refrigerantes e salgadinhos de pacote durante o dia. O número médio de refeições consumidas também foi calculado. Para a realização dessas avaliações, foram analisados somente os três dias da semana e não o dia de final de semana. 


\subsection{Avaliação dos níveis de colesterol e triglicérides}

Os níveis séricos de colesterol total, HDL colesterol, LDL colesterol e triglicérides foram obtidos por meio de exame de sangue, após 12 horas de jejum. A análise foi realizada pelo Centro de Diagnóstico Brasil, Departamento de Biopsicologia da UNIFESP - EPM. Utilizaram-se as recomendações da American Heart Association (KAVEY et al., 2003) para determinar os valores de corte. Foram considerados alterados os seguintes valores para cada uma das variáveis: colesterol total $\geq 200 \mathrm{mg} / \mathrm{dl}$; LDL colesterol $>130 \mathrm{mg} / \mathrm{dl} ;$ HDL colesterol $<35 \mathrm{mg} / \mathrm{dl}$; e triglicérides $>150 \mathrm{mg} / \mathrm{dl}$.

\subsection{Análise Estatística}

4.5.1 codificação e digitação dos dados

Os resultados dos questionários e das avaliações clínica, odontológica e do diário alimentar foram codificados e digitados em programa Excel (Windows XP). 


\subsection{2 análise estatística}

A análise estatística foi elaborada pelo CEA (Centro de Estatística Aplicada) da Universidade de São Paulo (TANAKA; GENSE; LAPA, 2004)e pelo Departamento de Nutrologia da Disciplina de Pediatria UNIFESP-EPM. Os programas computacionais utilizados foram Excel (Windows 2002); Microsoft Word; Minitab 14.0 for Windows; SAS for Windows e Stata software (StataCorp. College Station, TX).

Foi comparado o índice CPO-D com variáveis denominadas sociodemográfica, fisiológicas, dietéticas, hábitos alimentares e comportamentais.

Os dados foram analisados utilizando-se técnicas de estatística descritiva unidimensional. Primeiramente, foi realizada a análise estatística descritiva, obtendo-se a distribuição absoluta e percentual, média, mediana, desvio padrão, mínimo e máximo de cada variável pesquisada. A seguir, as variáveis foram dicotomizadas, segundo o risco ou a mediana. Para o CPO-D, o ponto de corte estabelecido para a dicotomização foi a mediana (ÖGAARD; RÖSLER, 1991). Para verificar a associação entre as variáveis estudadas e o CPO-D foi realizada análise univariada através do teste do Qui-quadrado de Pearson. Quando não era possível aplicar o teste do Qui-quadrado de Pearson, foi utilizado o teste exato de Fisher.

A seguir foi realizada a análise múltipla para identificar os indicadores de risco de cárie dentária na população avaliada. Para tal, foram selecionadas as variáveis que apresentaram associação significante com o CPO-D no nível 10\% e ajustou-se um modelo de regressão logística múltipla pelo procedimento do "backward stepwise", estimando-se a razão de chance (odds ratio), respectivos intervalos de confiança de $95 \%$ e nível de significância (p). 
Descrição de todas as variáveis e sua dicotomização:

\subsection{3 variáveis sócio demográficas}

- idade do adolescente:mediana

- idade da mãe: mediana

- idade do pai: mediana

- nível de escolaridade da mãe: fundamental incompleto; acima de fundamental incompleto

- renda: até 11 salários mínimos; acima de 11 salários mínimos

Para as variáveis idade do adolescente, do pai e da mãe e renda familiar foi utilizada a mediana como ponte de corte, e para as demais foi utilizado o fator de risco.

\subsection{4 variáveis fisiológicas}

- $\quad$ estado nutricional: eutrófico, sobrepeso, obeso

- nível de colesterol total: alterado ( $\geq 200 \mathrm{mg} / \mathrm{dl}$ ); normal

- nível de colesterol HDL: alterado (<35 mg/dl); normal

- nível de colesterol LDL: alterado (> $130 \mathrm{mg} / \mathrm{dl}$ ); normal

- $\quad$ nível de triglicérides: alterado (> 150mg/dl) ; normal 
O corte para dicotomização do estado nutricional foi segundo a classificação de Must, Dallal e Dietz (1991) e para as demais variáveis fisiológicas foi o fator de risco, segundo estipulado pela American Heart Association (KAVEY et al., 2003).

4.5.5 variáveis dietéticas, obtidas por meio da análise do diário alimentar

- número de refeições: mediana

- número de refeições que apresentavam sacarose: mediana

- média do consumo diário de refrigerantes normais: mediana

- média do consumo diário de refrigerantes diet-light por refeição: mediana

- média do consumo diário de salgadinhos de pacotes por refeição: mediana

- consumo de calorias totais: não adequado para sexo e idade; adequado para sexo e idade.

- consumo de lipídeos: alterado (acima de 30\% das calorias totais); normal

- consumo de carboidratos: alterado (acima de 60\% das calorias totais); normal

Das variáveis dietéticas que tinham valores contínuos, o ponto de corte para a dicotomização foi a mediana. Já para o consumo de calorias totais, lipídeos e carboidratos, foi segundo o risco. 
4.5.6 Variáveis dos hábitos alimentares obtidas por meio do questionário de freqüência do consumo semanal

- salgados: $\geq 4$ vezes por semana; $<4$ vezes por semana

- $\quad$ salgadinhos de pacote : $\geq 4$ vezes por semana ; < 4 vezes por semana

- lanches : $\geq 4$ vezes por semana; $<4$ vezes por semana

- balas: $\geq 4$ vezes por semana; $<4$ vezes por semana

- doces : $\geq 4$ vezes por semana; $<4$ vezes por semana

- queijo : $\geq 4$ vezes por semana; $<4$ vezes por semana refrigerante $: \geq 4$ vezes por semana $;<4$ vezes por semana

Para todas essas variáveis o ponto de corte para a dicotimização foi o risco, ou seja o consumo mais alto desses alimentos.

\subsection{7 comportamentais}

- numero de horas que assiste televisão por dia: $\geq 4$ horas por dia; $<4$ horas por dia

- última vez que foi a consulta odontológica: nos últimos 12 meses; 13 meses ou mais.

- numero de vezes ao dia que higieniza a cavidade oral: uma vez ou menos; duas vezes; três vezes; quatro ou mais vezes. 
Para o número de horas que assiste televisão e o tempo transcorrido desde a última consulta odontológica, o ponte de corte foi o fator de risco. Como a variável número de vezes que higienizava os dentes tinha grande importância optouse por não dicotomizar as respostas.

\subsection{Considerações éticas}

Conforme descrito anteriormente, quando os participantes eram menor de idade, os pais assinaram um termo de consentimento livre e esclarecido, autorizando a participação do filho menor de idade no estudo. Contudo, o adolescente tinha a liberdade de escolher participar ou não do projeto, mesmo os pais terem autorizado a sua participação. Quando o adolescente era maior de idade, ele próprio assinava o termo de consentimento livre e esclarecido.

Quando era diagnosticada alguma alteração na cavidade oral no momento do exame, era explicado ao adolescente essa alteração. Após a análise dos exames bucais, foi enviada a cada adolescente uma carta mencionando o resultado do exame clínico. 
5 RESULTADOS 


\section{RESULTADOS}

A análise descrita de todas as variáveis estão apresentadas nos Apêndices $\mathrm{F}$ até J. Será apresentada primeiramente a análise descritiva do componente caridado do índice CPO-D e o do CPO-D e, a seguir, as Tabelas das regressões logísticas univariadas, regressão logística múltipla e o modelo final da análise do backward stepwise.

Participaram deste estudo 230 adolescentes entre 15 e 19 anos de idade, sendo 104 do sexo feminino (45,22\%) e 126 do masculino (54,78\%). A maioria estava na faixa etária entre os 16 e 17 anos (Figura 5.1).

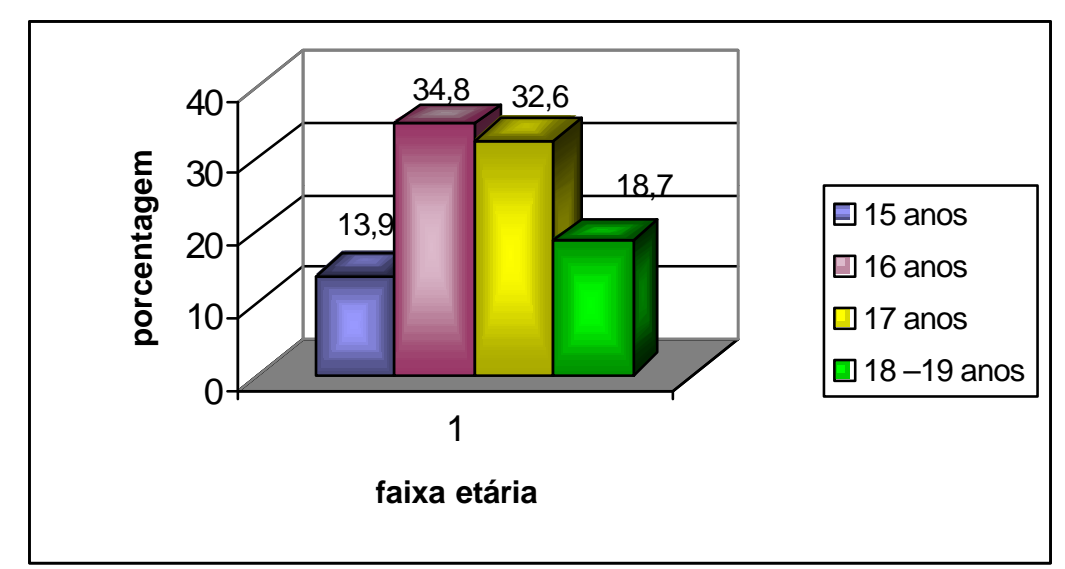

Figura 5.1 - Distribuição dos adolescentes segundo faixa etária 
Dos 230 adolescentes, 68 (29,57\%) não apresentaram lesão de cárie e 162 (70,43\%) apresentavam uma ou mais lesões de cárie. A Tabela 5.1 apresenta a distribuição dos adolescentes por faixa etária, na presença ou ausência da cárie dentária.

\begin{tabular}{|c|c|c|c|c|}
\hline $\begin{array}{c}\text { Idade } \\
\text { (anos completos) }\end{array}$ & $\begin{array}{c}\text { Cárie } \\
\mathrm{n}\end{array}$ & $\begin{array}{c}\text { Ausente } \\
\%\end{array}$ & $\begin{array}{c}\text { Cárie } \\
\mathrm{n}\end{array}$ & $\begin{array}{c}\text { Presente } \\
\%\end{array}$ \\
\hline 15 & 8 & 11,76 & 24 & 14,81 \\
\hline 16 & 27 & 39,71 & 53 & 32,72 \\
\hline 17 & 16 & 23,53 & 59 & 36,42 \\
\hline $18-19$ & 17 & 25,00 & 26 & 16,05 \\
\hline Total & 68 & 100,00 & 162 & 100,00 \\
\hline
\end{tabular}

A Tabela 5.2 apresenta a análise descritiva do índice CPO-D (número de dentes cariados, perdidos ou obturados) e seus componentes (cariados, perdidos e obturados). A média de dentes cariados e restaurados foi 3,03 e 2,71, respectivamente. A média do CPO-D foi 5,86 e a mediana 5,00. Conforme descrito anteriormente, foi utilizado o valor da mediana para dicotomizar o CPO-D. Após a dicotimização, 122 (53,04\%) adolescentes estavam no grupo de CPO-D $\leq 5$ e 108 (46,96\%) no grupo do CPO-D > 5. A Tabela 5.3 mostra a distribuição dos adolescentes por faixa etária e gravidade do CPO-D. 
Tabela 5.2 - Estatística descritiva do índice CPO-D e seus componentes. São Paulo, SP, 2002

\begin{tabular}{lcccc}
\hline Medidas Resumo & Cariados & Perdidos & Obturados & CPO-D \\
\hline Média & 3,03 & 0,04 & 2,71 & 5,86 \\
Mediana & 2,00 & 0 & 1,00 & 5,00 \\
Desvio-padrão & 3,33 & 0,26 & 3,72 & 4,65 \\
Mínimo & 0 & 0 & 0 & 0 \\
Máximo & 20 & 2 & 18 & 20 \\
\hline
\end{tabular}

Tabela 5.3 - Distribuição do número (n) e porcentagem (\%) de adolescentes de acordo com o CPO- D $\leq 5$ e CPO-D > 5 . São Paulo, SP, 2002

\begin{tabular}{|c|c|c|c|c|}
\hline \multirow{2}{*}{$\begin{array}{c}\text { Idade } \\
\text { (anos completos) }\end{array}$} & \multicolumn{2}{|c|}{ CPO-D $\leq 5$} & \multicolumn{2}{|c|}{ CPO-D > 5} \\
\hline & $\mathbf{n}$ & $\%$ & $n$ & $\%$ \\
\hline 15 & 19 & 15,57 & 13 & 12,04 \\
\hline 16 & 49 & 40,16 & 31 & 28,70 \\
\hline 17 & 29 & 23,77 & 46 & 42,59 \\
\hline $18-19$ & 25 & 20,49 & 18 & 16,67 \\
\hline Total & 122 & 100,00 & 108 & 100,00 \\
\hline
\end{tabular}

Observa-se que a prevalência de cárie dentária foi alta, havendo apenas 29,57\% de adolescentes sem história de cárie diagnosticada. Contudo, a prevalência de dentes perdidos foi baixa, 3,04\% (Tabela 5.4). 
Tabela 5.4 - Distribuição do número (n) e porcentagem (\%) de adolescentes de acordo com a presença de dentes cariados, obturados ou perdidos. São Paulo, SP, 2002

\begin{tabular}{lccrrrr}
\hline & \multicolumn{2}{c}{ Cariados } & \multicolumn{2}{c}{ Obturados } & \multicolumn{2}{c}{ Perdidos } \\
& $\mathbf{n}$ & \multicolumn{1}{c}{$\%$} & $\mathbf{n}$ & $\%$ & $\mathbf{n}$ & $\%$ \\
\hline Sim & 162 & 70,43 & 135 & 58,70 & 7 & 3,04 \\
Não & 68 & 29,57 & 95 & 41,30 & 223 & 96,96 \\
Total & 230 & 100,00 & 230 & 100,00 & 230 & 100,00 \\
\hline
\end{tabular}

O CPO-D médio para cada faixa etária está apresentado no Figura 5.2. Observa-se que há tendência de o CPO-D aumentar em função da idade, sendo que o aumento mais marcante ocorreu aos 17 anos de idade.

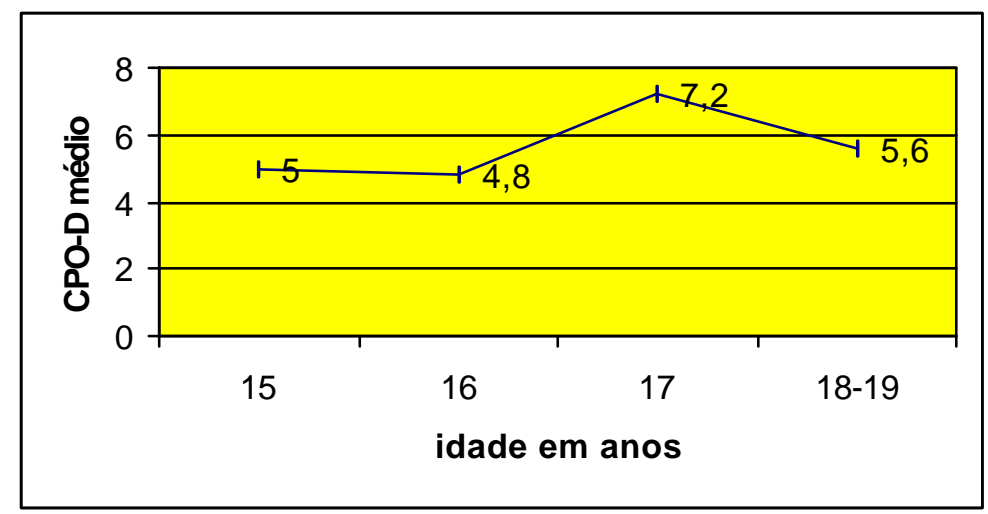

Figura 5.2 - CPO-D médio nas diferentes faixas etárias

\subsection{Regressão logística do índice CPO-D}

A seguir, serão apresentadas as tabelas obtidas através da análise univariada pelo teste do Qui-quadrado de Pearson ou Teste Exato de Fisher com as variáveis estudadas: sociodemográficas, fisiológicas, dietéticas, hábitos alimentares 
e comportamentais. Conforme citado anteriormente, as variáveis foram dicotomizadas, segundo a mediana obtida ou fator de risco.

Para as variáveis que apresentaram significância no nível 5\%, foi realizada uma análise dessas com os componentes do CPO-D.

\subsection{1 variáveis sociodemográficas}

A Tabela 5.5 mostra a prevalência e razão de chance (odds ratio, OR) e seus respectivos intervalos de confiança de 95\% (IC 95\%) para as variáveis sóciodemográficas. Observa-se que o nível de escolaridade da mãe $(p=0,025)$ e a idade do adolescente $(p=0,025)$ apresentaram significância de $5 \%$.

A estatística descritiva do CPO-D e seus componentes em função da idade do adolescente está apresentada na Tabela 5.6. Nota-se que aqueles adolescentes com 17 anos de idade ou mais apresentam CPO-D médio de 6,77 contra 4,89 naqueles com idade inferior a 17 anos. A média de dentes perdidos ou cariados foi muito semelhante entre essas duas faixas etárias estudadas. Entretanto, a média de dentes restaurados foi maior nos adolescentes com idade maior ou igual a 17 anos. 
Tabela 5.5 - Prevalência e razão de chance bruto (OR) com seus respectivos intervalos de confiança de $95 \%$ (IC 95\%) para variáveis sociodemográficas relacionadas ao baixo índice de cárie dentária (CPO-D $\leq 5)$ e ao alto índice (CPO-D > 5), obtidos por meio da regressão logística univariada. São Paulo, SP, 2002

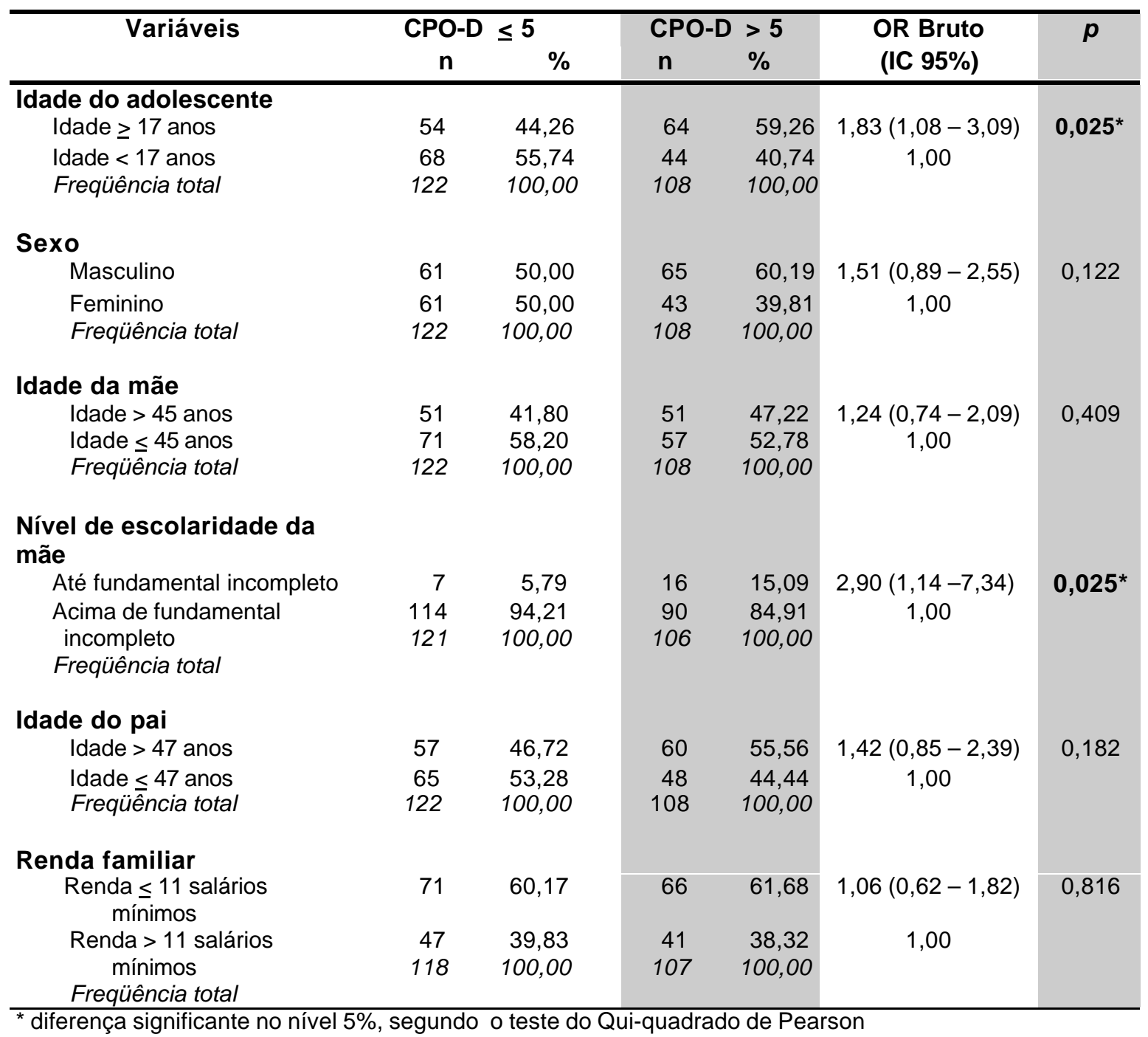

Observa-se, na Tabela 5.7, a relação do índice CPO-D e seus componentes com o nível de escolaridade da mãe, dicotomizada em fundamental incompleto e acima de fundamental completo. A média do CPO-D foi 7,96 para os adolescentes cujas mães tinham nível de escolaridade fundamental incompleto contra 5,56 do grupo do ensino formal acima do fundamental incompleto. A média de dentes obturados, cariados e perdidos também foi maior entre o grupo de adolescentes cujas mães tinham nível educacional mais baixo. 
Tabela 5.6 - Análise descritiva do CPO-D e seus componentes, segundo a idade dos adolescentes. São Paulo, SP, 2002

\begin{tabular}{llcc}
\hline CPO-D & Estatística & \multicolumn{2}{c}{ Idade do adolescente } \\
\cline { 3 - 4 } & & $<\mathbf{1 7}$ anos & $\mathbf{2 1 7}$ anos \\
\hline CPO-D & Média & 4,89 & 6,77 \\
& Mediana & 5,70 & 6,00 \\
& Desvio-padrão & 4,21 & 4,88 \\
& Mínimo & 0 & 0 \\
& Máximo & 18 & 20 \\
& Freqüência & 112 & 118
\end{tabular}

\section{Cariados}

$\begin{array}{lcc}\text { Média } & 3,04 & 3,03 \\ \text { Mediana } & 2,00 & 2,00 \\ \text { Desvio-padrão } & 3,10 & 3,56 \\ \text { Mínimo } & 0 & 0 \\ \text { Máximo } & 15 & 20 \\ \text { Freqüência } & 112 & 118\end{array}$

\section{Perdidos}

$\begin{array}{lcc}\text { Média } & 0,04 & 0,05 \\ \text { Mediana } & 0 & 0 \\ \text { Desvio-padrão } & 0,27 & 0,26 \\ \text { Mínimo } & 0 & 0 \\ \text { Máximo } & 2 & 2 \\ \text { Freqüência } & 112 & 118\end{array}$

\section{Obturados}

\begin{tabular}{lcc} 
Média & 1,75 & 3,62 \\
Mediana & 1,00 & 2,00 \\
Desvio-padrão & 2,60 & 4,34 \\
Mínimo & 0 & 0 \\
Máximo & 15 & 18 \\
Freqüência & 112 & 118 \\
\hline
\end{tabular}


Tabela 5.7 - Análise descritiva do CPO-D e seus componentes, segundo o nível de escolaridade da mãe dos adolescentes. São Paulo, SP, 2002

\begin{tabular}{llcc}
\hline CPO-D & Estatística & \multicolumn{2}{c}{ Nível educacional da mãe } \\
\cline { 3 - 4 } & & $\begin{array}{c}\text { Fundamental } \\
\text { incompleto }\end{array}$ & $\begin{array}{c}\text { Fundamental } \\
\text { completo ou maior }\end{array}$ \\
\hline CPO-D & Média & 7,96 & 5,56 \\
& Mediana & 7,00 & 5,00 \\
& Desvio-padrão & 4,50 & 4,55 \\
& Mínimo & 0 & 0 \\
& Máximo & 20 & 19 \\
& Freqüência & 23 & 204
\end{tabular}

\section{Cariados}

$\begin{array}{lcc}\text { Média } & 4,57 & 2,78 \\ \text { Mediana } & 4,00 & 2,00 \\ \text { Desvio-padrão } & 4,22 & 3,04 \\ \text { Mínimo } & 0 & 0 \\ \text { Máximo } & 20 & 15 \\ \text { Freqüência } & 23 & 204\end{array}$

\section{Perdidos}

$\begin{array}{lcc}\text { Média } & 0,13 & 0,02 \\ \text { Mediana } & 0 & 0 \\ \text { Desvio-padrão } & 0,46 & 0,18 \\ \text { Mínimo } & 0 & 0 \\ \text { Máximo } & 2 & 2 \\ \text { Freqüência } & 23 & 204\end{array}$

\section{Obturados}

\begin{tabular}{lcc} 
Média & 3,30 & 2,67 \\
Mediana & 3,00 & 1,00 \\
Desvio-padrão & 3,42 & 3,77 \\
Mínimo & 0 & 0 \\
Máximo & 12 & 18 \\
Freqüência & 23 & 204 \\
\hline
\end{tabular}




\subsection{2 variáveis fisiológicas}

$\mathrm{Na}$ Tabela 5.8, estão descritos a razão de chance (OR), os intervalos de confiança (IC) e valores de significância $(p)$ para as variáveis fisiológicas. Os adolescentes com sobrepeso aparecem com maior predisposição a alto índice de CPO-D $(p=0,04)$ quando comparados com os eutróficos e obesos. Não foi observada diferença significante entre o CPO-D e os níveis séricos de triglicérides e colesterol total e frações.

Tabela 5.8 - Prevalência e razão de chance (OR), com seus respectivos intervalos de confiança de 95\% (IC 95\%), para variáveis fisiológicas relacionadas ao baixo índice de cárie dentária (CPO-D $\leq 5)$ e ao alto índice (CPO-D > 5), obtidos por meio da regressão logística univariada. São Paulo, SP, 2002

\begin{tabular}{|c|c|c|c|c|c|c|}
\hline \multirow[t]{2}{*}{ Variáveis } & \multicolumn{2}{|c|}{ CPO-D $\leq 5$} & \multicolumn{2}{|c|}{ CPO-D > 5} & \multirow{2}{*}{$\begin{array}{l}\text { OR Bruto } \\
\text { (IC 95\%) }\end{array}$} & \multirow[t]{2}{*}{$p$} \\
\hline & $\mathbf{n}$ & $\%$ & $\mathbf{n}$ & $\%$ & & \\
\hline \multicolumn{7}{|l|}{ Estado Nutricional } \\
\hline Sobrepeso & 15 & 12,30 & 24 & 22,22 & $2,10(1,02-4,32)$ & $0,044^{\star}$ \\
\hline Obeso & 23 & 18,85 & 20 & 18,52 & $1,14(0,58-2,26)$ & 0,704 \\
\hline eutrófico & 84 & 68,85 & 64 & 59,26 & 1,00 & \\
\hline Freqüência total & 122 & 100,00 & 108 & 100,00 & & \\
\hline \multicolumn{7}{|l|}{ Colesterol Total } \\
\hline Colesterol total $>200 \mathrm{mg}-\mathrm{dl}$ & 14 & 11,48 & 13 & 12,40 & $1,06(0,47-2,36)$ & 0,895 \\
\hline Colesterol total $\leq 200 \mathrm{mg}$-dl & 108 & 88,52 & 95 & 87,96 & 1,00 & \\
\hline Freqüência total & & 100,00 & & 100,00 & & \\
\hline \multicolumn{7}{|l|}{ Colesterol HDL } \\
\hline Colesterol HDL $<35$ mg-dl & 12 & 9,84 & 11 & 10,19 & $1,04(0,44-2,46)$ & 0,930 \\
\hline Colesterol HDL $\geq 35 \mathrm{mg}$-dl & 110 & 90,16 & 97 & 89,81 & 1,00 & \\
\hline Freqüência total̄ & 122 & 100,00 & 108 & 100,00 & & \\
\hline \multicolumn{7}{|l|}{ Colesterol LDL } \\
\hline Colesterol LDL > $130 \mathrm{mg}-\mathrm{dl}$ & 10 & 8,20 & 10 & 9,26 & $1,14(0,46-2,86)$ & 0,775 \\
\hline $\begin{array}{l}\text { Colesterol LDL } \leq 130 \mathrm{mg} \text {-dl } \\
\text { Freqüência total }\end{array}$ & $\begin{array}{l}112 \\
122\end{array}$ & $\begin{array}{r}91,80 \\
100,00\end{array}$ & $\begin{array}{r}98 \\
108\end{array}$ & $\begin{array}{r}90,74 \\
100,00\end{array}$ & 1,00 & \\
\hline \multicolumn{7}{|l|}{ Triglicérides } \\
\hline Triglicérides > 150 mg-dl & 10 & 8,20 & 5 & 4,63 & $0,54(0,18-1,64)$ & 0,280 \\
\hline $\begin{array}{l}\text { Triglicérides } \leq 150 \mathrm{mg} \text {-dl } \\
\text { Freqüência total }\end{array}$ & $\begin{array}{l}112 \\
122\end{array}$ & $\begin{array}{r}91,80 \\
100,00\end{array}$ & $\begin{array}{l}103 \\
108\end{array}$ & $\begin{array}{r}95,37 \\
100,00\end{array}$ & 1,00 & \\
\hline \multicolumn{7}{|l|}{ Dislipidemia } \\
\hline Alterado & 26 & 21,31 & 24 & 22,22 & $1,05(0,56-1,98)$ & 0,867 \\
\hline Normal/Limítrofe & 96 & 78,69 & 84 & 77,78 & 1,00 & \\
\hline Freqüência total & 122 & 100,00 & 108 & 100,00 & & \\
\hline
\end{tabular}

* significante ao nível de 5\% segundo teste do Qui-quadrado de Pearson 
A Tabela 5.9 mostra a análise descritiva do CPO-D e seus componentes, segundo o estado nutricional. A média do CPO-D e dos componentes cariado, perdido e restaurado foi mais alta entre os adolescentes que tinham sobrepeso.

Tabela 5.9 - Estatística descritiva CPO-D e seus componentes, segundo estado nutricional. São Paulo, SP, 2002

\begin{tabular}{|c|c|c|c|c|}
\hline \multirow[t]{2}{*}{ CPO-D } & \multirow[t]{2}{*}{ Estatísticas } & \multicolumn{3}{|c|}{ Estado Nutricional } \\
\hline & & Eutrófico & Sobrepeso & Obeso \\
\hline CPO-D & $\begin{array}{l}\text { Média } \\
\text { Mediana } \\
\text { Desvio-padrão } \\
\text { Mínimo } \\
\text { Máximo } \\
\text { Freqüência }\end{array}$ & $\begin{array}{c}5,73 \\
5,00 \\
4,56 \\
0 \\
20 \\
148\end{array}$ & $\begin{array}{c}6,95 \\
7,00 \\
5,10 \\
0 \\
18 \\
39\end{array}$ & $\begin{array}{c}5,30 \\
5,00 \\
4,47 \\
0 \\
19 \\
43\end{array}$ \\
\hline Cariados & $\begin{array}{l}\text { Média } \\
\text { Mediana } \\
\text { Desvio-padrão } \\
\text { Mínimo } \\
\text { Máximo } \\
\text { Freqüência }\end{array}$ & $\begin{array}{c}2,89 \\
2,00 \\
3,32 \\
0 \\
20 \\
148\end{array}$ & $\begin{array}{c}3,64 \\
3,00 \\
3,75 \\
0 \\
17 \\
39\end{array}$ & $\begin{array}{c}2,98 \\
3,00 \\
2,92 \\
0 \\
10 \\
43\end{array}$ \\
\hline Perdidos & $\begin{array}{l}\text { Média } \\
\text { Mediana } \\
\text { Desvio-padrão } \\
\text { Mínimo } \\
\text { Máximo } \\
\text { Freqüência }\end{array}$ & $\begin{array}{c}0,03 \\
0 \\
0,25 \\
0 \\
2 \\
148\end{array}$ & $\begin{array}{c}0,10 \\
0 \\
0,38 \\
0 \\
2 \\
39\end{array}$ & $\begin{array}{c}0,02 \\
0 \\
0,15 \\
0 \\
1 \\
43\end{array}$ \\
\hline Obturados & $\begin{array}{l}\text { Média } \\
\text { Mediana } \\
\text { Desvio-padrão } \\
\text { Mínimo } \\
\text { Máximo } \\
\text { Freqüência }\end{array}$ & $\begin{array}{c}2,73 \\
1,00 \\
3,81 \\
0 \\
18 \\
148\end{array}$ & $\begin{array}{c}3,03 \\
2,00 \\
3,62 \\
0 \\
15 \\
39\end{array}$ & $\begin{array}{c}2,35 \\
1,00 \\
3,54 \\
0 \\
15 \\
43\end{array}$ \\
\hline
\end{tabular}




\subsection{3 variáveis dietéticas}

Com relação às variáveis dietéticas, foi analisado por meio do registro alimentar o consumo de carboidratos, lipídeos e calorias totais, segundo a idade e o sexo, pelas nutricionistas da Disciplina de Nutrologia do Departamento de Pediatria da UNIFESP-EPM. A pesquisadora também avaliou esses registros para pesquisar o número médio de refeições que continham sacarose e o consumo médio de refrigerantes e salgadinhos durante três dias da semana. Não foi encontrada nenhuma associação significativa $(p<0,05)$ dessas variáveis com o CPO-D conforme mostra a Tabela 5.10. Portanto, não foi construída uma tabela apresentando a análise descritiva do CPO-D e seus componentes com essas variáveis. O consumo médio de refeições com sacarose apresentou tendência de associação com CPO-D ( $p=0,085)$. 
Tabela 5.10 - Prevalência e razão de chance (OR), com seus respectivos intervalos de confiança de 95\% (IC 95\%), para variáveis dietéticas obtidas por meio do registro alimentar relacionadas ao baixo índice de cárie dentária (CPO-D $\leq 5)$ e ao alto índice (CPO-D> 5), obtidos por meio da regressão logística univariada. São Paulo, SP, 2002

\begin{tabular}{|c|c|c|c|c|c|c|}
\hline \multirow{2}{*}{ Variáveis } & \multicolumn{2}{|c|}{ CPO- $D \leq 5$} & \multicolumn{2}{|c|}{ CPO- D > 5} & \multirow{2}{*}{$\begin{array}{l}\text { OR Bruto } \\
\text { (IC 95\%) }\end{array}$} & \multirow[t]{2}{*}{$p$} \\
\hline & $\mathbf{n}$ & $\%$ & $\mathbf{n}$ & $\%$ & & \\
\hline \multicolumn{7}{|l|}{ Consumo de carboidrato } \\
\hline$>60 \%$ em relação as calorias totais & 23 & 19,83 & 22 & 21,78 & $1,13(0,58-2,17)$ & 0,723 \\
\hline$\leq 60 \%$ em relação as calorias totais & 93 & 80,17 & 79 & 78,22 & 1,00 & \\
\hline Freqüência total & 116 & 100,00 & 101 & 100,00 & & \\
\hline \multicolumn{7}{|l|}{ Consumo de lipídios } \\
\hline$>30 \%$ em relação as calorias totais & 63 & 54,31 & 57 & 56,44 & $1,09(0,64-1,86)$ & 0,753 \\
\hline$\leq 30 \%$ em relação as calorias totais & 53 & 45,69 & 44 & 43,56 & 1,00 & \\
\hline Freqüência total & 116 & 100,00 & 101 & 100,00 & & \\
\hline \multicolumn{7}{|l|}{$\begin{array}{l}\text { Consumo de calorias total segundo } \\
\text { sexo e idade }\end{array}$} \\
\hline Inadequado & 69 & 59,48 & 67 & 66,34 & $1,34(0,77-2,34)$ & 0,298 \\
\hline Adequado & 47 & 40,52 & 34 & 33,66 & 1,00 & \\
\hline Freqüência total & 116 & 100,00 & 101 & 100,00 & & \\
\hline \multicolumn{7}{|l|}{$\begin{array}{l}\text { Sacarose (média de refeições diárias } \\
\text { contendo sacarose) }\end{array}$} \\
\hline$\geq 3,3$ vezes & 60 & 51,28 & 40 & 39,60 & $0,62(0,36-1,07)$ & 0,085 \\
\hline$<3,3$ vezes & 57 & 48,72 & 61 & 60,40 & 1,00 & \\
\hline Freqüência total & 117 & 100,00 & 101 & 100,00 & & \\
\hline \multicolumn{7}{|l|}{$\begin{array}{l}\text { Refrigerante Normal (média do } \\
\text { consumo diário) }\end{array}$} \\
\hline$\geq 0,3$ vezes & 77 & 65,81 & 65 & 64,36 & $0,94(0,54-1,64)$ & 0,822 \\
\hline$<0,3$ vezes & 40 & 34,19 & 36 & 35,64 & 1,00 & \\
\hline Freqüência total & 117 & 100,00 & 101 & 100,00 & & \\
\hline \multicolumn{7}{|l|}{$\begin{array}{l}\text { Refrigerante Diet (média do consumo } \\
\text { diário) }\end{array}$} \\
\hline Consome & 12 & 10,26 & 14 & 13,86 & $1,41(0,62-3,20)$ & 0,414 \\
\hline Não consome & 105 & 89,74 & 87 & 86,14 & 1,00 & \\
\hline Freqüência total & 117 & 100,00 & 101 & 100,00 & & \\
\hline \multicolumn{7}{|l|}{$\begin{array}{l}\text { Salgadinhos (média do consumo } \\
\text { diário) }\end{array}$} \\
\hline Consome & 19 & 16,24 & 19 & 18,81 & $1,20(0,59-2,41)$ & 0,618 \\
\hline Não consome & 98 & 83,76 & 82 & 81,19 & 1,00 & \\
\hline Freqüência total & 117 & 100,00 & 101 & 100,00 & & \\
\hline \multicolumn{7}{|l|}{ Refeição (média diário) } \\
\hline$>4,7$ vezes ao dia & 57 & 49,14 & 51 & 50,50 & $1,06(0,62-1,80)$ & 0,842 \\
\hline$\leq 4,7$ vezes ao dia & 59 & 50,86 & 50 & 49,50 & 1,00 & \\
\hline Freqüência total & 116 & 100,00 & 101 & 100,00 & & \\
\hline
\end{tabular}




\subsection{4 variáveis dos hábitos alimentares}

As variáveis dos hábitos alimentares foram obtidas por meio do questionário geral de freqüência de consumo semanal de diversos alimentos. Não foi encontrada diferença significante entre o CPO-D e essas variáveis. Contudo, é interessante destacar alguns hábitos alimentares encontrados entre os adolescentes que participaram deste estudo. A minoria dos adolescentes relatou consumir salgadinhos de pacote mais de 4 vezes na semana; porém a maioria mencionou que consumia balas mais de 4 vezes na semana. Quanto ao consumo de doces, praticamente a metade dos adolescentes mencionou o consumo freqüente desse tipo de alimento (Tabela 5.11). 
Tabela 5.11 - Prevalência e razão de chance (OR), com seus respectivos intervalos de confiança de $95 \%$ (IC 95\%), para variáveis relativas à freqüência semanal de consumo, obtido através do questionário geral, ao baixo índice de cárie dentária (CPO-D $\leq 5)$ e ao alto índice_(CPO-D > 5), obtidos por meio da regressão logística univariada. São Paulo, SP, 2002

\begin{tabular}{|c|c|c|c|c|c|c|}
\hline \multirow[t]{2}{*}{ Variáveis } & \multicolumn{2}{|c|}{ CPO-D $\leq 5$} & \multicolumn{2}{|c|}{ CPO-D > 5} & \multirow{2}{*}{$\begin{array}{l}\text { OR Bruto } \\
\text { (IC 95\%) }\end{array}$} & \multirow[t]{2}{*}{$p$} \\
\hline & $\mathbf{n}$ & $\%$ & $\mathbf{n}$ & $\%$ & & \\
\hline \multicolumn{7}{|l|}{ Refrigerante } \\
\hline Consumo $\geq 4$ vezes por semana & 41 & 33,88 & 36 & 33,96 & $1,00(0,58-1,74)$ & 0,990 \\
\hline Consumo $<4$ vezes por semana & 80 & 66,12 & 70 & 66,04 & 1,00 & \\
\hline Freqüência total & 121 & 100,00 & 106 & 100,00 & & \\
\hline \multicolumn{7}{|l|}{ Salgados } \\
\hline Consumo $\geq 4$ vezes por semana & 21 & 17,21 & 25 & 23,36 & $1,47(0,77-2,81)$ & 0,248 \\
\hline Consumo $<4$ vezes por semana & 101 & 82,79 & 82 & 76,64 & 1,00 & \\
\hline Freqüência total & 122 & 100,00 & 107 & 100,00 & & \\
\hline \multicolumn{7}{|l|}{ Salgadinho de Pacote } \\
\hline Consumo $\geq 4$ vezes por semana & 2 & 1,67 & 5 & 4,76 & $2,95(0,56-15,53)$ & 0,202 \\
\hline Consumo $<4$ vezes por semana & 118 & 98,33 & 100 & 95,24 & 1,00 & \\
\hline Freqüência total & 120 & 100,00 & 105 & 100,00 & & \\
\hline \multicolumn{7}{|l|}{ Lanches } \\
\hline Consumo $\geq 4$ vezes por semana & 18 & 14,75 & 16 & 14,81 & $1,00(0,48-2,08)$ & 0,990 \\
\hline Consumo $<4$ vezes por semana & 104 & 85,25 & 92 & 85,19 & 1,00 & \\
\hline Freqüência total & 122 & 100,00 & 108 & 100,00 & & \\
\hline \multicolumn{7}{|l|}{ Balas } \\
\hline Consumo $\geq 4$ vezes por semana & 77 & 63,64 & 76 & 70,37 & $1,36(0,78-2,36)$ & 0,281 \\
\hline Consumo $<4$ vezes por semana & 44 & 36,36 & 32 & 29,63 & 1,00 & \\
\hline Freqüência total & 121 & 100,00 & 108 & 100,00 & & \\
\hline \multicolumn{7}{|l|}{ Doces } \\
\hline Consumo $\geq 4$ vezes por semana & 62 & 51,24 & 49 & 45,37 & $0,79(0,47-1,33)$ & 0,375 \\
\hline Consumo $<4$ vezes por semana & 59 & 48,76 & 59 & 54,63 & 1,00 & \\
\hline Freqüência total & 121 & 100,00 & 108 & 100,00 & & \\
\hline \multicolumn{7}{|l|}{ Queijo } \\
\hline Consumo $\geq 4$ vezes por semana & 34 & 28,33 & 24 & 23,08 & $0,76(0,41-1,39)$ & 0,371 \\
\hline $\begin{array}{l}\text { Consumo } \leq 4 \text { vezes por semana } \\
\text { Freqüência total }\end{array}$ & $\begin{array}{r}86 \\
120\end{array}$ & $\begin{array}{r}71,67 \\
100,00\end{array}$ & $\begin{array}{c}80 \\
104\end{array}$ & $\begin{array}{r}76,92 \\
100,00\end{array}$ & 1,00 & \\
\hline
\end{tabular}




\subsection{5 variáveis comportamentais}

As variáveis comportamentais avaliadas foram as seguintes: o número de horas que assiste televisão por dia, o que mais gosta de fazer, quantas vezes higieniza os dentes e quando foi àúltima visita ao cirurgião-dentista.

Ao serem indagados sobre o número de vezes que higienizavam os dentes, $186(80,87 \%)$ adolescentes relataram que escovavam seus dentes duas ou três vezes ao dia (Tabela 5.12).

Em relação ao tempo transcorrido desde a última visita ao cirurgiãodentista, $120(52,17 \%)$ adolescentes responderam que tinha sido nos últimos 12 meses. Destes, nota-se que 68 apresentavam média de CPO-D acima de 5 (Tabela 5.12).

Observa-se, na Tabela 5.12, que o número de vezes que os adolescentes higienizava os dentes por dia e o tempo transcorrido desde a última visita ao cirurgião-dentista apresentaram associação significante com o CPO-D no nível 5\%. 
Tabela 5.12 - Prevalência e razão de chance (OR), com seus respectivos intervalos de confiança de 95\% (IC 95\%), para variáveis comportamentais ao baixo índice de cárie dentária $(C P O-D \leq 5)$ e ao alto índice (CPO-D > 5), obtidas por meio da regressão logística univariada. São Paulo, SP, 2002

\begin{tabular}{|c|c|c|c|c|c|c|}
\hline \multirow[t]{2}{*}{ Variáveis } & \multicolumn{2}{|c|}{ CPO-D $\leq 5$} & \multicolumn{2}{|c|}{ CPO-D > 5} & \multirow{2}{*}{ 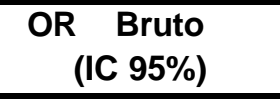 } & \multirow[t]{2}{*}{$p$} \\
\hline & $\mathbf{n}$ & $\%$ & $\mathbf{n}$ & $\%$ & & \\
\hline \multicolumn{7}{|l|}{ Assiste televisão } \\
\hline$\geq 4$ horas por dia & 23 & 18,85 & 20 & 18,52 & $0,98(0,50-1,90)$ & 0,948 \\
\hline $\begin{array}{l}<4 \text { horas por dia } \\
\text { Freqüência total }\end{array}$ & $\begin{array}{r}99 \\
122\end{array}$ & $\begin{array}{r}81,15 \\
100,00\end{array}$ & $\begin{array}{r}88 \\
108\end{array}$ & $\begin{array}{r}81,48 \\
100,00\end{array}$ & 1,00 & \\
\hline \multicolumn{7}{|c|}{$\begin{array}{l}\text { Última visita ao cirurgião- } \\
\text { dentista }\end{array}$} \\
\hline Há mais de um ano & 66 & 54,10 & 36 & 33,33 & $0,42(0,24-0,72)$ & $0,002^{*}$ \\
\hline Nunca foi & 4 & 3,28 & 4 & 3,70 & $0,76(0,18-3,20)$ & 0,714 \\
\hline No último ano & 52 & 42,62 & 68 & 62,96 & 1,00 & \\
\hline Freqüência total & 122 & 100,00 & 108 & 100,00 & & \\
\hline \multicolumn{7}{|c|}{$\begin{array}{l}\text { Quantas vezes higieniza os } \\
\text { dentes por dia? }\end{array}$} \\
\hline 2 vezes & 42 & 34,43 & 28 & 25,93 & $0,15(0,40-0,59)$ & $0,006^{*}$ \\
\hline 3 vezes & 66 & 54,10 & 50 & 46,30 & $0,18(0,47-0,65)$ & $0,009^{*}$ \\
\hline mais de 3 vezes & 11 & 9,02 & 17 & 15,74 & $0,36(0,08-1,55)$ & 0,168 \\
\hline $1 \mathrm{vez}$ & 3 & 2,46 & 13 & 12,04 & 1,00 & \\
\hline Freqüência total & 122 & 100,00 & 108 & 100,00 & & \\
\hline
\end{tabular}

* significante no nível 5\% segundo teste Exato de Fisher

Nas Tabelas 5.13 e 5.14 observam-se a estatística descritiva do CPO-D e seus componentes, segundo o tempo transcorrido desde a última visita ao cirurgiãodentista e o número de vezes que escova os dentes respectivamente.

Observa-se, na Tabela 5.13, que o CPO-D daqueles adolescentes que foram ao cirurgião-dentista no último ano foi mais alto (CPO-D $=6,27)$ quando comparado com aqueles que foram a mais de um ano (CPO-D $=5,43$ ) ou nunca foram e não se lembram (CPO-D =5,25). A média de dentes cariados foi maior naqueles que relataram que nunca foram ao cirurgião-dentista $(3,63)$ ou que não se lembravam quando tinha sido a sua última consulta odontológica. A média de dentes restaurados foi maior entre os adolescentes que já tinham ido ao cirurgiãodentista no último ano ou há mais de um ano $(2,77$ e 2,74$)$ quando comparados com 
aqueles que nunca foram ou não se lembraram de quando tinha sido sua última consulta $(1,50)$.

Tabela 5.13 - Estatística descritiva CPO-D e seus componentes, segundo o tempo transcorrido desde a última vez que foi ao cirurgião-dentista. São Paulo, SP, 2002

\begin{tabular}{|c|c|c|c|c|}
\hline \multirow[t]{2}{*}{ CPO-D } & \multirow[t]{2}{*}{ Estatísticas } & \multicolumn{3}{|c|}{ Última vez que foi ao cirurgião- dentista } \\
\hline & & Último ano & $\begin{array}{c}\text { Há mais de } 1 \\
\text { ano }\end{array}$ & Nunca foi \\
\hline \multirow[t]{6}{*}{ CPO-D } & Média & 6,27 & 5,43 & 5,25 \\
\hline & Mediana & 5,00 & 5,00 & 5,00 \\
\hline & Desvio-padrão & 5,01 & 4,28 & 3,65 \\
\hline & Mínimo & 0 & 0 & 0 \\
\hline & Máximo & 20 & 19 & 11 \\
\hline & Freqüência & 119 & 102 & 8 \\
\hline \multirow{6}{*}{ Cariados } & Média & 3,45 & 2,49 & 3,63 \\
\hline & Mediana & 3,00 & 2,00 & 3,00 \\
\hline & Desvio-padrão & 3,74 & 2,71 & 3,70 \\
\hline & Mínimo & 0 & 0 & 0 \\
\hline & Máximo & 20 & 10 & 11 \\
\hline & Freqüência & 119 & 102 & 8 \\
\hline \multirow[t]{6}{*}{ Perdidos } & Média & 0,06 & 0,02 & 0 \\
\hline & Mediana & 0 & 0 & 0 \\
\hline & Desvio-padrão & 0,33 & 0,17 & 0 \\
\hline & Mínimo & 0 & 0 & 0 \\
\hline & Máximo & 2 & 1 & 0 \\
\hline & Freqüência & 119 & 102 & 8 \\
\hline \multicolumn{5}{|c|}{ Obturados } \\
\hline & Média & 2,77 & 2,74 & 1,50 \\
\hline & Mediana & 1,00 & 1,00 & 1,00 \\
\hline & Desvio-padrão & 3,92 & 3,61 & 1,77 \\
\hline & Mínimo & 0 & 0 & 0 \\
\hline & Máximo & 17 & 18 & 5 \\
\hline & Freqüência & 119 & 102 & 8 \\
\hline
\end{tabular}

A Tabela 5.14 mostra a estatística descritiva do CPO-D e seus componentes em relação ao número de vezes que os adolescentes higienizavam seus dentes. A aqueles que mencionaram que higienizavam uma vez ao dia ou às 
vezes tinham valor médio de CPO-D praticamente o dobro $(10,00)$ daqueles que higienizavam duas $(5,37)$ ou três vezes $(5,39)$ ao dia. Seguindo essa mesma linha, a média de dentes cariados e restaurados também foi maior naqueles que higienizavam seus dentes às vezes ou uma vez ao dia.

Tabela 5.14 - Estatística descritiva do CPO-D e seus componentes, segundo o número de vezes que higieniza os dentes por dia. São Paulo, SP, 2002

\begin{tabular}{|c|c|c|c|c|c|}
\hline \multirow[t]{2}{*}{ CPO-D } & \multirow[t]{2}{*}{ Estatísticas } & \multirow{2}{*}{$\begin{array}{c}\text { Número de } \\
1 \text { vez ou } \\
\text { menos }\end{array}$} & \multirow{2}{*}{$\begin{array}{l}\text { vezes que } \\
2 \text { vezes }\end{array}$} & \multirow{2}{*}{$\begin{array}{l}\text { higieniza } \\
3 \text { vezes }\end{array}$} & \multirow{2}{*}{$\begin{array}{c}\text { os dentes } \\
\begin{array}{c}\text { Mais de } 3 \\
\text { vezes }\end{array}\end{array}$} \\
\hline & & & & & \\
\hline \multirow{6}{*}{ CPO-D } & Média & 10,00 & 5,37 & 5,39 & 6,64 \\
\hline & Mediana & 9,50 & 5,00 & 5,00 & 7,00 \\
\hline & Desvio-padrão & 6,11 & 4,40 & 4,21 & 4,98 \\
\hline & Mínimo & 0 & 0 & 0 & 0 \\
\hline & Máximo & 18 & 20 & 19 & 18 \\
\hline & Freqüência & 16 & 70 & 116 & 28 \\
\hline \multirow[t]{6}{*}{ Cariados } & Média & 4,63 & 3,09 & 2,69 & 3,39 \\
\hline & Mediana & 4,00 & 2,00 & 2,00 & 3,00 \\
\hline & Desvio-padrão & 3,93 & 3,76 & 2,90 & 3,37 \\
\hline & Mínimo & 0 & 0 & 0 & 0 \\
\hline & Máximo & 15 & 20 & 12 & 15 \\
\hline & Freqüência & 16 & 70 & 116 & 28 \\
\hline \multirow[t]{6}{*}{ Perdidos } & Média & 0,06 & 0,09 & 0,03 & 0 \\
\hline & Mediana & 0 & 0 & 0 & 0 \\
\hline & Desvio-padrão & 0,25 & 0,37 & 0,21 & 0 \\
\hline & Mínimo & 0 & 0 & 0 & 0 \\
\hline & Máximo & 1 & 2 & 2 & 0 \\
\hline & Freqüência & 16 & 70 & 116 & 28 \\
\hline \multicolumn{6}{|c|}{ Obturados } \\
\hline & Média & 4,56 & 2,10 & 2,65 & 3,43 \\
\hline & Mediana & 1,00 & 1,00 & 1,00 & 2,00 \\
\hline & Desvio-padrão & 5,73 & 2,81 & 3,60 & 4,47 \\
\hline & Mínimo & 0 & 0 & 0 & 0 \\
\hline & Máximo & 15 & 20 & 19 & 17 \\
\hline & Freqüência & 16 & 70 & 116 & 28 \\
\hline
\end{tabular}




\subsection{Regressão logística múltipla e modelo final do backward stepwise para o índice CPO-D}

Para verificar a influência das variáveis estudadas sobre o CPO-D, utilizando a regressão logística múltipla, foram selecionadas aquelas que apresentaram associação significante no nível 5\% na regressão logística univariada (Tabela 5.15). A seguir, foi realizado o teste backward stepwise. O modelo final do backward stepwise apresenta os indicadores de risco para gravidade do CPO-D (Tabela 5.16).

A Tabela 5.15 apresenta a regressão logística múltipla das variáveis selecionadas. As variáveis que apresentaram significância foram a higiene dos dentes duas e três vezes ao dia, quem consome sacarose em mais de três refeições diárias, nível de escolaridade materna baixo, ser sobrepeso e idade do adolescente superior ou igual a 17 anos.

A Tabela 5.16 apresenta o modelo final do backward stepwise, onde quatro variáveis mantiveram associação significante com o CPO-D. Três foram consideradas indicadores de risco para os adolescentes avaliados: o baixo nível de escolaridade materna ( $O R=3,05$ [IC 95\% $(O R)=1,15-8,07])$, o fato de ser sobrepeso $(\mathrm{OR}=2,23[\mathrm{IC} 95 \%(\mathrm{OR})=1,04-4,75])$ e idade superior ou igual a 17 anos $(\mathrm{OR}=2,19$ [IC 95\% $(\mathrm{OR})=1,24-3,87])$. O número de vezes que o adolescente escovava os dente foi um fator de proteção, sendo que apenas aqueles quem escovava os dentes duas vezes $\quad(O R=0,30[\operatorname{IC~95\% ~}(\mathrm{OR})=0,13-0,68])$ ou três vezes ao dia (OR =0,32 [IC 95\% $(\mathrm{OR})=0,15-0,68]$ ) apresentaram associação significante com índice CPO-D. 
Tabela 5.15 - Regressão logística múltipla das variáveis que foram significante a $10 \%$ para gravidade do CPO-D . São Paulo, SP, 2002

\begin{tabular}{|c|c|c|c|c|}
\hline Variável & Coeficiente & OR ajustado & IC (95\%) & $p$ \\
\hline $\begin{array}{l}\text { Escolaridade da mãe } \\
\text { acima do fundamental } \\
\text { incompleto } \\
\text { fundamental incompleto }\end{array}$ & $\begin{array}{l}\text { Referência } \\
1,10\end{array}$ & $\begin{array}{l}1,00 \\
3,01\end{array}$ & $(1,12-8,07)$ & 0,029 \\
\hline $\begin{array}{l}\text { Idade do adolescente } \\
\quad<17 \text { anos } \\
\geq 17 \text { anos }\end{array}$ & $\begin{array}{c}\text { Referência } \\
0,77\end{array}$ & $\begin{array}{l}1,00 \\
2,16\end{array}$ & $(1,21-3,84)$ & 0,009 \\
\hline $\begin{array}{l}\text { Estado nutricional } \\
\text { Eutrófico } \\
\text { Sobrepeso } \\
\text { Obeso }\end{array}$ & $\begin{array}{c}\text { Referência } \\
0,74 \\
0,11\end{array}$ & $\begin{array}{l}1,00 \\
2,09 \\
1,12\end{array}$ & $\begin{array}{l}(0,95-4,61) \\
(0,53-2,36)\end{array}$ & $\begin{array}{l}\mathbf{0 , 0 6 7} \\
0,762\end{array}$ \\
\hline $\begin{array}{l}\text { Média de refeições com } \\
\text { sacarose } \\
\leq 3,3 \text { vezes } \\
>3,3 \text { vezes }\end{array}$ & $\begin{array}{c}\text { Referência } \\
0,42\end{array}$ & $\begin{array}{l}1,00 \\
0,66\end{array}$ & $(0,37-1,18)$ & 0,162 \\
\hline $\begin{array}{l}\text { Vezes que higieniza os der } \\
1 \text { vez } \\
2 \text { vezes } \\
3 \text { vezes } \\
\text { mais de } 3 \text { vezes }\end{array}$ & $\begin{array}{c}\text { Referência } \\
-1,83 \\
-1,72 \\
-0,81\end{array}$ & $\begin{array}{l}1,00 \\
0,16 \\
0,18 \\
0,45\end{array}$ & $\begin{array}{l}(0,04-0,63) \\
(0,47-0,69) \\
(0,98-2,01)\end{array}$ & $\begin{array}{l}\mathbf{0 , 0 0 9} \\
\mathbf{0 , 0 1 2} \\
0,293\end{array}$ \\
\hline constante $=$ & 1,17 & & & 0,224 \\
\hline
\end{tabular}

Tabela 5.16- Modelo final para os indicadores de risco de alto índice CPO-D em adolescentes entre 15 e 19 anos de idade obtido por meio do "backward stepwise". São Paulo, SP, 2002

\begin{tabular}{|c|c|c|c|c|}
\hline Variável & Coeficiente & $\begin{array}{c}\text { OR } \\
\text { ajustado }\end{array}$ & IC (95\%) & $p$ \\
\hline $\begin{array}{l}\text { Escolaridade da mãe } \\
\text { acima do fundamental } \\
\text { incompleto } \\
\text { fundamental incompleto }\end{array}$ & $\begin{array}{l}\text { Referência } \\
\qquad 1,13\end{array}$ & $\begin{array}{l}1,00 \\
3,05\end{array}$ & $(1,15-8,07)$ & 0,025 \\
\hline $\begin{array}{c}\text { Idade adolescente } \\
\quad<17 \text { anos } \\
\geq 17 \text { anos }\end{array}$ & $\begin{array}{c}\text { Referência } \\
0,77\end{array}$ & $\begin{array}{l}1,00 \\
2,19\end{array}$ & $(1,24-3,87)$ & 0,007 \\
\hline $\begin{array}{l}\text { Estado nutricional } \\
\text { Eutrófico } \\
\text { Sobrepeso }\end{array}$ & $\begin{array}{c}\text { Referência } \\
0,81\end{array}$ & $\begin{array}{l}1,00 \\
2,23\end{array}$ & $(1,04-4,75)$ & 0,039 \\
\hline $\begin{array}{l}\text { Vezes que higieniza os dentes } \\
1 \text { vez } \\
2 \text { vezes } \\
3 \text { vezes } \\
\end{array}$ & $\begin{array}{c}\text { Referência } \\
-1,21 \\
-1,17 \\
\end{array}$ & $\begin{array}{l}1,00 \\
0,30 \\
0,32 \\
\end{array}$ & $\begin{array}{r}(0,13-0,68) \\
(0,15-0,68)\end{array}$ & $\begin{array}{l}0,004 \\
0,003 \\
\end{array}$ \\
\hline
\end{tabular}




\subsection{Regressão logística univariada do componente cariado do índice CPO-D}

Considerando-se que o índice CPO-D inclui dentes já restaurados ou perdidos, decidiu-se verificar a associação apenas do componente cariado do índice CPO-D com as variáveis estudadas, dicotomizando esta variável em zero, quando o adolescente não apresentava nenhuma lesão de cárie ou 1, quando ele apresentava uma ou mais lesões de cárie. A dicotomização de todas as outras variáveis foi igual àquela utilizada anteriormente. Dos 230 adolescentes que participaram deste estudo, 68 (29,73\%) não apresentaram lesão de cárie, contra 162 (70,43\%) que apresentaram pelo menos uma lesão.

\subsection{1 variáveis sóciodemográficas}

Dentre as variáveis sóciodemográficas avaliadas, nenhuma apresentou associação significante com a presença ou ausência da cárie dentária. Apesar de o nível da escolaridade materna não ter sido significante $(p=0,174)$, vale salientar que 94,12\% dos adolescentes que não apresentaram lesão de cárie tinham mães com alto nível de escolaridade (acima de fundamental incompleto) (Tabela 5.17). 
Tabela 5.17 - Prevalência e razão de chance (OR) com seus respectivos intervalos de confiança de 95\% (IC 95\%) para variáveis sóciodemográficas relacionadas ao grupo sem ou com cárie dentária, obtidas por meio da regressão logística univariada. São Paulo, SP, 2002

\begin{tabular}{|c|c|c|c|c|c|c|}
\hline Variáveis & $\begin{array}{c}\text { Cárie } \\
n\end{array}$ & $\begin{array}{c}\text { ausente } \\
\%\end{array}$ & $\begin{array}{c}\text { Cárie } \\
\mathrm{n}\end{array}$ & $\begin{array}{l}\text { presente } \\
\%\end{array}$ & $\begin{array}{l}\text { OR Bruto } \\
\text { (IC 95\%) }\end{array}$ & $p$ \\
\hline Idade do adolescente & & & & & & \\
\hline Idade $\geq 17$ anos & 33 & 48,53 & 85 & 52,47 & $1,17(0,66-2,06)$ & 0,586 \\
\hline Idade $<17$ anos & 35 & 51,47 & 77 & 47,53 & 1,00 & \\
\hline Freqüência total & 68 & 100,00 & 162 & 100,00 & & \\
\hline \multicolumn{7}{|l|}{ Sexo } \\
\hline Masculino & 36 & 47,06 & 90 & 55,56 & $1,11(0.63-1,96)$ & 0,716 \\
\hline Feminino & 32 & 52,94 & 72 & 44,44 & 1,00 & \\
\hline Freqüência total & 68 & 100,00 & & 100,00 & & \\
\hline \multicolumn{7}{|l|}{ Idade da mãe } \\
\hline Idade $\geq 45$ anos & 33 & 48,53 & 85 & 52,47 & $1,71(0,66-2,06)$ & 0,586 \\
\hline Idade $<45$ anos & 35 & 51,47 & 77 & 47,53 & 1,00 & \\
\hline Freqüência total & 68 & 100,00 & 162 & 100,00 & & \\
\hline \multicolumn{7}{|l|}{ Nível de escolaridade da mãe } \\
\hline Até fundamental incompleto & 4 & 5,88 & 19 & 11,95 & $2,17(0,71-6,64)$ & 0,174 \\
\hline Acima de fundamental incompleto & 64 & 94,12 & 140 & 88,05 & 1,00 & \\
\hline Freqüência total & 68 & 100,00 & 159 & 100,00 & & \\
\hline \multicolumn{7}{|l|}{ Idade do pai } \\
\hline Idade $\geq 47$ anos & 33 & 48,53 & 85 & 52,47 & $1,17(0,66-2,06)$ & 0,586 \\
\hline Idade $<47$ anos & 35 & 51,47 & 77 & 47,53 & 1,00 & \\
\hline Freqüência total & 68 & 100,00 & 162 & 100,00 & & \\
\hline \multicolumn{7}{|l|}{ Renda familiar } \\
\hline Renda $\leq 11$ salários mínimos & 37 & 56,06 & 100 & 62,89 & $0,75(0,42-1,35)$ & 0,340 \\
\hline Renda $>11$ salários mínimos & 29 & 43,94 & 59 & 37,11 & 1,00 & \\
\hline Freqüência total & 66 & 100,00 & 159 & 100,00 & & \\
\hline
\end{tabular}

\subsection{2 variáveis fisiológicas}

A Tabela 5.18 mostra que não houve associação significante $(p>0,05)$ entre as variáveis fisiológicas e a presença ou ausência de cárie dentária. Contudo, dentre aqueles adolescentes que se apresentaram sem cárie dentária, 10,29\% tinham nível de triglicérides acima do recomendado, contra 4,94\% daqueles que tinham alguma lesão de cárie dentária. 
Tabela 5.18 - Prevalência e razão de chance (OR), com seus respectivos intervalos de confiança de 95\% (IC 95\%), para fisiológicas relacionadas ao grupo sem cárie dentária ou com cárie dentária , obtidas por meio da regressão logística univariada. São Paulo, SP, 2002

\begin{tabular}{|c|c|c|c|c|c|c|}
\hline Variáveis & $\begin{array}{l}\text { Cárie } \\
\mathrm{n}\end{array}$ & $\begin{array}{l}\text { ausente } \\
\%\end{array}$ & $\begin{array}{c}\text { Cárie } \\
\text { n }\end{array}$ & $\begin{array}{l}\text { presente } \\
\%\end{array}$ & $\begin{array}{l}\text { OR Bruto } \\
\text { (IC 95\%) }\end{array}$ & $p$ \\
\hline \multicolumn{7}{|l|}{ Estado Nutricional } \\
\hline Sobrepeso & 11 & 16,18 & 28 & 17,28 & $1,08(0,49-2,35)$ & 0,853 \\
\hline Obeso & 13 & 19,12 & 30 & 18,52 & $0,98(0,47-2,05)$ & 0,949 \\
\hline Eutrófico & 44 & 64,71 & 104 & 64,20 & 1,00 & \\
\hline Freqüência total & 68 & 100,00 & 162 & 100,00 & & \\
\hline \multicolumn{7}{|l|}{ Colesterol Total } \\
\hline Colesterol total $>200 \mathrm{mg} / \mathrm{dl}$ & 6 & 8,82 & 19 & 11,73 & $1,37(0,52-3,60)$ & 0,520 \\
\hline Colesterol total $\leq 200 \mathrm{mg} / \mathrm{dl}$ & 62 & 91,18 & 143 & 88,27 & 1,00 & \\
\hline Freqüência total & & 100,00 & 108 & 100,00 & & \\
\hline \multicolumn{7}{|l|}{ Colesterol HDL } \\
\hline Colesterol HDL $<35$ mg/dl & 8 & 11,76 & 15 & 9,26 & $0,77(0,31-1,90)$ & 0,564 \\
\hline Colesterol HDL $\geq 35 \mathrm{mg} / \mathrm{dl}$ & 60 & 88,24 & 147 & 90,74 & 1,00 & \\
\hline Freqüência total & 68 & 100,00 & 108 & 100,00 & & \\
\hline \multicolumn{7}{|l|}{ Colesterol LDL } \\
\hline Colesterol LDL > $130 \mathrm{mg} / \mathrm{dl}$ & 4 & 5,88 & 16 & 9,88 & $1,75(0,56-5,45)$ & 0,332 \\
\hline Colesterol LDL $\leq 130 \mathrm{mg} / \mathrm{dl}$ & 64 & 94,12 & 146 & 90,12 & 1,00 & \\
\hline Freqüência total & 68 & 100,00 & 162 & 100,00 & & \\
\hline \multicolumn{7}{|l|}{ Triglicérides } \\
\hline Triglicérides > 150 mg/dl & 7 & 10,29 & 8 & 4,94 & $0,45(0,16-1,30)$ & 0,142 \\
\hline Triglicérides $\leq 150 \mathrm{mg} / \mathrm{dl}$ & 61 & 89,71 & 154 & 95,06 & 1,00 & \\
\hline Freqüência total & 68 & 100,00 & 162 & 100,00 & & \\
\hline \multicolumn{7}{|l|}{ Dislipidemia } \\
\hline Alterado & 14 & 20,59 & 36 & 22,22 & $1,02(0,55-2,21)$ & 0,784 \\
\hline Normal/Limítrofe & 54 & 79,41 & 126 & 77,78 & 1,00 & \\
\hline Freqüência total & 68 & 100,00 & 162 & 100,00 & & \\
\hline
\end{tabular}

\subsection{2 variáveis dietéticas}

Observa-se, na Tabela 5.19, que o consumo médio diário de refrigerantes normais apresentou tendência de associação com a cárie dentária $\quad(p=0,124)$. Entre os adolescentes que tinham uma ou mais lesões de cárie, $68,42 \%$ consumiam refrigerantes normais mais de 0,3 vezes ao dia, contra $31,58 \%$ daqueles que consumiam esta bebida com menor freqüência. 
Tabela 5.19 - Prevalência e razão de chance (OR), com seus respectivos intervalos de confiança de 95\% (IC 95\%), para variáveis dietéticas obtidas por meio do registro alimentar relacionadas ao grupo sem ou com cárie dentária, obtidas por meio da regressão logística univariada. São Paulo, SP, 2002

\begin{tabular}{|c|c|c|c|c|c|c|}
\hline \multirow[t]{2}{*}{ Variáveis } & \multicolumn{2}{|c|}{ Cárie ausente } & \multicolumn{2}{|c|}{ Cárie presente } & \multirow{2}{*}{$\begin{array}{l}\text { OR Bruto } \\
\text { (IC 95\%) }\end{array}$} & \multirow{2}{*}{$p$} \\
\hline & $\mathrm{n}$ & $\%$ & $\mathrm{n}$ & $\%$ & & \\
\hline $\begin{array}{l}\text { Consumo de carboidrato } \\
>60 \% \text { em relação æ̀̀ calorias totais } \\
\leq 60 \% \text { em relação às calorias totais } \\
\text { Freqüência total }\end{array}$ & $\begin{array}{l}15 \\
50 \\
65\end{array}$ & $\begin{array}{r}23,08 \\
76,92 \\
100,00\end{array}$ & $\begin{array}{r}30 \\
122 \\
152\end{array}$ & $\begin{array}{r}19,74 \\
80,26 \\
100,00\end{array}$ & $\begin{array}{c}0,820(0,41-1,65) \\
1,00\end{array}$ & 0,579 \\
\hline $\begin{array}{l}\text { Consumo de lipídios } \\
>30 \% \text { em relação à̀ calorias totais } \\
\leq 30 \% \text { em relação às calorias totais } \\
\text { Freqüência total }\end{array}$ & $\begin{array}{l}34 \\
31 \\
65\end{array}$ & $\begin{array}{r}52,31 \\
47,69 \\
100,00\end{array}$ & $\begin{array}{r}86 \\
66 \\
152\end{array}$ & $\begin{array}{r}56,58 \\
43,42 \\
100,00\end{array}$ & $\begin{array}{c}1,19(0,66-1,13) \\
1,00\end{array}$ & 0,562 \\
\hline $\begin{array}{l}\text { Consumo de calorias total, } \\
\text { segundo o sexo e a idade } \\
\text { Inadequado } \\
\text { Adequado } \\
\text { Freqüência total }\end{array}$ & $\begin{array}{l}32 \\
33 \\
65\end{array}$ & $\begin{array}{r}49,23 \\
50,77 \\
100,00\end{array}$ & $\begin{array}{r}70 \\
82 \\
152\end{array}$ & $\begin{array}{r}46,05 \\
53,96 \\
100,00\end{array}$ & $\begin{array}{c}0,88(0,49-1,57) \\
1,00\end{array}$ & 0,668 \\
\hline $\begin{array}{l}\text { Sacarose (média do consumo } \\
\text { diário) } \\
\geq 3,33 \text { vezes ao dia } \\
<3,33 \text { vezes ao dia } \\
\text { Freqüência total }\end{array}$ & $\begin{array}{l}34 \\
32 \\
66\end{array}$ & $\begin{array}{r}51,52 \\
48,48 \\
100,00\end{array}$ & $\begin{array}{r}66 \\
86 \\
152\end{array}$ & $\begin{array}{r}43,42 \\
56,58 \\
100,00\end{array}$ & $\begin{array}{c}0,72(0,40-1,29) \\
1,00\end{array}$ & 0,271 \\
\hline $\begin{array}{l}\text { Refrigerante normal (média do } \\
\text { consumo diário) } \\
\geq 0,3 \text { vezes ao dia } \\
<0,3 \text { vezes ao dia } \\
\text { Freqüência total }\end{array}$ & $\begin{array}{l}38 \\
28 \\
66\end{array}$ & $\begin{array}{r}57,58 \\
42,42 \\
100,00\end{array}$ & $\begin{array}{r}104 \\
48 \\
152\end{array}$ & $\begin{array}{r}68,42 \\
31,58 \\
100,00\end{array}$ & $\begin{array}{c}1,60(0,88-2,90) \\
1,00\end{array}$ & 0,124 \\
\hline $\begin{array}{l}\text { Refrigerante diet- light (média do } \\
\text { consumo diário) } \\
\text { Consome } \\
\text { Não consome } \\
\text { Freqüência total }\end{array}$ & $\begin{array}{r}9 \\
57 \\
66\end{array}$ & $\begin{array}{r}13,64 \\
86,36 \\
100,00\end{array}$ & $\begin{array}{r}17 \\
135 \\
152\end{array}$ & $\begin{array}{r}11,18 \\
88,82 \\
100,00\end{array}$ & $\begin{array}{c}0,80(0,34-1,90) \\
1,00\end{array}$ & 0,608 \\
\hline $\begin{array}{l}\text { Salgadinhos (média do consumo } \\
\text { diário) } \\
\text { Consome } \\
\text { Não consome } \\
\text { Freqüência total }\end{array}$ & $\begin{array}{l}13 \\
53 \\
66\end{array}$ & $\begin{array}{r}19,70 \\
80,30 \\
100,00\end{array}$ & $\begin{array}{r}25 \\
127 \\
152\end{array}$ & $\begin{array}{r}16,45 \\
83,55 \\
100,00\end{array}$ & $\begin{array}{c}0,80(0,38-1,69) \\
1,00\end{array}$ & 0,562 \\
\hline $\begin{array}{l}\text { Refeição (média do consumo } \\
\text { diário) } \\
>4,7 \text { vezes ao dia } \\
\leq 4,7 \text { vezes ao dia } \\
\text { Freqüência total }\end{array}$ & $\begin{array}{l}36 \\
30 \\
66 \\
\end{array}$ & $\begin{array}{r}54,55 \\
45,45 \\
100,00 \\
\end{array}$ & $\begin{array}{r}72 \\
79 \\
151 \\
\end{array}$ & $\begin{array}{r}47,68 \\
52,39 \\
100,00 \\
\end{array}$ & $\begin{array}{c}0,76(0,43-1,36) \\
1,00\end{array}$ & 0,353 \\
\hline
\end{tabular}




\subsection{4 variáveis dos hábitos alimentares}

A Tabela 5.20 mostra que não foi encontrada associação entre a cárie dentária e as variáveis dos hábitos alimentares. A distribuição dos adolescentes apresenta-se semelhante entre aqueles que têm cárie dentária e aqueles sem de cárie dentária.

Tabela 5.20 - Prevalência e razão de chance (OR), com seus respectivos intervalos de confiança de 95\% (IC 95\%), para variáveis dos hábitos alimentares relacionadas ao grupo sem ou com cárie dentária, obtidas por meio da regressão logística univariada. São Paulo, SP, 2002

\begin{tabular}{lrrrrrr}
\hline Variáveis & & ausente & Cárie & presente & OR Bruto & $p$ \\
& Cárie & $\mathrm{n}$ & $\%$ & $\mathrm{n}$ & $\%$ & (IC 95\%) \\
\hline
\end{tabular}

\section{Refrigerante}

Consumo $>4$ vezes por semana

18
48
66

Consumo $\leq 4$ vezes por semana

Freqüência total

\section{7,27}

72,73

100,00

59

102

161

\section{Salgados}

Consumo $>4$ vezes por semana

Consumo $\leq 4$ vezes por semana

Freqüência total

\section{5}

53

68

\section{Salgadinho de pacote}

Consumo $>4$ vezes por semana Consumo $\leq 4$ vezes por semana Freqüência total

\section{Lanches}

Consumo $>4$ vezes por semana Consumo $\leq 4$ vezes por semana Freqüência total

Balas

Consumo $>4$ vezes por semana Consumo $\leq 4$ vezes por semana Freqüência total

0

7
151
158

151

158

13

\section{1}

80,88

100,00

141

162

43

25

68

63,24

36,76

100,00

110

51

161

Doces

Consumo $>4$ vezes por semana Consumo $\leq 4$ vezes por semana Freqüência total

\section{0}

38

68

44,12

55,88

100,00

81

80

161

26,87

73,13 100,00

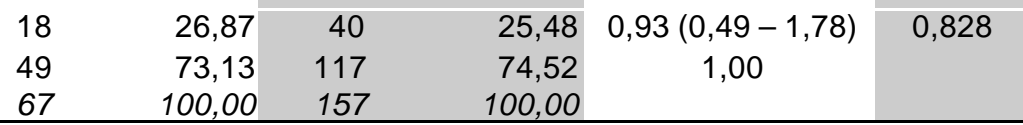

\section{Consumo $>4$ vezes por semana Consumo $\leq 4$ vezes por semana Freqüência total}

36,6

63,35

100,00

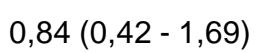

\section{4,43}

95,57

100,00

12,96

87,04

100,00

68,3

31,68

100,00

50,31

100,00

1,28

$(0,73$

1,00 100,00

0,177 1,00

***

1,00

$0,63(0,30-1,35)$

0,223

0,629
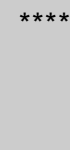

0,455

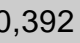

0,392

100,00 stica 


\subsection{5 variáveis comportamentais}

Semelhante ao que ocorreu com o CPO-D, as variáveis última visita ao cirurgião-dentista e o número de vezes que higieniza os dentes por dia tiveram associação significante com a cárie dentária $(p=0,10)$. Entre os adolescentes sem cárie dentária, 52,94\% relataram que a última consulta odontológica tinha sido há mais que um ano; e entre aqueles com cárie dentária, 52,28\% mencionaram que tinham ido ao cirurgião-dentista pela última vez no último ano. Em relação ao número de vezes que higieniza os dentes por dia, 57,35\% daqueles sem cárie dentária mencionaram que o fazem três vezes ao dia (Tabela 5.21).

Tabela 5.21 - Prevalência e razão de chance (OR) com seus respectivos intervalos de confiança de 95\% (IC 95\%) para variáveis comportamentais relacionadas ao grupo sem cárie dentária ou com cárie dentária , obtidos por meio da regressão logística univariada. São Paulo, SP, 2002

\begin{tabular}{|c|c|c|c|c|c|c|}
\hline \multirow[t]{2}{*}{ Variáveis } & \multirow{2}{*}{$\begin{array}{r}\text { Cárie } \\
\text { n }\end{array}$} & \multirow{2}{*}{$\begin{array}{c}\text { ausente } \\
\% \\
\end{array}$} & \multicolumn{2}{|c|}{ Cárie presente } & \multirow{2}{*}{$\begin{array}{l}\text { Razão } \\
\text { de chance } \\
\text { Bruto } \\
\text { (IC 95\%) }\end{array}$} & \multirow[t]{2}{*}{$p$} \\
\hline & & & $\mathbf{n}$ & $\%$ & & \\
\hline \multicolumn{7}{|l|}{ Assiste televisão } \\
\hline$\geq 4$ horas por dia & 12 & 17,65 & 31 & 19,14 & $1,10(0,53-2,31)$ & 0,792 \\
\hline $\begin{array}{l}<4 \text { horas por dia } \\
\text { Freqüência total }\end{array}$ & $\begin{array}{l}56 \\
68\end{array}$ & $\begin{array}{r}82,35 \\
100,00\end{array}$ & $\begin{array}{l}131 \\
162\end{array}$ & $\begin{array}{r}80,86 \\
100,00\end{array}$ & 1,00 & \\
\hline \multicolumn{7}{|l|}{$\begin{array}{l}\text { Última visita ao cirurgião- } \\
\text { dentista }\end{array}$} \\
\hline Há mais de um ano & 36 & 52,94 & 66 & 40,99 & $0,62(0,35-1,10)$ & 0,104 \\
\hline $\begin{array}{l}\text { Nunca foi } \\
\text { No último ano } \\
\text { Freqüência total }\end{array}$ & $\begin{array}{r}2 \\
30 \\
68\end{array}$ & $\begin{array}{r}2,94 \\
44,12 \\
100,00\end{array}$ & $\begin{array}{r}6 \\
89 \\
161\end{array}$ & $\begin{array}{r}3,73 \\
52,28 \\
100,00\end{array}$ & $\begin{array}{c}1,01(0,19-5,28) \\
1,00\end{array}$ & 0,989 \\
\hline \multicolumn{7}{|l|}{ Quantas vezes higieniza-dia? } \\
\hline $\begin{array}{l}\text { Higieniza } 2 \text { vezes } \\
\text { Higieniza } 3 \text { vezes } \\
\text { Higieniza mais de } 3 \text { vezes } \\
\text { Higieniza } 1 \text { vez } \\
\text { Freqüência total }\end{array}$ & $\begin{array}{r}20 \\
39 \\
7 \\
2 \\
68\end{array}$ & $\begin{array}{r}29,41 \\
57,35 \\
10,29 \\
2,94 \\
100,00\end{array}$ & $\begin{array}{r}50 \\
77 \\
21 \\
14 \\
162\end{array}$ & $\begin{array}{r}30,86 \\
47,53 \\
12,96 \\
8,64 \\
100,00\end{array}$ & $\begin{array}{c}0,36(0,07-1,71) \\
0,28(0,06-1,30) \\
0,43(0,08-2,37) \\
1,00\end{array}$ & $\begin{array}{l}0,199 \\
0,105 \\
0,332\end{array}$ \\
\hline
\end{tabular}




\subsection{Regressão logística múltipla e backward stepwise para o componente cariado do índice CPO-D}

Para construir o modelo de regressão logística múltipla e, posteriormente, o modelo final dos indicadores de risco para cárie dentária através do processo do backward stepwise, foram selecionadas aquelas com valor de significância $p \leq 10 \%$ na regressão logística univariada. Dessa maneira, as variáveis selecionadas foram: o tempo transcorrido desde a última visita ao cirurgião-dentista e o número de vezes que higienizava os dentes.

A Tabela 5.22 apresenta a regressão logística múltipla das variáveis selecionadas. Há uma tendência daqueles adolescentes que mencionaram que escovavam os dentes três vezes apresentarem 3,49 vezes menos chance de terem lesão de cárie $(p=110)$ quando comparados com aqueles que escovavam uma vez ao dia ou às vezes.

Tabela 5.22 - Regressão logística múltipla das variáveis que foram significante a 10\% para cárie dentária na análise univariada. São Paulo, SP, 2002

\begin{tabular}{|c|c|c|c|c|}
\hline Variável & Coeficiente & $\begin{array}{c}\text { OR } \\
\text { ajustado }\end{array}$ & IC (95\%) & $p$ \\
\hline \multicolumn{5}{|c|}{ Última visita ao cirurgião-dentista } \\
\hline No último ano & Referência & 1,00 & & \\
\hline Mais que um ano & $-0,45$ & 0,64 & $(0,36-1,15)$ & 0,135 \\
\hline Nunca foi & 0,16 & 1,18 & $(0,22-6,22)$ & 0,847 \\
\hline \multicolumn{5}{|c|}{$\begin{array}{l}\text { Quantas vezes higieniza os dentes } \\
\text { por dia }\end{array}$} \\
\hline 1 vez & Referência & 1,00 & & \\
\hline 2 vezes & $-1,01$ & 0,36 & $(0,08-1,76)$ & 0,209 \\
\hline 3 vezes & $-1,25$ & 0,29 & $(0,06-1,33)$ & 0,110 \\
\hline mais de 3 vezes & $-0,85$ & 0,43 & $(0,08-2,39)$ & 0,334 \\
\hline Constante & 2,13 & & & 0,006 \\
\hline
\end{tabular}


Na Tabela 5.23, observa-se o modelo final da regressão por meio do backward stepwise. Nota-se que não há indicador de risco, mas apenas um fator de proteção mostrando que a chance de apresentar lesão de cárie dos adolescentes que foram ao cirurgião-dentista há mais de um ano foi 1,61 vezes menor quando comparado com aqueles que foram há um ano $(\mathrm{OR}=0,62[\mathrm{IC} 95 \%(\mathrm{OR})=0,35-1,09])$.

Tabela 5.23 - Modelo final para os indicadores de risco de cárie dentária, em adolescentes entre 15 e 19 anos de idade obtido por meio do backward stepwise a 10\%. São Paulo, SP, 2002

\begin{tabular}{|c|c|c|c|c|}
\hline Variável & Coeficiente & OR ajustado & IC (95\%) & $p$ \\
\hline \multicolumn{5}{|c|}{ Última visita ao cirurgião-dentista } \\
\hline No último ano & Referência & 1,00 & & \\
\hline Há mais de um ano & $-0,48$ & 0,62 & $(0,35-1,09)$ & 0,098 \\
\hline
\end{tabular}




\section{DISCUSSÃO}




\section{DISCUSSÃO}

Em função do grande número de variáveis estudadas, a discussão também será subdividida, seguindo os moldes dos resultados, com a finalidade de facilitar a apresentação.

\subsection{Epidemiologia}

Os adolescentes que fizeram parte da amostra deste estudo freqüentavam uma escola pública do bairro de Vila Mariana, zona sul de São Paulo, considerado um bairro de classe média.

Foi constatado um índice CPO-D médio de 5,86 para esses adolescentes entre 15 e 19 anos de idade, e foi praticamente igual à prevalência $(5,94)$ encontrada na região Sudeste no último levantamento epidemiológico realizado no Brasil em 2003 nessa mesma faixa etária (BRASIL, 2004). No levantamento epidemiológico em saúde bucal realizado no estado de São Paulo, em 1998, o CPO-D médio aos 12 e 18 anos de idade foi 3,72 e 8,64 respectivamente (SÃO PAULO, 1999). Nesse estudo, não foi realizado exame aos 15 anos de idade.

O CPO-D médio em adolescentes encontrado em diferentes partes do mundo variou muito, desde 0,79 encontrado no estudo longitudinal de Swedberg, Fredén e Norén (1997) em adolescentes aos 19 anos de idade na Suécia, até 14,3 na cidade de Paulínea, em 1980, em adolescentes com 14 anos de idade 
(MOREIRA; PEREIRA; OLIVEIRA, 1996). Essa grande divergência nos valores de CPO-D podem ser atribuídos àdiferença na faixa etária, época realizada e local do estudo. No levantamento epidemiológico mais recente realizado no Brasil, o CPO-D aos 12 anos de idade foi 2,78 e na faixa etária entre 15 e 19 anos foi 6,17 (Brasil, 2004).

Uma comparação direta dos dados epidemiológicos dos estudos realizados em outras partes do mundo e em épocas diferentes com os resultados do presente estudo não pode ser feita, pois em alguns estudos, foram consideradas cárie dentária apenas as lesões que atingiam a dentina (HAWLEY; HOLLOWAY; DAVIES, 1997; KINIRONS; STEWART, 1998); outros contavam com recursos de diagnóstico adicionais como radiografias interproximais (DUMMER et al., 1987; STECKSÉN-BLICKS; GUSTAFSSON, 1986) ou aparelho de fibra ótica para transluminação (HAWLEY; HOLLOWAY; DAVIES, 1997); em alguns países, o sistema de saúde bucal contava com um programa estruturado, com aplicação tópica de flúor e selantes, além de orientações de higiene bucal e dieta (KÄLLESTÅL,1991; LARSSON et al., 1995; LARSSON; JOHANSSON; ERICSON, 1992; STECKSÉN-BLICKS; GUSTAFSSON, 1986); e, em algumas localidades, não havia água de abastecimento fluoretada (CANGUSSU et al., 2002; IRIGOYEN; MAUPOMÉ; MEJÍA, 1999; KINGMAN et al., 1988; LARSSON et al., 1995; MIYASAKI; MORIMOTO, 1996) (Quadros 2.1 e 2.2). Além disso, a faixa etária dos adolescentes que compunham essa amostra foi diferente. Isto influencia muito, pois estudos mostram que há incremento acentuado no CPO-D e CPO-S dos adolescentes entre 12 e 18 anos de idade (Quadros 2.1 e 2.2) (ALEKSEJUNIENE; ARNEBERG; ERIKSEN, 1996; ATTWOOD; BLINKHORN; MACMILLAN, 1990; BRASIL, 2004; CANGUSSU et al., 2002; IRIGOYEN; MAUPOMÉ; MEJÍA, 1999; 
KÄLLESTÅL, 1991; KINGMAN et al., 1988; MIYASAKI; MORIMOTO, 1996; MOREIRA; PEREIRA; OLIVEIRA, 1996; POULSEN, 1996; SÃO PAULO, 1999; SUNDBERG, 1996 ).

Contudo, pôde-se observar que houve diminuição na prevalência de cárie dentária em diversas partes do mundo e no Brasil, nos últimos 30 anos, em crianças e adolescentes (ATTWOOD; BLINKHORN; MACMILLAN, 1990; BOLIN et al., 1997; BÖNECKER; CLEATON-JONES, 2003; ESTIOKO; WRIGHT, 1995; FRAZÃO, 2000; LARSSON et al., 1995; MOREIRA; PEREIRA; OLIVEIRA, 1996; NARVAI; CASTELLANOS; POULSEN, 1996; SUNDBERG, 1996) (Quadros 2.1 e 2.2).

No estudo de Moreira (2003), o CPO-D médio para o grupo aos 15 anos de idade foi 4,49 , praticamente o dobro daquele observado aos 12 anos de idade (2,33). Como o grupo avaliado no presente estudo abrangeu idades entre 15 e 19 anos, podemos comparar apenas com o CPO-D médio para os adolescentes com 15 anos de idade, que foi 5,0, semelhante àquele encontrado por Moreira (2003), em João Pessoa.

\subsection{Variáveis sociodemográficas}

No presente estudo, foram considerados fatores sociodemográficos a idade do adolescente, o sexo, a idade do pai e da mãe, o nível de escolaridade materna e a renda familiar.

Em relação ao sexo do adolescente, o CPO-D médio no sexo feminino foi 5,35 e no masculino, 6,28 . Não foi encontrada diferença significante concordando 
com a maioria dos estudos pesquisados (DUMMER et al., 1987; ESTIOKO; WRIGHT, 1995; JONES et al., 1999; KÄLESTÅL, 1991; LARSSON; JOHANSSON; ERICSON, 1992; MOREIRA; SEVERO; ROSENBLATT, 2002; RAITIO; PIENIHÄKKINEN; SCHEININ, 1996). Bonini et al. (2004) constataram que a prevalência de cárie dentária no grupo de crianças e adolescentes obesos foi maior no sexo feminino, e que no grupo dos não obesos não houve diferença estatisticamente significante em relação ao sexo.

Na maioria dos estudos que avaliaram a prevalência de cárie dentária em relação às diferentes faixas etárias, pôde ser observado que esta aumentava de acordo com a idade (ALEKSEJUNIENE; ARNEBERG; ERIKSEN, 1996; ATTWOOD; BLINKHORN; MACMILLAN, 1990; BRASIL, 2004; CANGUSSU et al., 2002; FRAZÃO, 2000; IRIGOYEN; MAUPOMÉ; MEJÍA, 1999; KÄLLESTÅL, 1991; KINGMAN et al., 1988; MIYASAKI; MORIMOTO, 1996; MOREIRA; PEREIRA; OLIVEIRA, 1996; NARVAI; CASTELLANOS; MOREIRA, 2003; POULSEN, 1996; SÃO PAULO, 1999; SUNDBERG, 1996) (Quadros 2.1 e 2.2). Uma tendência de aumento do CPO-D com a idade também foi observado neste estudo, sendo 5,0 aos 15 anos de idade, 4,8 aos 16 anos, 7,2 aos 17 anos e 5,6 entre 18 e 19 anos de idade (Figura 5.2). Ao dicotomizar a idade em com menos de 17 anos e maior ou igual a 17 anos de idade, observa-se que o CPO-D médio para os adolescentes da faixa etária menor foi 4,89, e naqueles na faixa etária maior foi 6,77 (Tabela 5.6). A idade do adolescente foi indicador de risco de alto índice do CPO-D, sendo que os adolescentes com 17 anos de idade ou mais apresentavam 2,19 vezes mais chances de terem CPO-D alto quando comparados com aqueles com idade inferior a 17 anos $(\mathrm{OR}=2,19$ [IC 95\% $(1,24-3,87)]$. 
Em relação àidade do pai e da mãe, não foi encontrada associação entre o índice CPO-D e estas variáveis ( $p=0,182$ e 0,409 (Tabelas 5.5), semelhante aos resultados encontrado por Bolin et al. (1997), estudando adolescentes com 12 anos de idade da Bélgica, Itália, Grécia, Irlanda, Escócia, Espanha e Suécia. Contudo, esses autores encontraram que o índice CPO-D entre os adolescentes com 12 anos de idade, da Alemanha, era maior quando a idade do pai era igual ou inferior a 42 anos.

Também não foi encontrada significância entre a idade do adolescente, do pai ou da mãe e o componente cariado do índice CPO-D ( $p=0,586)$ (Tabela 5.17).

Os fatores utilizados para classificar os adolescentes em classe social ou nível socioeconômico foram diferentes nos estudos pesquisados, que verificaram a associação desses fatores com a cárie dentária. Alguns compararam adolescentes de zona urbana com aqueles que residiam em zona rural (KÄLLESTÅL, 1991); tipo de trabalho ou ocupação dos pais (DUMMER et al., 1987; HAUSEN; HEINONEN; PAUNIO, 1981; KINIRONS; STEWARD, 1998); valor médio da residência onde moram (DU PLESSIS, 1997); segundo a classificação do governo (TAANI, 1996); se o adolescente freqüenta escola pública ou particular (CANGUSSU, 2002; IRIGOYEN; MAUPOMÉ; MEJÍA, 1999; MOREIRA, 2003; NARVAI; CASTELLANOS; FRAZÃO, 2000; TAANI, 2002); nível educacional dos pais e/ou renda família (MALTZ; SILVA, 2001; MOREIRA, 2003; NICOLAU et al., 2003; PERES; BASTOS; LATORRE, 2000).

Neste estudo, foi avaliada a renda familiar, que não mostrou influência significante com índice CPO-D ou cárie, e a escolaridade materna (ensino fundamental incompleto), que foi fator de risco de alto índice CPO-D $(\mathrm{OR}=3,05$ [ IC 95\% $(1,15-8,07]) \quad$ (Tabelas 5.5 e 5.17$).$ Os adolescentes cujas 
mães tinham nível de escolaridade de fundamental incompleto apresentavam 3,05 vezes mais chances de terem CPO-D alto, quando comparado com adolescentes cujas mães tinham nível de escolaridade mais alto (Tabela 5.16).

A maioria dos trabalhos pesquisados constatou que adolescentes de nível socioeconômico mais baixo apresentavam índice CPO mais alto que aqueles com níveis mais altos em países e locais distintos, tais como aqueles realizados por Hausen, Heinonen e Paunio (1981), na Finlândia, Dummer et al. (1987), na GrãBretanha, Attwood, Blinkhorn e MacMillan (1990), em Glasglow, Inglaterra, Treasure e Dever (1994), na Nova Zelândia, du Plessis (1997), em Port Elizabeth e Despatch, África do Sul, Bolin, Bolin e Koch (1996), em vários países da Europa (Bélgica, Alemanha, Grécia, Irlanda, Itália, Escócia, Espanha e Suécia), Kinirons e Stewart, (1998), em Blefast, Irlanda do Norte, e no Brasil por Peres, Bastos e Latorre (2000), em Florianópolis, Freire, Sheiham e Hardy (2001), em Goiânia, Nicolau et al. (2003), em Cianorte, Paraná, e Moreira (2003) em João Pessoa, Paraíba (Quadros 2.1 e 2.2).

Por outro lado, os estudos realizados por Estioko e Wright (1995), na Austrália, e Taani (1996), na Jordânia, não encontraram diferença significante entre CPO-D e o nível socioeconômico.

Os resultados deste estudo estão de acordo com aqueles encontrados por Nadanovsky e Sheiham (1995) em adolescentes europeus, no qual quanto maior a educação formal da mãe, menor o CPO-D dos adolescentes europeus, e nos estudos realizados no Brasil por Freire, Sheiham e Hardy (2001) em Goiânia e Moreira (2003) com adolescentes de João Pessoa. Curiosamente, esta última autora salientou que o nível escolaridade da mãe foi a única variável das variáveis demográficas e socioeconômicas que mostrou associação significante com a 
presença ou ausência de cárie dentária, sendo que os adolescentes cujas mães tinham nível de escolaridade fundamental incompleto apresentaram 2,44 vezes mais chances de terem cárie dentária que aqueles cujas mães tinham nível de escolaridade superior.

Na cidade de Florianópolis, Peres, Bastos e Latorre (2000) constataram que o alto grau de escolaridade paterna estava associada aos adolescentes com baixo índice CPO-D (igual ou menor que 1), porém o nível de escolaridade materna não apresentou associação. Em contrapartida, em outra cidade brasileira, Cianorte, no Estado do Paraná, Nicolau et al. (2003) não observaram relação entre o nível de educação formal dos pais e a prevalência de cárie dentária.

Naquelas pesquisas que observaram a prevalência de cárie dentária em crianças e adolescentes que freqüentavam escolas públicas ou particulares, a maioria constatou que aqueles das instituições particulares apresentavam menor prevalência de cárie dentária (FREIRE et al., 1999; IRIGOYEN; MAUPOMÉ ; MEJÍA, 1999; MALTZ; SILVA, 2001; MOREIRA, 2003; SÃO PAULO, 1999).

No interior de Goiás, Freire et al. (1999) constataram que apenas 4,4\% dos estudantes com 12 anos de idade não tinham lesões de cárie e que praticamente a metade (47,3\%) apresentava CPO-D entre 4 e 7 , e 20\% CPO-D superior a 8 . Esses resultados foram diferentes daqueles encontrados no presente estudo, onde $29,6 \%$ dos adolescentes não tinham cárie dentária. Apesar dos adolescentes serem de uma escola pública na cidade de São Paulo, eles apresentaram condição bucal melhor que aqueles pesquisados por Freire et al. (1999) em Goiás.

No levantamento epidemiológico realizado no Estado de São Paulo em 1998 verificou-se que os alunos com 12 e 18 anos de idade, de escolas públicas, 
apresentaram CPO-D (3,83 e 8,84) maior que aqueles matriculados em escolas particulares $(1,72$ e 6,15$)$ respectivamente (SÃO PAULO, 1999). No estudo de Irigoyen, Maupomé e Mejía (1999), no México, 28,6\% dos adolescentes das escolas particulares não apresentaram lesões de cárie, contra $9,5 \%$ daqueles de escolas públicas. Observa-se, novamente, que os adolescentes do presente estudo, apesar de freqüentarem uma escola pública no bairro da Vila Mariana, São Paulo, apresentaram condição bucal semelhante à dos adolescentes de escolas particulares do México. Contudo, vale lembrar que, na cidade do México, não havia água de abastecimento fluoretada. No município de João Pessoa, Paraíba, Moreira (2003) observou diferença significante de CPO-D entre os adolescentes que freqüentavam escolas públicas e particulares, tendo uma prevalência de cárie dentária de 51,6\% naqueles da escola pública contra 9,3\% daqueles da escola particular, sendo o CPO-D médio 1,91 e 4,26 respectivamente.

Moreira (2003) observou que, além de haver diferença no CPO-D médio entre os adolescentes de escolas públicas $(4,26)$ e particulares $(1,91)$, houve também diferença na freqüência de escovação dental em relação ao tipo de escola que o adolescente freqüentava. Daqueles que mencionaram que escovavam duas vezes ao dia, a maior prevalência de cárie dentária estava nos adolescentes das escolas públicas $(26,7 \%)$, comparados com da escola particular (13,6\%). O inverso ocorreu naqueles que mencionaram que escovavam os dentes quatro ou mais vezes ao dia, sendo a prevalência de $31,9 \%$ para os adolescentes das escolas particulares, contra $21 \%$ dos públicas, sendo essas diferenças estatisticamente significantes.

No levantamento realizado em 1996, com 2491 estudantes com 12 anos de idade no município de São Paulo, observou-se maior valor para o índice CPO-D aos 
12 anos, nas escolas públicas $(2,23)$, porém não foi encontrada diferença significante entre os adolescentes de escolas públicas e aqueles das escolas particulares. Na cidade de Salvador, não houve diferença estatisticamente significante entre o CPO-D dos adolescentes aos 15 anos de idade, das escolas públicas (CPO-D médio de 2,38), quando comparadas com os de escolas particulares (CPO-D médio de 2,69) (CANGUSSU et al., 2002). O CPO-D médio do grupo estudado no presente estudo foi praticamente o dobro daquele encontrado em Salvador. Na Jordânia, Taani (2002) também não observou diferença entre o CPO-S e o tipo de escola (Quadros 2.1 e 2.2).

Källestå (1991) comparou os índices CPO-D e CPO-S em adolescentes do norte da Suécia de uma cidade urbana e outra rural. Esses índices foram estatisticamente menores naqueles residentes na zona rural quando comparados com os da cidade da região urbana (Quadros 2.1 e 2.2).

O estudo de Nicolau et al. (2003) mostrou que houve associação entre fatores socioeconômicos e biológicos na primeira infância com a prevalência de cárie dentária na adolescência. $O$ fato de a moradia não ser feita com tijolos e a renda familiar ser inferior a 5 salários mínimos, foram considerados fatores de risco de cárie dentária.

Embora vários estudos encontrados na literatura tenham demonstrado a associação entre a renda familiar e o CPO-D, no presente estudo isso não foi constatado (ATTWOOD; BLINKHORN; MACMILLAN, 1990; BALDANI; NARVAI; ANTUNES, 2002; BOLIN; BOLIN; KOCH, 1996; DU PLESSIS, 1997; DUMMER et al., 1987; HAUSEN; HEINONEN; PAUNIO, 1981; KINIRONS; STEWART, 1998; NICOLAU et al., 2003; PERES; BASTOS; LATORRE, 2000; TREASURE; DEVER, 1994) (Quadros 2.1 e 2.2). 
A maioria dos estudos apontou haver diferença de CPO-D em relação ao nível social, ou condição social no qual o adolescente estava inserido. $O$ fato de a mãe ter nível de educação formal mais alto talvez permita melhor e mais conhecimento e conscientização da saúde bucal.

\subsection{Variáveis fisiológicas}

Alguns autores já destacaram a associação entre a cárie dentária e aobesidade (BONINI et al., 2004; LARSSON et al., 1995; TRAEBERT et al., 2004; TUOMI, 1989), pois a cárie dentária e a obesidade têm no hábito alimentar um importante componente etiológico comum, e que ambas podem se instalar precocemente, segundo Tuomi (1989) e Traebert et al. (2004).

Ao observar o CPO-D, segundo o estado nutricional, observa-se que o CPO-D mais alto encontrava-se no grupo daqueles com sobrepeso $(6,95)$, seguidos pelos eutróficos $(5,73)$ e obesos $(5,30)$, sendo que o valor mínimo foi igual em todos os grupos, zero, e o máximo muito semelhante, 18, 20 e 19, respectivamente, para cada grupo nutricional (Tabela 5.9). No modelo final, o fato de ser sobrepeso foi um indicador de risco de CPO-D alto (OR = 2,22 [IC 95\% $(1,04-4,75)$ ] (Tabela 5.16). Ao fazer a dicotomização do CPO-D em $\leq 5$ e > 5, observa-se que 61,54\% daqueles com sobrepeso tinham CPO-D alto, contra 43,24\% dos eutróficos e $46,51 \%$ dos obesos (Tabela 5.8).

A obesidade e a cárie dentária têm no hábito alimentar um importante fator de risco em comum (FREIRE; CANNON; SHEIHAM, 1994; TRAEBERT et al., 
2004). Segundo Traebert et al. (2004), hábitos alimentares relacionados àobesidade podem também determinar uma maior prevalência de cárie dentária, pois a quantidade e a freqüência de ingestão de sacarose são fatores importantes envolvidos na sua etiologia.

Uma vez que o índice CPO-D pode mascar a atividade de cárie dentária, foram analisados os componentes do CPO-D separadamente para cada estado nutricional, encontrou-se que a média de dentes cariados foi maior naqueles com sobrepeso $(3,64)$, quando comparados com os eutróficos $(2,88)$ e obesos $(2,98)$, o mesmo ocorrendo com os dentes restaurados, sendo a média de 3,03 para aqueles com sobrepeso, e 2,73 e 2,35 para os eutróficos e obesos respectivamente. Nestas análises, pôde-se observar que os valores daqueles com sobrepeso é maior que aqueles encontrados para os obesos e eutróficos e que, nestes dois últimos grupos, os resultados são semelhantes. Contudo, ao verificar a associação entre o componente cariado do CPO-D e o estado nutricional, não foi encontrada diferença estatisticamente significante (Tabela 5.18).

Ao avaliar a prevalência de cárie dentária segundo estado nutricional, observa-se que foi semelhante nos três grupos, sendo 70,27\% nos eutróficos, $71,77 \%$ naqueles com sobrepeso e $69,77 \%$ nos obesos. Resultados semelhantes foram encontrados por Moreira, Severo e Rosenblatt (2002) nos eutróficos (72,2\%), porém diferentes nos obesos $(76,5 \%)$ e naqueles com sobrepeso $(78,3 \%)$. Bonini et al. (2004) encontraram prevalência mais alta nos obesos (76,4\%), quando comparada com os não-obesos, 45,3\%. Porém, é importante salientar que no estudo de Bonini et al. (2004) participaram crianças e adolescentes, sendo a faixa etária do estudo entre 2 e 14 anos. 
Os resultados do presente estudo são diferentes daqueles encontrados por Moreira, Severo e Rosenblatt (2002), no qual o CPO-D médio para o grupo foi 4,26 , sendo maior nos obesos $(5,29)$ e nos eutróficos $(4,33)$, quando comparados com aqueles com sobrepeso $(3,70)$, porém elas não encontraram associação significante entre a cárie dentária e o estado nutricional nos adolescentes de João Pessoa. Essas pesquisadoras verificaram também que a média de dentes cariados foi maior nos eutróficos $(2,36)$ e obesos $(2,18)$ e menor naqueles com sobrepeso $(1,74)$; em relação aos dentes restaurados, a média foi maior nos obesos $(2,65)$ e praticamente igual entre os eutróficos $(1,64)$ e com sobrepeso $(1,65)$. O valor mínimo do CPO-D nos grupos foi zero e o máximo foi 9 para os obesos, e 13 e 14 para os eutróficos e com sobrepeso. Os valores descritos nesse estudo não podem ser comparados diretamente com aqueles do presente estudo, pois Moreira, Severo e Rosenblatt (2002) avaliaram adolescentes entre 12 e 15 anos de idade. Verificou no presente estudo, que os adolescentes com sobrepeso apareceram como grupo de risco e no estudo de Moreira, Severo e Rosenblatt (2002) foram os obesos, apesar de essas autoras não terem encontrado diferença significante entre os estados nutricionais e a cárie dentária. No ano seguinte, Moreira (2003) avaliou a prevalência de cárie dentária em adolescentes obesos e eutróficos do município de João Pessoa, e constatou que o CPO-D médio dos obesos $(3,09)$ eram praticamente igual a ao dos eutróficos $(3,08)$. A pesquisadora encontrou uma prevalência de cárie dentária de $30,5 \%$ nos adolescentes, menos da metade daquela encontrada neste estudo. Essa diferença pode ser explicada em parte pela diferença na faixa etária dos estudos, pois é de conhecimento geral que a prevalência de cárie dentária aumenta com a idade. 
No presente estudo, o fato de estar com sobrepeso foi indicador de risco de alto índice de CPO-D. No decorrer do estudo, foi observado que a maioria dos resultados daqueles adolescentes com sobrepeso se comportava de maneira inesperada e com um padrão atípico, diferentemente daqueles obesos ou eutróficos. Uma hipótese que surgiu para explicar essas diferenças entre os obesos e aqueles com sobrepeso em relação ao CPO-D foi uma diferença na alimentação, de maneira que os obesos consumissem mais produtos ricos em gordura, e aqueles com sobrepeso, consumiam mais alimentos contendo sacarose. Dessa maneira, a hipótese inicial era que os obesos poderiam estar, de certa forma, protegidos contra a cárie dentária em virtude do maior consumo de produtos protetores da cárie dentária, quando comparados com os sobrepesos. Porém, analisando os dados dietéticos e os hábitos alimentares, isso não foi comprovado, como será mostrado mais adiante.

Esses resultados são semelhantes em alguns aspectos, e diferentes em outros daquele realizado por Moreira, Severo e Rosenblatt (2002) e Moreira (2003). Nestes dois estudos, não foi encontrada diferença entre o estado nutricional e CPO-D, sendo que no primeiro estudo foram avaliados eutróficos, sobrepesos e obesos e no segundo, apenas eutróficos e obesos.

A associação entre o alto índice de cárie dentária e os fatores de risco para aterosclerose, como alto nível de colesterol total e triglicérides, baixo nível de colesterol HDL, pressão alta e obesidade foi descrito por Larsson et al. (1995). Nesse estudo realizado na Suécia com adolescentes com 15 anos de idade, aqueles com um ou dois fatores de risco para doença cardiovascular tinham CPO-S mais alto que aqueles sem fator de risco, e os autores mencionaram que os adolescentes com o alto índice de cárie dentária coincidiram com aqueles que 
apresentaram fatores de risco para doença cardiovascular. Diante desses resultados, foi testado no presente estudo a associação entre os níveis de colesterol total, HDL colesterol, LDL colesterol e triglicérides e o CPO-D e o componente cariado do índice CPO-D, porém não houve significância (Tabelas 5.8 e 5.18).

Uma das repercussões metabólicas claramente associada à obesidade são os adversos níveis de lipídios (ERNET; OBARZANEK, 1994; ESCRIVÃO et al., 2003; GIDDING et al., 1995; GUTIN et al., 1997). No presente estudo, foi encontrada associação entre o índice CPO-D e o sobrepeso, e não com a obesidade. A associação dessas duas doenças, a cárie dentária e a obesidade, talvez seja difícil de ser estabelecida, pois as duas são multifatoriais e com etiologia e fisiopatologia complexas (AXELSSON, 2000a; ESCRIVÃO et al., 2003; NAVIA, 1996; RIBEIRO, 2001).

\subsection{Dieta e hábitos alimentares}

A adolescência é um período marcado por grandes transformações corporais e rápido crescimento, necessitando, portanto, de aporte adequado de calorias e nutrientes. $\mathrm{O}$ adolescente é facilmente influenciado pelo relacionamento grupal e desconhece o valor nutritivo real dos alimentos, e assim está sujeito a hábitos alimentares impróprios, que podem vir a comprometer sua saúde (VITALLE, 2003). Além disso, os padrões das refeições dos adolescentes são freqüentemente irregulares, omitindo ou substituindo-as (SAITO; ABREU, 1991; SPEAR, 2002). O uso de fast food para refeições ou lanches é especialmente popular entre os 
adolescentes ocupados (SPEAR, 2002), e mais ainda, a alimentação pode ser vista por eles como uma maneira de contestar autoridade, com quebra de padrões, entre os quais o hábito alimentar da família, da necessidade de rever seus próprios comportamentos, o que leva o adolescente a mudanças muitas vezes danosas (SAITO; ABREU, 1991).

Vista a importância de conhecer os hábitos alimentares dos adolescentes, a dieta dos adolescentes foi analisada de duas maneiras distintas: (1) através de entrevista, anotando a freqüência de consumo semanal de diferentes alimentos, tais como balas, doces, refrigerantes, queijo, salgados, salgadinhos de pacote e lanches, por meio de questionário com os adolescentes; e (2) através de um registro alimentar de 3 dias da semana, que foi analisado pelas nutricionistas para quantificar a ingestão de carboidratos, lipídios e calorias totais, segundo o sexo e a idade, e pela pesquisadora do presente estudo, com o objetivo de pesquisar a média de consumo diário de sacarose, refrigerantes normal e diet/light, salgadinhos de pacote e o número de refeições.

Para nenhuma dessas variáveis encontrou-se associação com o CPO-D (Tabela 5.10 e 5.11). Alguns resultados surpreenderam como o fato de quase todos os adolescentes indagados consumirem salgadinhos menos de 4 vezes na semana, assim como a maioria relatar que consumia refrigerante menos de 4 vezes por semana. Segundo Majewski (2001), os adolescentes apresentam hábitos alimentares particulares, com um consumo irregular de refeições principais, consumo freqüente de lanches e alimentos contendo açúcar e diminuição da ingestão de alimentos saudáveis.

Esses resultados foram diferentes daqueles coletados por Priore (1998) em escola públicas e particulares da cidade de São Paulo, e Gama (1999), também 
no bairro da Vila Mariana, São Paulo, com adolescentes, onde mais da metade relatou consumo diário de refrigerantes.

A preocupação específica com esses alimentos não se refere apenas a cárie dentária, mas também à prevenção da obesidade. A população estudada apresentou hábitos de consumo de refrigerante bem diferentes dos americanos, o que é uma boa notícia em virtude dos danos que o consumo excessivo de refrigerantes pode gerar (BIRKHED, 1984; BRIMACOMBE, 2001; ERICKSON; ALEVIZOS; RINDELAUB, 2001; HELLER; BURT; EKLUND, 2001; ISMAIL; BURT; EKLUND, 1984; JONES et al., 1999; MAJEWSKI, 2001), não só pelo conteúdo de sacarose, mas também pelo baixo pH (BIRKHED, 1984; ERICKSON; ALEVIZOS; RINDELAUB, 2001). O consumo em alguns lugares do mundo é tão alto que pode chegar entre 8 e 12 latas por dia, por pessoa (BRIMACOMBE, 2001; ERICKSON; ALEVIZOS; RINDELAUB, 2001). A Organização Mundial da Saúde no relatório sobre Dieta, Nutrição e prevenção de doenças crônicas de 2003, alertou e enfatizou que a prevenção da obesidade em crianças e adolescentes deve ter muita prioridade, sendo que para tal deveria restringir o consumo de alimentos ricos em calorias e pobres em micronutrientes, como os salgadinhos e refrigerantes $(\mathrm{WHO}$, 2003).

Em relação ao componente cariado do índice CPO-D, as variáveis da dieta e dos hábitos alimentares não tiveram associação com a presença ou ausência de lesões de cárie (Tabelas 5.19 e 5.20).

É obvio que o açúcar da dieta é importante no desenvolvimento da cárie dentária, porém ele não é o único fator etiológico responsável por essa doença (NAVIA, 1996). Axelsson (2000a) apresenta a dieta como um fator externo, modificador e não especificamente como fator etiológico. Apesar da complexidade 
da etiologia dessa doença multifatorial, o autor destaca o biofilme dental como fator etiológico.

A doença cárie dentária é multifatorial, que envolve o biofilme dental, a saliva, os minerais e a alimentação como fatores locais, além daqueles dependentes do hospedeiro, tais como genética, comportamento, idade, nível de escolaridade e cuidado com a cavidade bucal (AXELSSON, 2000b; NAVIA, 1996; THYLSTRUP; FERJESKOV, 2001). A interação de todos esses fatores determinará a presença ou não da doença e sua severidade (AXELSSON, 2000a; MOBLEY, 2003; NAVIA, 1996; THYLSTRUP; FERJESKOV, 2001). O próprio estudo clássico de Vipeholm demonstrou isso em meados do século passado, pois $20 \%$ dos pacientes desse estudo não desenvolveram nenhuma lesão cariosa apesar do consumo freqüente de doces entre as refeições por um período prolongado (KRASSE, 1989).

Segundo Axelsson (2000b), o consumo freqüente de carboidratos fermentáveis é, sem dúvida, um fator externo muito importante para o desenvolvimento da cárie dentária em populações que não utilizam dentifrício regularmente e apresentam higiene bucal ruim. Por outro lado, em populações que tem boa higiene bucal e uso diário de dentifrícios contendo flúor, o açúcar torna-se um fator externo muito fraco. Uma idéia similar foi apresentada por van Loveren (2001), o qual propôs um modelo denominado "janela de risco" para explicar e guiar a prevenção da cárie dentária.

O efeito do consumo de açúcar e outros carboidratos fermentáveis na cárie dentária assume características diferentes no final do século XX.

Não se pode negar que a dieta exerce um efeito local, servindo de substrato para os microrganismos do biofilme dental; porém, em virtude de outros fatores externos envolvidos na cárie dentária estarem mais presentes, como o uso 
de flúor seja em dentifrícios ou nas águas de abastecimento, o impacto que a dieta apresentava anteriormente no desenvolvimento da cárie dentária, não se observa em algumas populações. Isso foi demonstrado nos estudos de revisão sistemática da literatura, conduzidos por Burt e Pai (2001) e Anderson e Curzon (2003).

Os estudos com adolescentes que pesquisaram a relação entre o consumo de sacarose ou alimentos contendo açúcar e a prevalência de cárie dentária apresentaram metodologias diversas. Alguns utilizaram registro recordatório das últimas 24 horas, registros alimentares ou anotação da freqüência de consumo de certos alimentos. A maneira de analisar estes dados também foi diferente, sendo que em alguns estudos foi observada a freqüência de consumo diário desses alimentos, enquanto outros verificaram o consumo diário de açúcar em gramas, ou a média do consumo total de açúcar, consumo total de açúcar, consumo diário.

Dentre os estudos que analisaram a freqüência de consumo de alimentos cariogênicos e consumo diário de açúcar e não encontraram associação com CPO-D em adolescentes, encontram-se aqueles realizados por Stecksén-Blicks e Gustafsson (1986) na Suécia, Aleksejuniene, Arneberg e Eriksen, (1996); Larsson, Johansson e Ericson (1992) e Walker et al. ${ }^{6}$ (2000 apud WHO, 2003).

Kleemola-Kujala e Räsänen (1982) encontraram pouca associação entre o consumo total de açúcar e carie dentária e Rugg-Gunn et al. (1984) e Szpunar, Eklund e Burt (1995) observaram o contrário, aqueles que consumiam mais açúcar, em gramas por dia apresentarem maior número de novas lesões de cárie dentária quando comparados com aqueles que consumiam menos quantidade. Por outro lado, Bjarnason, Finngogason e Norén (1989) na Islândia, Beighton, Adamson e Rugg-Gunn (1996), na Inglaterra, e Rocha et al. (1998) e Peres, Bastos e Latorre

\footnotetext{
${ }^{6}$ Walker et al. National diet and nutrition survey: young people aged 4 to 18 years. vol. 2. Report of the oral health survey. London: The Stationary Office, 2000.
} 
(2000) no Brasil, constataram que a alta freqüência de consumo de alimentos cariogênicos estava associada àcárie dentária.

Arnadóttir et al. (1998) constataram que o alto consumo de alimentos cariogênicos entre as refeições foi fator de risco para cárie dentária interproximal nos adolescentes da Islândia. No primeiro estudo nacional de saúde e nutrição (NHNES I), realizado nos Estados Unidos entre 1971 e 1974, foi constatado que o consumo de alimentos contendo sacarose entre as refeições estava associado a altos índices de CPO-D (ISMAIL, 1986). No Brasil, Moreira (2003) observou que, à medida que aumentava o número de lanches cariogênicos entre as refeições principais, havia aumento na média do CPO-D.

Moreira, Severo e Rosenblatt (2002) constataram um fato interessante: os adolescentes que consumiam alimentos cariogênicos até 2 vezes por dia apresentavam prevalência de cárie dentária mais alta $(77,3 \%)$ do que aqueles que consumiam quatro ou mais vezes $(70,7 \%)$, porém a diferença não foi estatisticamente significante. No estudo realizado por Moreira em 2003, o autor constatou um fato semelhante: os adolescentes que consumiam alimentos cariogênicos até duas vezes por dia apresentavam um CPO-D médio $(3,68)$ mais alto do que aqueles que consumiam três $(2,78)$, quatro $(2,89)$, cinco $(3,22)$ ou seis vezes $(3,36)$.

No presente estudo, esse fato também ocorreu, ou seja, à medida que aumentava o número de refeições contendo sacarose, o CPO-D diminuía. A princípio, este fato causou perplexidade e decidiu-se verificar o consumo médio de refeições contendo, sacarose o segundo estado nutricional, e o fato se repetiu nos três grupos avaliados. Decidiu-se, então, fazer um gráfico cruzando o número de vezes que o adolescentes escovava os dentes, com a média de refeições diárias 
que continham sacarose e o estado nutricional. Pode-se observar que conforme aumentava o número de refeições contendo sacarose, aumentava também a freqüência de escovação nos eutróficos e obesos; porém, não foi possível observar um padrão entre os sobrepesos (Gráficos 6.1, 6.2 e 6.3). Vale ressaltar, porém, que associação foi realizada com valor CPO-D $\leq 5$ ou $>5$. Portanto, o consumo mais freqüente de sacarose estava associada a gravidade do CPO-D e não a presença ou ausência da cárie dentária. Esses resultados vão de encontro æ̀s afirmações de Axelsson (2000a), que menciona que a cárie dentária não se desenvolve em dentes limpos, mesmo com consumo freqüente de açúcar e sem a presença de flúor, e com os achados de Kleemola-Kujala e Räsänen (1982) que verificaram que houve aumento na prevalência de cárie dentária nas crianças e nos adolescentes apenas quando a higiene bucal era ineficiente mesmo tendo alto consumo total de açúcar. No presente estudo, não foi verificada a qualidade da higiene bucal dos adolescentes, apenas foi indagado quantas vezes eles escovavam os dentes por dia. Outro fato importante a ser mencionado é que, nesta contagem do número médio de refeições que continham sacarose, foram incluídos tanto os alimentos sólidos como os líquidos, e não foi realizada nenhuma diferenciação desses. Uma das idéias iniciais deste estudo era separar os alimentos contendo sacarose em retentivos e não-retentivos, e dar um escore para cada vez que eles fossem consumidos. Ao realizar esse tipo de análise no projeto-piloto, percebeu-se que muitos alimentos não podiam ser definidos como retentivos nem como nãoretentivos, pois ficavam no meio termo. Os líquidos, a princípio, eram classificados como não-retentivos e os sólidos, como retentivos. À medida que os registros alimentares eram analisados, surgiram dúvidas quanto à classificação de alguns alimentos, como por exemplo sundae de chocolate, gelatina, sorvete de massa com 
cobertura de chocolate, pudim com calda de caramelo, entre outros. Além do mais, não era possível medir o grau de retentividade de todos os alimentos consumidos por esses adolescentes, para aí sim ter um padrão de comparação. Resolveu-se, então, não classificar os alimentos contendo sacarose quanto ao grau de retentividade, e apenas calcular em quantas refeições a sacarose estava presente, seja na forma líquida, pastosa ou sólida.

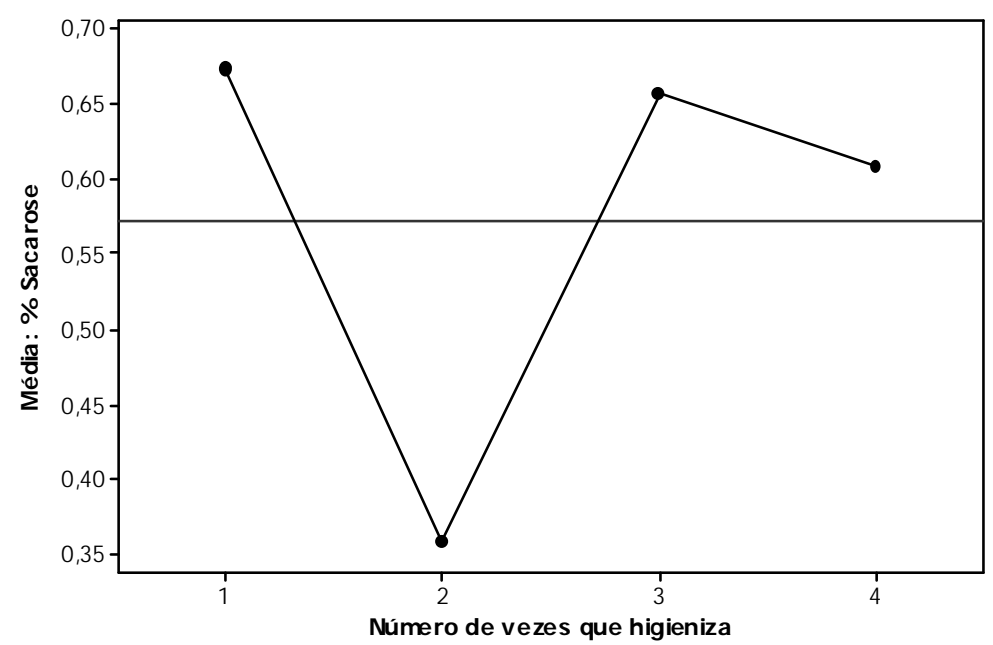

Figura 6.1 - Relação entre o consumo de sacarose e o número de vezes que higienizava os dentes, no grupo dos sobrepeso

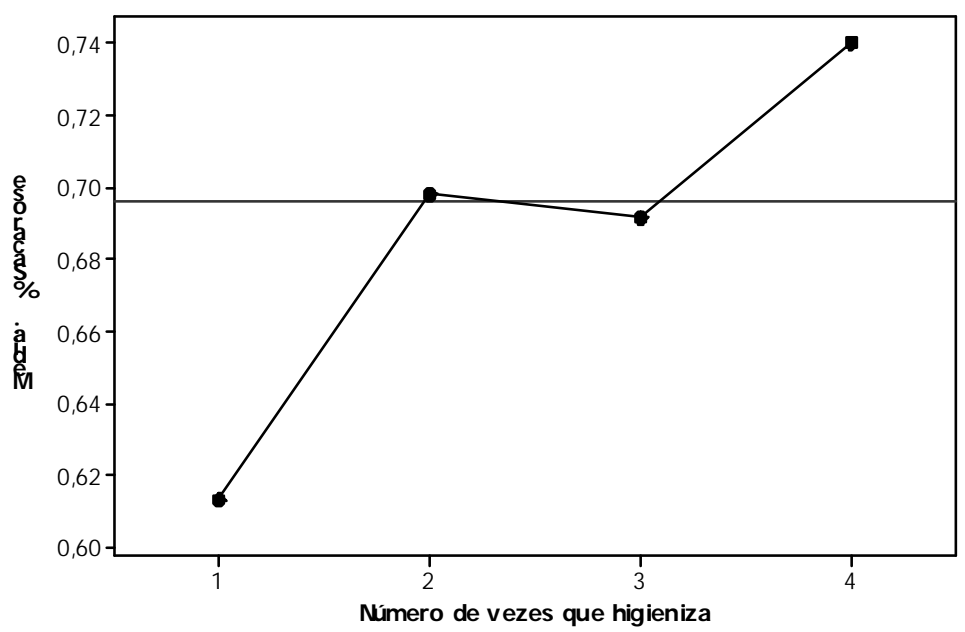

Figura 6.2 - Relação entre o consumo de sacarose e o número de vezes que higienizava os dentes, no grupo dos eutróficos 


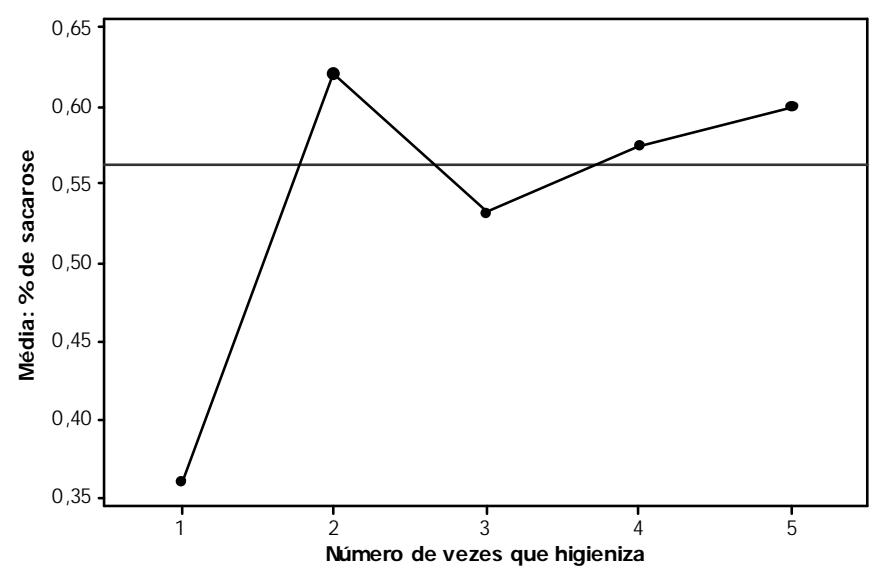

Figura 6.3 - Relação entre o consumo de sacarose e o número de vezes que higienizava, os dentes no grupo dos obeso

Os resultados do presente estudo estão de acordo com a nova tendência, pois a maioria dos adolescentes entrevistados e examinados era residente de São Paulo desde o nascimento e, portanto, se beneficiaram da fluoretação da água de abastecimento. Alem disso, observa-se que a maioria escovava os dentes pelo menos duas vezes ao dia, segundo o relato dos próprios adolescentes.

\subsection{Variáveis comportamentais}

As variáveis comportamentais foram: quantas horas de televisão assistia por dia, a última vez que foi ao cirurgião-dentista e quantas vezes higienizava os dentes por dia.

A maioria (81\%) dos adolescentes relatou assistir menos de 4 horas de televisão diariamente. Não foi encontrada relação entre as horas que o adolescente assistia televisão por dia e o alto ou baixo índice CPO-D (Tabela 5.12). Segundo 
alguns estudos, o fato de assistir televisão por um tempo prolongado está relacionado à obesidade (HERNÁNDEZ et al., 1999; RIBEIRO, 2001; SCHLICKER; BORRA; REGAN, 1994; TADDEI, 1998; WHO, 2003).

Em relação aos cuidados com a cavidade bucal, foi indagado aos adolescentes quantas vezes eles higienizavam os dentes e quando foi a última vez que foram ao cirurgião-dentista. Os resultados da regressão logística univariada mostraram que estas duas variáveis apresentaram associação com o CPO-D (Tabela 5.12) e a análise do backward stepwise mostrou que a higiene bucal duas ou três vezes ao dia é fator de proteção da cárie dentária (Tabela 5.16).

O motivo da higiene bucal é remover o biofilme dental da superfície do esmalte e os alimentos retidos. Ela assume um papel importantíssimo na prevenção da cárie dentária, não só por desorganizar o biofilme dental ou removê-lo, mas também por ser um meio de aplicação tópica de flúor freqüente na cavidade bucal, quando do uso de dentifrícios fluoretados. Atualmente, no comércio, já existem dentifrícios sem flúor nacionais, porém, são bem mais caros que aqueles com flúor, e são encontrados em farmácias de manipulação ou homeopáticas, dificultando à população o acesso a esses produtos. Embora não apresentado, foi questionado aos adolescentes qual a marca do dentifrício que utilizavam regularmente, e todos continham flúor.

O CPO-D médio para aqueles que escovavam os dentes uma vez ao dia foi 10,00 e para aqueles o faziam duas vezes ao dia ou três vezes foi 5,37 e 5,39 respectivamente (Tabela 5.14). Esses resultados vão ao encontro daqueles observados por Moreira (2003), que quanto mais freqüente a escovação dental, menor o CPO-D. Essa autora encontrou diferença estatisticamente significante no CPO-D médio daqueles adolescentes de João Pessoa, que realizavam uma a duas 
escovações dentais por dia $(3,62)$ quando comparados com aqueles que o faziam três a quatro vezes $(2,93)$.

Analisando os componentes do CPO-D separadamente com o número de vezes que o adolescente escovava os dentes, observa-se que a média de dentes cariados diminui ao aumentar a freqüência de escovação de uma para três vezes ao dia. A média de dentes cariados para quem escovava uma vez ao dia foi de 4,6 contra 2.7 daqueles que escovavam três vezes ao dia. A mesma tendência foi encontrada para a média de dentes restaurados, sendo 4,6 para aqueles que realizavam higiene bucal uma vez ao dia, contra 2,6 daqueles que a realizavam três vezes ao dia (Tabela 5.14).

Observou-se que $62,61 \%$ dos adolescentes entrevistados relataram que escovavam os dentes três ou mais vezes ao dia, $30,43 \%$ duas vezes ao dia e $6,52 \%$ apenas uma vez (Apêndice J.3). Esses valores estão um pouco abaixo daqueles encontrados por Moreira (2003), que observou que $71,4 \%$ dos adolescentes responderam escovar três ou quatro vezes ao dia.

No estudo longitudinal realizado por Stecksén-Blicks e Gustafsson (1986), foi constatado que aqueles que tiveram menor aumento no número de lesões de cárie dentária no período de 2 anos apresentaram freqüência de escovação mais alta e menores escores de sangramento gengival que aqueles com maior número de novas lesões de cárie. Assim, este estudo demonstrou a importância de uma boa higiene bucal e, principalmente, do uso freqüente de dentifrícios fluoretados como fatores modificadores da progressão da cárie dentária.

$\mathrm{Na}$ cidade de Istambul, Kulak-Ozkan et al. (2001) observaram que entre os adolescentes com 15 a 18 anos de idade, entrevistados, 48\% mencionaram que escovavam os dentes menos de uma vez ao dia e $74 \%$ que nunca utilizaram o fio 
dental. Os autores concluíram que havia necessidade de envolver a comunidade, a família, escola e o governo para implementar e desenvolver programas de promoção de saúde, em virtude da condição bucal encontrada nesses adolescentes.

Segundo Axelsson (2000a), a cárie dentária não se desenvolve em dentes limpos, mesmo com consumo freqüente de açúcar e sem a presença de flúor; ou seja, em dentes limpos a cárie dentária não se desenvolve. Isso foi confirmado no estudo de Kleemola-Kujala e Räsänen (1982), realizado na Finlândia, onde observaram que houve aumento na prevalência de cárie dentária nas crianças e nos adolescentes, apenas quando a higiene bucal era ineficiente, mesmo tendo alto consumo total de açúcar. Da mesma maneira, os resultados desta pesquisa mostraram que quando a higiene bucal é ruim, mesmo o indivíduo tendo baixo consumo total de sacarose, poderá haver o surgimento da cárie dentária. Isto porque além da sacarose, há outros carboidratos da dieta, que junto com o acúmulo do biofilme, são responsáveis pela formação da cárie dentária. Em outras palavras, independentemente do consumo de sacarose, se há uma boa higiene bucal, a cárie dentária não irá se desenvolver. O estudo de Beighton, Adamson e Rugg-Gunn (1996) também encontraram resultados similares, descrendo que nos adolescentes que tinham uma higiene bucal ruim, independentemente da freqüência ou consumo total de açúcar, haveria uma influência nos níveis salivares de $S$. mutans e lactobacilos, levando a um risco mais alto de cárie dentária.

A importância da higiene bucal também foi ressaltada no estudo realizado por Brathall, Hansel-Petersson e Sundberg (1996), com 30 especialistas mundiais da cariologia para verificar como esses profissionais graduaram o impacto de vários fatores na prevalência da cárie dentária. Foi constatado nesse estudo que apenas o uso do dentifrício fluoretado foi apontado pela maioria e associado ao seu efeito 
preventivo, sendo que $65 \%$ assinalaram como muito importante e $33 \%$, como importante. Em relação à higiene bucal e redução do biofilme dental, 29\% e 10\% descreveram como sendo importante ou muito importante, respectivamente, contra $35 \%$ que mencionaram ser pouco importante.

Silva, Paixão e Pordeus (1997) constataram que 45,2\% dos adolescentes entrevistados mencionaram que escovavam os dentes para evitar a cárie dentária, sendo que $86 \%$ realizavam apenas a escovação dental. O incentivo da escovação de $29,9 \%$ dos adolescentes era o fato de sair para passear e/ou se divertir e para $21,4 \%$ após o consumo de doces ou alimentos pegajosos.

Segundo Nicolau et al. (2003), é possível que crianças e adolescentes que nascerem em condições socioeconômicas desfavoráveis (adversas) e com poucos recursos biológicos apresentem poucas chances de ter uma dieta alimentar saudável e assistência odontológica, assim como também diminui as chances deles adotarem uma higiene bucal com escovação freqüente com dentifrícios fluoretados.

Apesar de vários autores afirmarem a importância da higiene bucal para a prevenção da cárie dentária, alguns estudos não encontraram associação entre o CPO-D e a quantidade do biofilme ou o número de vezes que higienizava os dentes (NICOLAU et al., 2003) e Aleksejunieni, Arnebertg Ericksen (1996) encontraram uma fraca associação entre o nível de higiene bucal e a cárie dentária.

No estudo conduzido por Taani (2002), na Jordânia, foi constatado condição gengival ruim e higiene bucal ineficiente naqueles do grupo socioeconômico menos favorecido, porém a diferença não foi significante. Portanto, o autor alerta para o fato de que educação em saúde é recomendável, tanto para aqueles de nível socioeconômico mais baixo como nos de níveis mais altos. Dummer et al. (1987) encontraram resultados similares, pois aqueles adolescentes 
de nível socioeconômico menos favorecido apresentavam índices de biofilme dental mais alto e menos freqüência de escovação, quando comparados com aqueles de nível socioeconômico mais alto.

Ao analisar o tempo transcorrido desde a última visita ao cirurgiãodentista, destaca-se o fato de que o CPO-D médio diminuiu com o aumento do tempo transcorrido desde a última visita, sendo 6,27 naqueles que foram durante 0 último ano e 5,43 naqueles que foram há mais de um ano (Tabela 5.13). Esses resultados vão ao encontro daqueles encontrados por Moreira (2003), que observou CPO-D médio de 2,58 para aqueles que foram ao cirurgião-dentista pela última vez há mais de 5 anos, ou nunca foram, e de 3,20 para aqueles que foram há menos de 6 meses. Em relação ao componente cariados do CPO-D, constatou-se que aqueles que relataram terem ido ao cirurgião-dentista há mais de um ano, apresentaram menor chance de ter lesão de cárie quando comparados com aqueles que foram no último ano, sendo esta diferença estatisticamente significante (Tabela 5.23). Este resultado, possivelmente demonstre que aqueles que procuraram o cirurgiãodentista mais freqüentemente, o fizeram por já apresentar algum problema. Moreira (2003) encontrou resultados distintos, onde a prevalência de cárie dentária tendeu a aumentar quanto mais tempo os adolescentes levaram para procurar o atendimento, sendo que aqueles que visitaram o cirurgião-dentista num período inferior a 6 meses apresentaram prevalência de cárie dentária de $27,6 \%$, comparados a $39,4 \%$ daqueles que haviam ido há mais de 5 anos ou nunca tinham ido. Resultados similares foram encontrado por Kinirons e Stewart (1998), que verificaram que a média de dentes cariados foi maior entre os adolescentes que tinham ido a uma consulta odontológica há mais de 12 meses $(3,16)$ quando comparados com aqueles que tinham ido há menos de 6 meses $(1,10)$. Esses resultados parecem lógicos, pois 
indo regularmente ao cirurgião-dentista e as lesões de cárie dentária sendo diagnosticadas, acredita-se que também sejam restauradas. Esses autores também encontraram no grupo estudado que muitos não realizam retornos periódicos ao consultório odontológico e só procuram atendimento quando apresentam dor. Entretanto, Moreira, Severo e Rosenblatt (2002) verificaram que a prevalência de cárie dentária foi maior nos adolescentes que relataram ir periodicamente ao cirurgião-dentista, porém não houve diferença significante entre esses e aqueles que não tinham este costume (73,6\% versus $65,7 \%)$. Em Salvador, Cangussu et al. (2002) observaram que a visita ao cirurgião-dentista no último ano foi realizada por $51,5 \%$ dos adolescentes com 12 anos de idade e 47,4\% por aqueles com 15 anos de idade, e estava associado positivamente ano nível socioeconômico. Segundo esses autores, esse fato ocorreu porque aqueles com melhor nível socioeconômico no Brasil têm mais regularidade no acesso a bens de consumo e serviços de saúde.

Peres, Bastos e Latorre (2000) verificaram que, no grupo de escolares que tinham baixa severidade de cárie dentária (CPO-D igual a zero ou um), o motivo da ida ao cirurgião-dentista mais freqüente foi para controle; em contrapartida, no grupo com alto índice CPO-D (CPO-D maior que 5 ou igual), o mais freqüente foi tratamento.

Hawley, Holloway e Davies (1997) observaram que os adolescentes que procuravam atendimento odontológico sem apresentar nenhuma sintomatologia tinham menos dentes extraídos e maior número de selantes de fóssulas e fissuras que aqueles que iam ao cirurgião-dentista quando apresentavam alguma sintomatologia. 


\subsection{Considerações finais}

Frente àgrande preocupação existente atualmente no mundo todo com o crescente número de crianças e adolescentes obesos e com sobrepeso, o objetivo inicial deste estudo era apresentar todas as variáveis aqui analisadas, segundo o estado nutricional e CPO-D e CPO-S. Contudo, ao dividir as variáveis por estado nutricional, foi observado que em muitas a distribuição não permitia uma análise estatística adequada, pois havia resposta com valores inferiores a 5.

Além dos objetivos já descritos na proposição, queríamos mostrar a importância da interação e trabalho conjunto com outras especialidades da área da saúde como a nutrição e a pediatria. Através dos trabalhos descritos, observou-se a interação de alguns fatores comuns à cárie dentária e a obesidade, como a alimentação, estilo de vida e níveis sangüíneos de colesterol total e traços e triglicérides. Apesar de não ter sido encontrado associação destes fatores com a cárie dentária no presente estudo, é importante ressaltar a necessidade de observar o indivíduo como um todo ao realizarmos um diagnóstico.

Observou-se também que inúmeros autores destacaram a importância da escovação dental, salientando o uso freqüente de dentifrícios fluoretados, como meio efetivo na prevenção de cárie dentária. No presente estudo, o modelo de regressão logística múltipla indicou que a higiene bucal apresentou-se como fator de proteção de o alto índice CPO-D e de presença ou não de cárie dentária. Aqueles que mencionaram que higienizavam seus dentes três vezes ao dia, apresentaram 3,45 menos chances de terem lesão de cárie quando comparados com aqueles que higienizavam somente uma vez ao dia. Segundo o modelo de regressão logística 
múltipla, a variável higiene bucal foi mais significante que o da última consulta odontológica, salientando mais uma vez o papel de destaque da higiene bucal na prevenção da doença cárie.

Geralmente, a mãe é citada como principal responsável pelo ensinamento da escovação dental aos seus filhos, destacando a importância da família no estabelecimento de práticas de higiene. Acreditamos que isso se estenda também para a nossa população, pois ainda é de costume da maioria das famílias, que a mãe se ocupe com o cuidado das crianças; e conforme apresentado em outros estudos, há uma interação forte entre o nível de escolaridade da mãe e a higiene bucal nas crianças e nos adolescentes.

Em relação a última consulta odontológica, verificou-se que os adolescentes que foram há mais de um ano, tinham 1,61 menos chances de terem cárie dentária quando comparados com aqueles que tinham ido no último ano. Este resultado, a princípio, parece contraditório e confuso; mas, ele pode indicar um fato comumente observado na nossa população, a procura do cirurgião-dentista apenas quando há alguma alteração ou dor e desconforto na cavidade bucal.

Embora fosse esperado maior influência das variáveis dietéticas e dos hábitos alimentares sobre o alto índice CPO-D e presença de cárie dentária, isto provavelmente não ocorreu devido a semelhança dos costumes alimentares observado no grupo estudado. 


\section{CONCLUSÕES}




\section{CONCLUSÕES}

Com base no exposto é lícito afirmar que:

a prevalência de cárie dentária nos adolescentes entre 15 e 19 anos de idade foi $70,43 \%$

o índice CPO-D médio foi 5,86

os indicadores de risco de alto índice CPO-D entre os adolescentes foram:

- $\quad$ o fato de ter mãe com nível de escolaridade de fundamental incompleto

- o fato de ser sobrepeso

- $\quad$ ter 17 anos de idade ou mais

$>$ os adolescentes que escovavam os dentes duas ou três vezes ao dia, apresentaram menor chance de ter um alto índice CPO-D quando comparado com aqueles que higienizam uma vez ou menos ao dia

os adolescentes que foram ao cirurgião-denstista há mais de um ano apresentaram menor chance de terem lesão de cárie quando comparados com aqueles que foram no último ano 
REFERÊNCIAS 


\section{REFERÊNCIAS 1}

Aleksejuniene J, Arneberg P, Eriksen HM. Caries prevalence and oral hygiene in Lithuanian children and adolescents. Acta Odontol Scand 1996;54(1):75-80.

American Academy of Pediatric Dentistry. Guideliness for the dental health of the adolescent. Pediatric Dent 2000;21(5):47-9.

American Heart Association. Cholesterol and atherosclerosis in children. Disponível em URL: http://www.americanheart.org/presenter.jhtml?=4499 [2004 out. 19].

Anderson CA, Curzon MEJ. Dietary sugars and caries: a systematic literature review [abstract 45]. Caries Res 2003;37(3):282.

Arnadóttir IB, Rozier RG, Sæmundsson SR, Sigurjóns H, Holbrook WP. Approximal caries and sugar consumption in Iceland teenagers. Community Dent Oral Epidemiol 1998;26(6):115-21.

Artega HP, Santos JE, Oliveira JED. Obesity among schoolchildren of different socioeconomic levels in a developing country. Int J Obese 1982;6:291-7.

Attwood D, Blinkhorn AS, MacMillan AS. A three year follow up study of the dental health of 12-and 15-year-old schoolchildren in Glasgow. Community Dent Health $1990 ; 7(2): 143-8$.

Axelsson P. Etiologic factors involved in dental caries. In: Diagnosis and risk prediction of dental caries, vol.2. Coral Streams: Quintessence; 2000a. cap.1. p.1-42.

\footnotetext{
${ }^{1}$ De acordo com Estilo Vancouver. Abreviatura de periódicos segundo base de dados MEDLINE.
} 
Axelsson P. External modifying factors involved in dental caries. In: Diagnosis and risk prediction of dental caries, vol.2. Coral Streams: Quintessence; 2000b. cap.2. p.43-90.

Baldani MH, Narvai PC, Antunes JLF. Cárie dentária e condições sócioeconômicas no Estado do Paraná, Brasil, 1996. Cad Saúde Pública 2002;18(3):755-63.

Beighton D, Adamson A, Rugg-Gunn A. Associations between dietary intake, dental caries experience and salivary bacterial levels in 12-year-old English schoolchildren. Arch Oral Biol 1996;41(3):271-80.

Bezerra BC, Toledo AO. Nutrição, dieta e cárie. In: Kringer L., coordenador. ABOPREV. Promoção de saúde bucal. São Paulo:Artes Médicas;1997. p. 43-67.

Birkhed D. Sugar content, acidity and effect on plaque $\mathrm{pH}$ of fruit juices, fruit drinks, carbonated beverages and sport drinks. Caries Res 1984;18(2):120-7.

Bjarnason S, Finnbogason SY, Norén JG. Sugar consumption and caries experience in 12-and 13-year-old Iceland children. Acta Odontol Scand 1989;47(5):315-21.

Bjarnason S, Köhler B. Caries risk assessment in adolescents. Swed Dent J 1997;21(1 e 2):41-8.

Bjarnason S. High caries levels: problems still to be tackled. Acta Odontol Scand 1998;56(3):176-8.

Bolin A-K, Bolin A, Jansson L, Calltorp J. Children's dental health in Europe sociodemographic factors associated with dental caries in groups of 5-and 12-yearold children from eight Eu-countries. Swed Dent J 1997;21(1):25-40.

Bolin A-K, Bolin A, Koch G. Children's dental health in Europe: caries experience of 5-and 12-year-old children from eight Eu countries. Inter $\mathrm{J}$ Paediatric Dent 1996;6(3):155-62. 
Bönecker M, Cleaton-Jones P. Trends in dental caries in Latin American and Caribbean 5-6 and 11-13-year-old children: a systematic review. Community Dent Oral Epidemiol 2003;31(2):152-7.

Bonini GAV, Imparato JCP, Valentim C, Raggio DP, Bussadori SK. Prevalência de cárie em crianças obesas e não-obesas. [resumo Pa 173].Braz Oral Res 2004;18(Suppl):132

Brasil. Plano Nacional para a promoção da alimentação adequada e do peso saudável. Brasília:Ministério da Saúde, 1999.

Brasil. Ministério da Saúde. Secretaria de Atenção a Saúde. Departamento de Atenção básica. Projeto SB Brasil 2003:condições de saúde bucal da população brasileira 2002-2003:resultados principais. Brasília: Ministério da Saúde; 2004. 68p. Disponível em URL:

http://dtr2001.saude.gov.br/sps/areastenicas/bucal/RELATORIO_SB_BRASIL.pdf. [2004 maio 22].

Bratthall D, Hänsel-Petersson G, Sundberg $H$. Reasons for the caries decline: what do the experts believe? Eur J Oral Sci 1996;104(4 pt2):416-22.

Brimacombe C. The effect of extensive consumption of soda pop on the permanent dentition: a case report. Northwest Dent 2001;80(3):23-5.

Burt BA, Pai S. Sugar consumption and caries risk: a systematic review. J Dent Edu $2001 ; 65(10): 1017-23$.

Campain AC, Morgan MV, Evans RW, Ugoni A, Adams GG, Conn JA, et al. Sugarstarch combinations in food and the relationship to dental caries in low-risk adolescents. Eur J Oral Sci 2003;111(4):316-25.

Cangussu MCT, Castellanos RA, Pinheiro MF, Albuquerque SR, Pinho C. Cárie dentária em escolares de 12 e 15 anos de escolas públicas e privadas de Salvador, Bahia, Brasil, em 2001. Pesqui Odontol Bras 2002;16(4):379-84. 
Ctenas MLB. Obesidade - um grave problema. Crescendo com Saúde - o guia de crescimento da criança. São Paulo: C2 Editora e Consultoria em Nutrição;1999. cap. 7, p. 175-99.

Duggal MS, van Loveren C. Dental considerations for dietary counselling. Int Dent J $2001 ; 51$ (Suppl 6):408-12.

Dummer PMH, Addy M, Hicks R, Kingdon A. The effect of social class on the prevalence of caries, plaque, gingivitis and pocketing in 11-12-year-old children in South Wales. J Dent 1987;15(5):185-90.

du Plessis JB. The effect of socio-economic status on dental caries experience in 6,12 and 15 year-old children in Port Elizabeth and Despatch. J Dent Ass South Afr $1997 ; 52(7): 483-6$.

Edgar WM. Prediction of the cariogenicity of various foods. Int Dent $\mathrm{J}$ 1985;35(1):190-4.

Edmondson EMS. Food composition and food cariogenicity factors affecting the cariogenic potencial of foods. Caries Res 1990;24(Suppl 1):60-71.

Erickson PR, Alevizos DL, Rindelaub DJ. Soft Drinks: hard on teeth?. Northwest Dent 2001;80(2)15-9.

Ernst ND, Obarzanek E. Child health and nutrition: obesity and high blood cholesterol. Prev Med 1994;23(4):427-36.

Escrivão MAMS, Lopez FA. Repercussões. In: Nobrega FJ. Distúrbios da nutrição. São Paulo: Revinter; 1998. cap. 65, p.392-3.

Escrivão MAMS, Oliveira FLC, Taddei JAAC, Lopez FA. Obesidade na infância e adolescência. In: Lopez FA, Brasil ALD. Nutrição e dietética em clínica pediátrica. São Paulo: Atheneu;2003. cap. 8, p.188-99. 
Estioko LJ, Wright FAC. The oral health of children and adolescents in Heidelberg, Victoria, 1991. Aust Dent J 1995;40(3):193-6.

Fisberg M, Amâncio OMS, Lottenberg AMP. O uso de refrigerantes e a saúde humana. Pediatria Mod 2002;38(6):261-71.

Freedman DS, Dietz WH, Srinivasan SR, Berenson GS. The relation of overweight to cardiovascular risk factors among children and adolescents: The Bogalusa Heart Study. Pediatrics 1999;130:1175-82.

Freire MCM, Cannon G, Sheiham A. Análise das recomendações internacionais sobre o consumo de açúcares publicadas entre 1961 e 1991. Rev Saúde Pública 1994;28(3):228-37.

Freire MCM, Pereira MF, Batista SMO, Borges MRS, Barbosa MI, Rosa AGF. Prevalência de cárie e necessidade de tratamento em escolares de 6 a 12 anos da rede pública de ensino. Rev Saúde Pública 1999;33(4):385-90.

Freire MCM, Sheiham A, Hardy R. Adolescents' sense of coherence, oral health status, and oral health-related behaviours. Community Dent Oral Epidemiol $2001 ; 29(3): 204-12$.

Gama CM. Consumo alimentar e estado nutricional de adolescentes matriculados em escolas da rede particular e estadual do bairro de Vila Mariana, São Paulo [Tese de Doutorado]. São Paulo: Escola Paulista de Medicina da UNIFESP; 1999.

Gibbons R. The caries decline: a comment. Eur J Oral Sci 1996;104(4Pt2):444-51.

Gidding SS, Bao W, Srinivasan SR, Berenson GS. Effects of secular trends in obesity on coronary risk factors in children: The Bogalusa Heart Study. J Pediatrics 1995;127(6):868-74. 
Gustafsson B, Quensel C, Lanke LS, Lundqvist C, Grahnen H, Bonow B, et al. The Vipeholm dental caries study; the effect of different levels of carbohydrate intake on caries activity in 436 individuals observed for five years. Acta Odontol Scand 1954;11(3-4):232-64.

Gutin B, Owens S, Treiber F, Islam S, Karp W, Slavens G. Weight-independent cardiovascular fitness and coronary risk factors. Arch Pediatr Adolesc Med 1997; $151(5): 462-5$.

Harris R. Biology of the children of Hopewood House, Bowral, Australia, 4 (1957-61). Observations on dental caries experience extending over 5 years. J Dent Res 1963; 42:1387-99.

Hausen $\mathrm{H}$, Heinonen OP, Paunio I. Caries in permanent dentition and social class of children participating in public dental care in fluoridated and nonfluoridated areas. Community Dent Oral Epidemiol 1981;9(6):289-91.

Hausen H. Caries prediction- state of the art. Community Dent Oral Epidemiol 1997;25(1):87-96.

Hawley GM, Holloway PJ, Davies RM. Dental health status associated with documented dental attendance patterns in adolescents. Community Dental Health $1997 ; 14(1): 22-4$.

Helfenstein U, Steiner M, Marthaler TM. Caries prediction on the basis of past caries including precavity lesions. Caries Res 1991;25(5):372-6.

Heller KE, Burt BA, Eklund SA. Sugared soda consumption and dental caries in the United States. J Dent Res 2001;80(10):1949-53.

Helöe LA, Haugejorden O. "The rise and fall" of dental caries: some global aspects of dental caries epidemiology. Community Dent Oral Epidemiol 1981;9(6):294-9. 
Hernandéz B, Gortmaker SL, Colditz GA, Peterson KE, Laird NM, Parra-Cabrera S. Association of obesity with physical acitivity, television programs and other forms of video viewing among children in Mexico City. Int J Obesity Relat Metab Disord 1999;23(8):845-54.

Herod EL. The effects of cheese on dental caries: a review of the literature. Aust Dent J 1991;36(2):120-5.

Hunter PB. Risk factors in dental caries. Int Dent J 1988;38(4):211-7.

Irigoyen ME, Maupomé G, Mejía AM. Caries experience and treatment needs in a 6to12-year-old urban population in relation to socio-economic status. Community Dent Health 1999;16(4):245-9.

Ismail AI, Burt BA, Eklund SA. The cariogenicity of soft drinks in the United States. J Am Dent Ass 1984;109(2):241-5.

Ismail Al. Food cariogenicity in Americans Aged from 9 to 29 years assessed in a National Cross-section survey, 1971-1974. J Dent Res 1986;65(12):1435-40.

Jebb SA, Lambert J. Overweight and obesity in European children and adolescents. Eur J Pediatr 2000;159:(Suppl 1):S2-S4.

Jensen ME. Diet and dental caries. Dent Clin North Am 1999;43(4):615-33.

Johansson I, Birkhed D. A dieta e o processo cariogênico. In: Thylstrup A, Ferjeskov O. Cariologia clinica. São Paulo: Santos; 2001. cap. 19. p.283-310.

Jones C, Woods K, Whittle G, Worthington H, Taylor, G. Sugar, drinks, deprivation and dental caries in 14-year-old children in the north west of England in 1995. Community Dent Health 1999;16(2):68-71.

Källestäl C. Dental caries in 16- and 18-year-old adolescents in northern Sweden. Scand J Dent Res 1991;99(1):100-5. 
Katz S. A diet counseling program. J Am Dent Ass 1981;102(6):840-5.

Kavey RE, Daniels SR, Lauer RM, Atkins DL, Hayman LL, Taubert K. American Heart Association. American Heart Association guidelines for primary prevention of atherosclerotic cardiovascular disease beginning in childhood.

Circulation 2003;107(11):1562-6.

Kingman A, Little W, Gomez I, Heifetz SB, Driscoll WS, Sheats R, et al. Salivary levels of Streptococcus mutans and lactobacilli and dental caries experience in a US adolescent population. Community Dent Oral Epidemiol 1988;16(2):98-103.

Kinirons MJ, Stewart C. Factors affecting levels of untreated caries in a sample of 1415-year-old adolescents in Northern Ireland. Community Dent Oral Epidemiol 1998;26(1):7-11.

Kleemola-Kujala E, Räsänen L. Relationship of oral hygiene and sugar consumption to risk of caries in children. Community Dent Oral Epidemiol 1982;10(5):224-33.

Koch G, Modeer T, Pousen S, Ramussen P. Cáries dentárias: prevenção.

Odontopediatria: uma abordagem clínica. 2 ed. São Paulo: Santos, 1995. p.117-42

Kramer PF. Tratamento não invasivo. In Promoção de saúde bucal em Odontopediatria. São Paulo: Artes Médicas; 1997. cap. 6, p.89-128.

Krasse B. Why was the Vipeholm study done and why have this symposium? Scand J Dent Res 1989;97(2):99-102.

Kulak-Özkan Y, Ozkan Y, Kazazoglu E, Arikan A. Dental caries prevalence, toothbrushing and periodontal status in 150 young people in Istanbul: a pilot study. Int Dent J 2001;51(6):451-6.

Kuusela S, Honkala E, Rimpelä A. How does the use of different sugar products predict caries in 18-year-old Finns? J Dent Child 1997;64(2):123-7. 
Kuusela S, Kannas L, Tynjälä J, Honkala E, Tudor-Smith C. Frequent use of sugar products by schoolchildren in 20 European countries, Israel and Canada in 1993/1994. Int Dent J 1999; 49(2):105-14.

Larsson B, Johansson I, Hallmans G, Ericsson T. Relationship between dental caries and risk factors for atherosclerosis in Swedish adolescents: Community Dent Oral Epidemiol 1995;23(4):205-10.

Larsson B, Johansson I, Erickson T. Prevalence of caries in adolescents in relation to diet. Community Dent Oral Epidemiol 1992;20(3):133-7

Leber M, Corrêa MSNP. Dieta. In: Corrêa MSNP. Odontopediatria na primeira infância. São Paulo: Santos; 1998. p. 279-89.

Livingstone B. Epidemiology of childhood obesity in Europe. Eur J Pediatr 2000;159(Suppl 1):s14-s34.

Maffeis C. Aetiology of overweight and obesity in children and adolescents. Eur $\mathrm{J}$ Pediatr 2000;159:(Suppl 1):S35-S44.

Majewski RF. Dental caries in adolescents associated with caffeinated carbonated beverages. Pediatr Dent 2001;23(3):198-203.

Maltz M, Silva BB. Relação entre cárie, gengivite e fluorose e nível socioeconômico em escolares. Rev Saúde Publica 2001;35(2):170-6.

Mateos A. Brasileiros comem cada vez mais e com pior qualidade(entrevista). Rev Ass Paul Cir Dent 1999;53(1):8-20.

Miyazaki H, Morimoto M. Changes in caries prevalence in Japan. Eur J Oral Sci 1996(4);104:452-8.

Mobley CC. Nutrition and dental caries. Dent Clin North Am 2003;47(2):319-36. 
Moreira B-H W, Pereira AC, Oliveira SP. Avaliação da prevalência de cárie dentária em escolares de localidade urbana da região Sudeste do Brasil. Rev Saúde Pública 1996;30(3):280-4.

Moreira PVL. Estudo comparativo da prevalência de cárie em adolescentes eutróficos e obesos de 12 a 15 anos de idade em escolas públicas e privadas na cidade de João Pessoa - PB [Tese Doutorado]. Caramajibe: Faculdade de Odontologia da UP; 2003.

Moreira PVL, Severo AMR, Rosenblatt A. Cárie dentária e estado nutricional em adolescentes de João Pessoa - Paraíba - Brasil. Rev Bras Ciênc da Saúde 2002;6(2):123-34.

Must A. Morbidity and mortality associated with elevated body weight in children and adolescents. American J Clin Nutrition 1996;63:445-7.

Must A, Dallal GE, Dietz WH. Reference data for obesity: $85^{\text {th }}$ and $95^{\text {th }}$ percentiles of body mass index $\left(w t / h^{2}\right)$ and triceps skinfold thickness. Am $J$ Clin Nutri 1991;53(4):839-46.

Nadanovsky P, Sheiham A. Relative contribution of dental services to the changes in caries levels of 12-year-old children in industrialized countries in the 1970s and early 1980s. Community Dent Oral Epidemiol 1995;23(6):331-9.

Narvai PC, Castellanos RA, Frazão P. Prevalência de cárie em dentes permanentes de escolares do Município de São Paulo, SP, 1970-1996. Rev Saude Pública 2000;34(2):196-200.

National Research Council, Subcommittee on the 10th ed of the RDAs, Food and Nutrition Board - Commission on Life Sciences. Recommended Dietary Allowances 10 ed. Washington, DC: National Academy Press; 1989.

Navia JM. Nutrition and dental caries: ten findings to be remembered. Int Dent $\mathrm{J}$ 1996;46(Suppl 1):381-7. 
Newbrun E. Frequent sugar intake - then and now: interpretation of the main results. Scand J Dent Res 1989;97(2):103-9.

Nicolau B, Marcenes W, Bartley M, Sheiham A. A life course approach to assessing causes of dental caries experience: the relationship between biological, behavioural, socio-economic and psychological conditions and caries in adolescents. Caries Res 2003;37(5):319-26.

Nowak A, Crall J. Prevention of dental disease. In: Pinkham JR(editor) Pediatric dentistry: infancy through adolescence. 3 ed. Philadelphia: W.B. Saunders Company; 1999. Cap. 38, p. 618-21.

Ögaard B, Rösler M. Incidence and prediction of filled teeth from 12 to 18 years of age in a district in Norway. Scand J Dent Res 1991;99(1):106-12.

Ogden CL, Flegal KM, Carroll MD, Johnson CL. Prevalence and trends in overweight among US children and adolescents, 1999-2000. JAMA 2002;288(14):1728-32.

OMS. Levantamento epidemiológico básico de saúde bucal. São Paulo: Santos. 1999. $65 \mathrm{p}$.

Paixão DF. Tecnologia para todos [entrevista]. Rev Ass Paul Cir Dent 2002;56(6):408-17

Peres KGA, Bastos JRM, Latorre MRDO. Severidade de cárie em crianças e relação com aspectos sociais e comportamentais. Rev Saúde Pública 2000;34(4):402-8.

Petersen PE. The World Oral Health Report 2003: continuous improvement of oral health in the 21 st century- the approach of the WHO Global Oral Health Programme. Comm Dent Oral Epidemiol 2003;31(Suppl 1):3-24.

Petersson HG, Bratthall D. The caries decline: a review of reviews. Eur J Oral Sci 1996;104(4):436-43. 
Pinkham JR. The dynamics of change. In: Pinkham JR, editor. Pediatric dentistry: infancy through adolescence. 3. ed. Philadelphia: W.B. Saunders Company; 1999. cap 36. p.581-93.

Pinto VG. Saúde bucal: odontologia social e preventiva. Identificação de problemas. 3 ed. São Paulo:Santos; 1992. p.415.

Poulsen S. Dental caries in Danish children and adolescents 1988-94. Community Dent Oral Epidemiol 1996;24(4):282-5.

Powell LV. Caries prediction: a review of the literature. Community Dent Oral Epidemiol 1998;26(6):361-71.

Priore SE. Composição corporal e hábitos alimentares de adolescentes: uma contribuição à interpretação de indicadores do estado nutricional [Tese de Doutorado]. São Paulo: Escola Paulista de Medicina da UNIFESP; 1998.

Raitio M, Pienihäkkinen K, Scheinin A. Assessment of single risk indicators in relation to caries increment in adolescents. Acta Odontol Scand 1996;54(2):113-21.

Ribeiro IC. Obesidade entre escolares da rede pública de ensino de Vila Mariana São Paulo: estudo de caso controle [Dissertação de Mestrado]. São Paulo: Escola Paulista de Medicina da UNIFESP; 2001.

Rocha CM, Abreu CAAD, Araújo DR, Issac SZ, Pordeus IA, Paixão HH. Relação dieta/cárie na Odontopediatria: uma análise do consumo de sacarose. Arq Odontol 1998;34(1):25-31.

Rugg-Gunn AJ. Diet and dental caries. In: Murray JJ. The prevention of dental disease. 2. ed. New York: Oxford University Press; 1989. p. 4-114.

Rugg-Gunn AJ. Nutrition and dental health. New York: Oxford Medical Publications; 1993, p. 36-52, 91-260, 304-322. 
Rugg-Gunn AJ, Hackett AF, Appleton DR, Jenkins GN, Eastoe JE. Relationship between dietary habits and caries increment assessed over two years in 405 English adolescent school children. Arch Oral Biol 1984;29(12):983-92.

Russell JI, MacFarlane TW, Aitchison TC, Stephen KW, Burchell CK. Prediction of dental caries in Scottish adolescents. Community Dent Oral Epidemiol $1991 ; 19(2): 74-7$.

Saito MI, Abreu MRM. Adolescência e nutrição. In: Carrazza FR, Marcondes, E. Nutrição clinica em pediatria. São Paulo: Sarvier; 1991. p. 154-9.

São Paulo (Estado). Levantamento epidemiológico em saúde bucal: Estado de São Paulo, 1998. São Paulo: Secretaria de Estado da Saúde de São Paulo; p.1999. 95p.Disponível em URL: http://www. Saude.sp.gov.br/ftpsessp/bucal/relsp98.zip. [2003 abril 6]

Sarue HE, Bertoni A; Diaz AG, Serrano CV. O conceito de risco e a programação dos cuidados de saúde - Manual básico de aprendizagem inicial. Montevideo. Centro Latino-Americano de Perinatologia e Desenvolvimento Humano CLAP, 1984 (Publicação Científica no 1007).

Schachtele CF. Changing perspectives on the role of diet in dental caries formation. Nutrion News 1982;45:13-5.

Scheinin A, Makinen KK, Tammisalo E, Rekola M. Turku sugar studies XVIII. Incidence of dental caries in relation to 1-year consumption of xylitol chewing gum. Acta Odontol Scand 1975;33(5):269-78.

Schlicker AS, Borra ST, Regan C. The weight and fitness status of United States Children. Nutrition Rev 1994;52(1):11-7.

Sheiham A. Why free sugars consumption should be below $15 \mathrm{~kg}$ per person per year in industrialised countries: the dental evidence. Br Dent J 1991;171(2):63-5.

Silva TA, Paixão HH, Pordeus IA. Fatores do comportamento relacionado àhigiene bucal em adolescentes. Arq Odontol 1997;33(1), 5-14. 
Silveira D. Fatores de risco para excesso de peso em adolescentes brasileiros de baixa renda: estudo caso-controle [Dissertação Mestrado]. São Paulo: Escola

Paulista de Medinca da UNIFESP;2004.

Spear BA. Nutrição na adolescência. In: Mahan LK, Escott -Stump S, editores. Krause Alimentos, Nutrição e Dietoterapia. $10^{a}$ ed . São Paulo: Roca; 2002. cap.11, p.247-60.

Splieth C, Meyer G. Factors for changes of caries prevalence among adolescents in Germany. Eur J Oral Sci 1996;104(4 Pt2):444-51.

Stecksén-Blicks C, Gustaffson L. Impact of oral hygiene and use of fluorides on caries increment in children during one year. Community Dent Oral Epidemiol 1986;14(4):185-9.

Sundberg $\mathrm{H}$. Changes in the prevalence of caries in children and adolescents in Sweden 1985-1994. Eur J Oral Sci 1996;104(4 Pt2):470-6.

Swedberg Y, Fredén H, Norén JG. Caries extreme groups among adolescents, leaving organized dental care in Göteborg, Sweden. Swed Dent J 1997;21(6):221-6.

Szpunar SM, Eklund AS, Burt BA. Sugar consumption and caries risk in schoolchildren with low caries experience. Community Dent Oral Epidemiol $1995 ; 23(3) 142-6$.

Taani DSQ. Dental health of 13-14-year-old Jordanian school children and its relationship with socio-economic status. Int J Paediatric Dent 1996;6(3):183-6.

Taani DSQ. Relationship of socioeconomic background to oral hygiene, gingival status, and dental caries in children. Quintessence Int 2002;33(3):195-8.

Taddei JAAC. Epidemiologia. In: Nobrega FJ. Distúrbios da nutrição. São Paulo: Revinter; 1998. cap. 63, p.384-5. 
Tanaka NI, Gense JCRF, Lapa MG. Relatório de análise estatística sobre o projeto: Avaliação dos índices CPO-D e CPO-S em função dos hábitos alimentares de adolescentes eutróficos, sobrepesos e obesos do bairro da Vila Mariana - SP. São Paulo: IME-USP; 2004. (ERA-CEA 04P08).

Thylstrup A, Ferjeskov O. Diferentes conceitos da cárie dentaria e suas implicações. In:___ Cariologia clinica. 3. ed. São Paulo: Santos; 2001. cap. 9. p.209-217.

Toledo AO, Bezerra ACB, Bezerra VLV, Dristig EB. Cárie e estado nutricional. RGO 1989;37(4):295-8.

Touger-Decker R. Role of nutrition in the dental practice. Quintessence Int 2004;35(1):67-70.

Traebert J, Moreira EAM, Bosco VL, Almeida ICS. Transição alimentar: problema comum àobesidade e àcárie dental. Rev Nutr 2004;17(2):247-53.

Treasure ET, Dever JG. Relationship of caries with socieconomic status in 14-yearold children from four communities with different fluoride histories. Community Dent Oral Epidemiol 1994;22(4):226-30.

Tuomi T. Pilot study on obesity in caries prediction. Community Dent Oral Epidemiol 1989;17(6):289-91.

van Loveren C, Duggal MS. The role of diet in caries prevention. Int Dent $\mathrm{J}$ 2001;51(Suppl 6):399-406.

Vitalle MSS. Alimentação do adolescente. In: Lopez FA, Brasil ALD. Nutrição e dietética em clínica pediátrica. São Paulo: Atheneu; 2003. cap. 1.6, p.72-84.

Wabitsch M. Overweight and obesity in European children and adolescents: causes and consequences, treatment and prevention- an introduction. Eur J Pediatr 2000a; 159:(Suppl 1):S5-S7. 
Wabitsch M. Overweight and obesity in European children: definition and diagnostic procedures, risk factors and consequences for later health outcome. Eur J Pediatr 2000b;159(Suppl 1):S8-S13

WHO. Technical Report Series 916. Diet, Nutrition and the prevention of chronic diseases. Report of a joint WHO/FAO Expert Consultation. Geneva: World Health Organization; 2003. $149 \mathrm{p}$.

WHO. Oral health information systems. Disponível em URL: http://www.who.int/oral_health/action/informantion/surveillance/en [2004 nov. 7]. 
APÊNDICES 


\section{APÊNDICE A - TERMO DE CONSENTIMENTO LIVRE E ESCLARECIDO USP}

\section{UNIVERSIDADE DE SÃO PAULO \\ FACULDADE DE ODONTOLOGIA \\ TERMO DE CONSENTIMENTO LIVRE E ESCLARECIDO}

Eu responsável pelo

menor autorizo sua participação na

pesquisa intitulada "Avaliação das condições bucais de adolescentes obesos, eutróficos e de baixa estatura da cidade de São Paulo" realizada pela pesquisadora Cristina Giovannetti Del Conte Zardetto, sob a orientaçăo da Profa. Dra. Célia Regina Martins Delgado Rodrigues, na Disciplina de Nutrição do Departamento de Pediatria da Escola Paulista de Medicina.

O objetivo deste estudo é comparar o indice de cárie (quantidade) e os hábitos dietéticos de adolescentes eutróficos (peso e estatura com padrão normal), baixa estatura e obesos. Após análise estatística, os resultados serão comparados com dados já existentes na literatura.

Será realizado um exame clínico bucal com espelho clínico, espátula de madeira e ianterna de māo para verificar as superficies dentais e oclusão (posição dos dentes com a boca fechada) do paciente com duração aproximada de 15 minutos. Este procedimento năo oferece nenhum risco adicional ao paciente. $\mathrm{A}$ participação na pesquisa é voluntária e o paciente pode-se retirar a qualquer momento sem que sofra nenhuma penalização.

Quando da publicaçăo dos dados coletados não será revelada a identificaçẩo dos participantes.

A pesquisadora esta á disposição para esciarecer qualquer dúvida.

Este documento é apresentado em duas vias.

Săo Paulo, de de 200

Assinatura do responsável:

RG do responsável

Dra. Cristina G. Zardetto

Fone: 3091-7854

Av, Prof. Lineu Prestes, 2227 - Cidade Universitária "Armando de Salles Oliveira" CEP 05508-900 São Paulo - SP Diretori:s Telefax(011) 38140062 - $38187817 / 60$ Compras Telefax (011) 38149281 Săo Paulo 
APÊNDICE B - TERMO DE CONSENTIMENTO LIVRE E ESCLARECIDO - UNIFESP - EPM
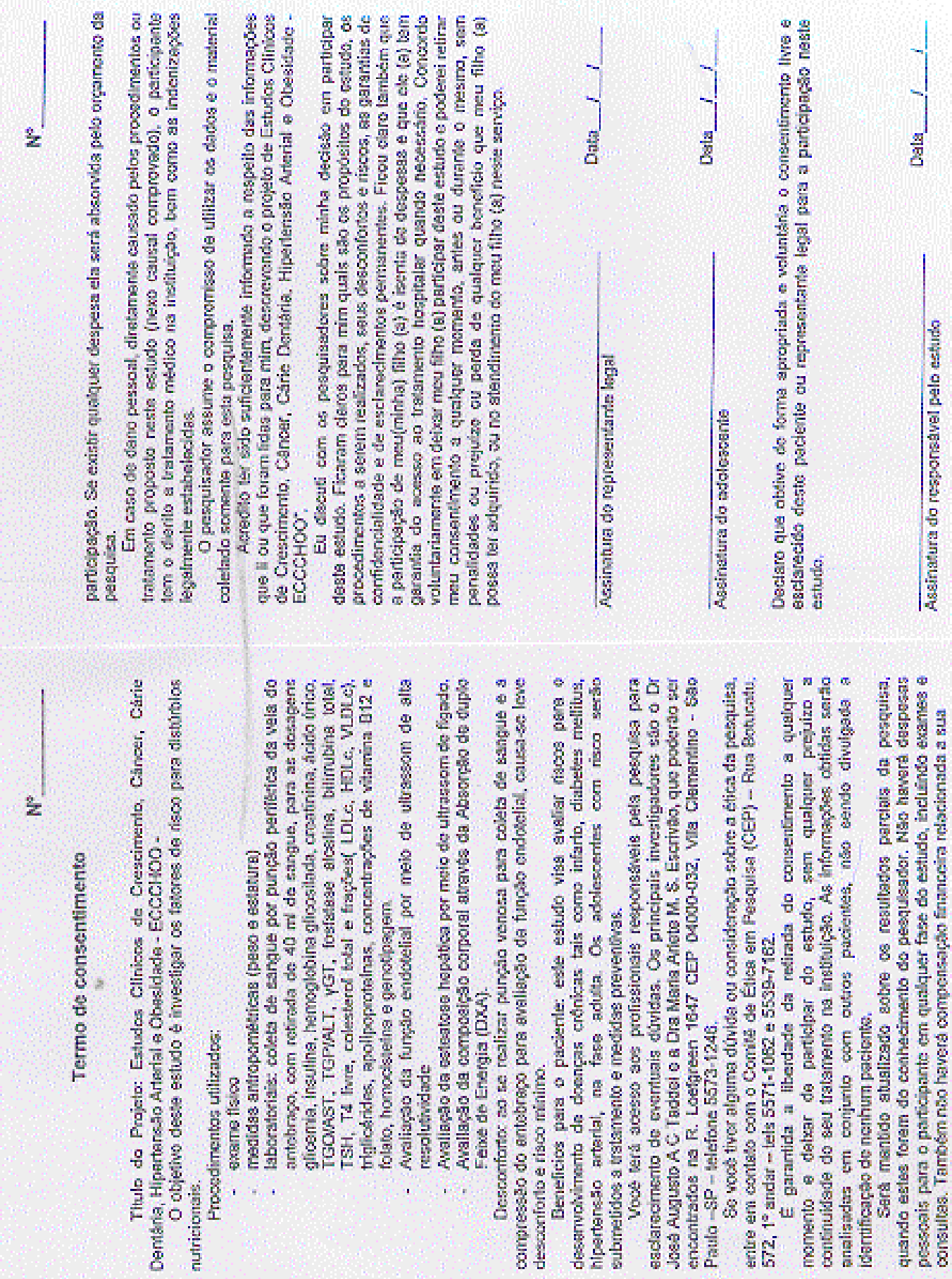


\section{APÊNDICE C - Questionário Geral}

\section{1 - Identificação do adolescente}

Série: Sala:

Data:

Nome:

$\mathrm{DN}$ :

Cor: branca

(1) negra

(2) parda

(3) amarela

(4) outras

(5)

Endereço:

Bairro: CEP: tel: e-mail:

\section{Fase - 1}

Entrevistador

1 - Peso kg 2 - Altura: cm 3 - IMC: $\mathrm{kg} / \mathrm{m}^{2}$

4 - Dig Nutricional: Obeso

(1) Eutrófico

(2) Baixa Estatura

(3)

5 - Percentil: E/l: 6 - Tanner

7 Menarca (anos) 8 - DUM

9 - PAS - intervalos de 5 minutos: 1 $\mathrm{mmHg} 2$ $\mathrm{mmHg} 3$ $\mathrm{mmHg}$

PAD - intervalos de 5 minutos: $\mathrm{mmHg} 2$ $\mathrm{mmHg} 3$ $\mathrm{mmHg}$

\section{Fase - 2}

\section{2 - Família}

Entrevistador

10 - Nome do acompanhante responsável:

11 - Parentesco: mãe (1) pai (2) mãe e pai (3) outros (4):

12 - Nat.: Cidade de São Paulo (1) Estado de São Paulo (2) Outros (3)

13 - $N^{\circ}$ irmãos:

Primogênito? Sim

(1) não

(2) Caçula? Sim

(1) Não (2)

14- Idade materna: anos 15-Estatura materna: cm 16-Peso materno: $\mathrm{kg}$

17 - PA materna mmHg 18 -Toma remédio para pressão alta? Sim

(1) Não

19-Fez exame de sangue para saber como estão o colesterol e os triglicérides?

Sim (1) Não (2) 20-Se sim o colesterol estava alto? Sim (1) Não (2) Não sei

21 - E os triglicérides também estavam altos? Sim

(1) Não

(2) Não sei

(3)

22- Idade paterna: anos 23- Estatura paterna: cm 24- Peso paterno:

25 - PA paterno: mmHg 26 -Toma remédio para pressão alta? Sim

(1) Não

27-Fez exame de sangue para saber como estão o colesterol e os triglicérides?

Sim (1) Não (2) 28-Se sim o colesterol estava alto? Sim (1) Não (2) Não sei (3) 
29 - E os triglicérides também estavam altos? Sim (1) Não (2) Não sei (3) 30 - Doenças crônicas na família:

\begin{tabular}{|c|l|c|c|c|c|c|c|}
\hline & & & & \multicolumn{2}{c|}{ Pai } & \multicolumn{2}{c|}{ Mãe } \\
\hline & Doença & Pai & Mãe & Avô & Avó & Avô & Avó \\
\hline A & Obesidade & & & & & & \\
\hline B & Dislipidemias & & & & & & \\
\hline C & Hipertensão arterial & & & & & & \\
\hline D & Infarto ou AVC ou angina & & & & & & \\
\hline E & Diabetes & & & & & & \\
\hline F & Câncer & & & & & & \\
\hline G & Tumores hepáticos & & & & & & \\
\hline H & Cirurgias hepato-biliares & & & & & & \\
\hline I & Cálculos hepáticos (colesterol) & & & & & & \\
\hline J & $\begin{array}{l}\text { Morte súbita do coração em homem } \\
\text { com menos de 55 anos de idade }\end{array}$ & & & & & & \\
\hline L & $\begin{array}{l}\text { Morte súbita do coração em mulher } \\
\text { com menos de 65 anos de idade }\end{array}$ & & & & & & \\
\hline
\end{tabular}

\section{3 - Antecedentes pessoais}

31 - Peso de nascimento: g 32 - Estatura de nascimento: $\mathrm{cm}$

33 - Nasceu prematuro Sim

(1) Não (2)

34 - Informação: do cartão

(1) da mãe

(2) do adolescente

(3)

35 - Já foi obeso anteriormente? Sim (1) Não (2)

36 - Se sim, quando? Lactente (1) Pré-Escolar (2) Escolar (3) Adolescente (4)

37 - Se é obeso (obesidade atual), há quanto tempo? ano/s e mês/es

38 - Já fez tratamento para emagrecer? Sim (1) Não (2)

39 - Tomou remédios para emagrecer? Sim (1) Não

Se sim, qual ou quais?

40 - Por quanto tempo? meses

41 - Fez dieta? Sim (1) não (2) 42 - Por quanto tempo? meses

43 - Antecedentes Patológicos: Hepatite Sim

Não

(2)

44 - Imobilização ortopédica Sim (1) Não (2) 45 - Se sim, por quanto tempo?

46 - Quantas vezes?

47 - Já foi internado? Sim (1) Não (2)

48 - Qual ou quais foi ou foram os motivo/s da/s internação/ões:

49 - No total quantos dias ficou internado? 


\section{4 - Nível Sócio-Econômico}

51 - A casa ou apartamento onde a família mora é:
própria (1)
alugada
(2)
cedida (3)
invadida (4)

52 - A casa ou apartamento tem banheiro dentro? Sim

(1) Não (2)

53 - A coleta de lixo acontece:
todos os dias
(1) 2 a $3 x /$ semana
(2) $1 x /$ semana
(3) não acontece
(4)

54 - Há quanto tempo a mãe ou o responsável mora no Bairro:
menos de um ano
de 1 a 5 anos
(2) mais de 5 anos
55 - O adolescente morou em outra cidade? Sim
(1) Não
(2)

Se sim qual?

56 - Por quanto tempo?

57 - Qual era a idade do adolescente na época em que morou em outra cidade?

58 - A mãe do adolescente:

mora com o pai do adolescente

mora com outro companheiro (não é o pai do adolescente)

mora sem companheiro

59 - Escolaridade da mãe do adolescente:
Fundamental
(1) Médio
(2) Superior
(3) completo
(1) incompleto
(2)

60 - Qual a profissão ou ocupação da mãe do adolescente?

está desempregada

está empregada e registrada
(1) autônoma

(3) está empregada sem registro
(2)

(4)

61 - Qual a profissão ou ocupação do pai do adolescente?

está desempregado

está empregado e registrado
(1) autônomo

(3) está empregado sem registro
(4)

DESTA PARTE DO QUESTIONÁRIO EM DIANTE AS PERGUNTAS DEVERÃO SER RESPONDIDAS SOMENTE PELO ADOLESCENTE E EM CARÁTER CONFIDENCIAL

Entrevistador

\section{5 - Adolescente}

\section{Atividade Física}

62 - Você pratica regularmente algum esporte fora das aulas de Educação Física? 
$\operatorname{Sim}$ (1) Não (2)

63 - Se sim, quantas vezes e horas por semana você pratica?

Vezes por semana

Tempo por vez

$1 \times$ por semana

30 minutos

2x por semana

de 30 minutos até 1 hora

$3 x$ por semana

mais de 1 hora

mais de $3 x$ por semana

64-Quantas horas você dorme a noite? $<7$ horas (1) de 7 a 10 horas (2) $>10$ horas

65 - O que você mais gosta de fazer nos momentos de lazer?

ouvir música sem dançar

ouvir música e dançar

usar o computador

assistir TV ou jogar videogame

jogar bola (esporte)

66 - Você tem o hábito de dormir durante o dia? Sim

(1)
(1) dormir

(2) andar de bicicleta ou de patins

(3) outras atividades

(4) Quais?

(5)

67- Se sim durante quanto tempo? até 1 hora

(1) de 1 a 2 horas
Não (2)
Não (2)

(2) $>2$ horas

(3)

68 - Como você se vê?

mais ativo que os outros

igual aos outros

menos ativo que os outros

(2)

não sei

(4)

69 - Em termos de atividade física como você se define?

sedentário (1) pouco ativo (2) ativo (3) muito ativo (4)

70 - Quanto tempo por dia você fica sentado em um dia de semana?

$<4$ horas (1) de 4 a 6 horas (2) de 6 a 8 horas (3) > 8 horas (4)

71 - Quanto tempo por dia você fica sentado em um dia de fim de semana? 
$<4$ horas (1) de 4 a 6 horas (2) de 6 a 8 horas (3) $>8$ horas (4)

72 - Em geral como você vai àescola?
a pé (1) de ônibus
(2) de perua
(3) por outros meios
(4)Quais?

73 - Você tem o hábito de andar a pé ou de bicicleta? Sim (1) Não

74 - Se sim, quanto tempo por dia?

até 1 hora (1) de 1 a 2 horas (2) de 2 a 4 horas (3) mais do que 4 horas (4)

75 - Participa de alguma associação, clube ou equipe de algum esporte, na escola ou fora dela? Sim (1) Não (2)

76 - Quantas horas por dia você assiste televisão?

até 1 hora (1) 1 a 2 horas (2) 2 a 4 horas (3) 4 a 6 horas (4) mais de 6 horas

\section{Tabagismo}

77 - Você já fumou pelo menos 100 cigarros em toda a sua vida? Sim (1) Não (2) 78 - Fuma atualmente? Sim (1) Não (2) 79 - Quantos cigarros por dia? $\begin{array}{llllll}\text { menos que } 5 & \text { (1) } 5 \text { a } 10 & \text { (2) } 10 \text { a } 20 & \text { (3) mais que20 }\end{array}$

\section{Etilismo}

80 - Você costuma beber? Sim (1) Não (2) 81 - Com que freqüência?

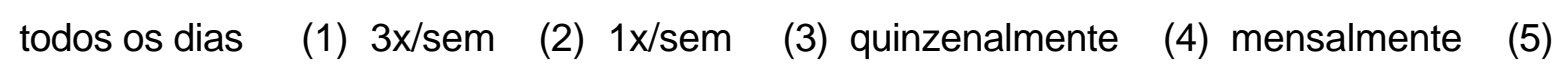
82 - Qual bebida alcoólica você mais gosta?

Cerveja (1) Vinho Tinto (2) Vinho Branco (3) Vinho Rose (4) Whisky (5)

Vodka (6) Pinga (7) Outras (8) Quais? Não bebe (9)

83 - Quando você bebe, em festas, qual a quantidade?

Um copo de requeijão (1) Dois copos de requeijão (2) Mais que dois (3)

Menos que um copo (4) Goles (5) 
84- Você costuma ir àfestas quantas vezes por semana ? Nunca (1) Uma vez por semana (2) Duas vezes por semana (3) Três vezes ou mais por semana (4) 85 - Como é seu relacionamento com seu pai?

Ótimo (1) Bom (2) Regular (3) Ruim (4) Péssimo (5) 86 - Como é seu relacionamento com sua mãe?
Ótimo
(1) Bom
(2) Regular
(3) Ruim
(4) Péssimo

87 - Como é seu relacionamento com seus irmãos?
Ótimo
(1) Bom
(2) Regular
(3) Ruim
(4) Péssimo

88 - Você tem grupo de amigos? Sim

(1) Não

89 - Você tem um melhor amigo? Sim

(1) Não

90 - Você tem namorado/a atualmente? Sim

(1) Não (2)

91-Caso tenha, há quanto tempo?

Até 1 semana (1) >1 semana até 1 mês

(2) $>3$ meses até 6 meses

(3) $>1$ ano

92-Como você vai na Escola? Ótimo (1) Bom

(2) Regular

(3) Ruim

(4) Péssimo

(5) 93 - Qual a matéria que você tem mais dificuldade?

94 - Você já foi reprovado? Sim

(1) Não

(2) 95 - Quantas vezes?

Zero

(1) Uma

(2) Duas

(3) Três

(4) Mais que 3

(5)

96 - Em qual situação você costuma beliscar?

Quando está triste (1) Entediado (2) Com raiva (3) Alegre (4)

Quando tem algum problema (5)

97 - Em que horário você costuma beliscar?

Pela manhã

(1) àtarde

(2) ànoite

(3) de madrugada

(4) 


\section{Medicamentos}

98 - Você usa medicamentos continuamente? Sim (1) Não (2)

Se sim qual ou quais?

99 - Atualmente você está tomando algum medicamento? Sim

(1) Não (2)

Se sim qual ou quais?

100 - Toma anticoncepcional? Sim (1) Não (2)

Se sim qual ou quais?

101 - Há quanto tempo?

102 - Toma suplementação de Cálcio? Sim (1) Não (2)

Se sim qual ou quais?

103 - Há quanto tempo?

104 - Toma suplementação vitamínica? Sim (1) Não (2)

Se sim qual ou quais?

105 - Há quanto tempo?

106 - Toma chás com finalidades terapêuticas? Sim

(1) Não

(2)

Se sim qual ou quais? 107 - Há quanto tempo?

108 - Toma outros remédios? Sim (1) Não (2)

Se sim qual ou quais? 109 - Há quanto tempo?

\section{Drogadição}

110 - Você já experimentou alguma droga? Sim (1) Não (2) Qual?

111-Continua usando?Sim (1) Não (2) 112-Se sim, qual a freqüência e o tipo de droga?

\begin{tabular}{|l|l|l|l|l|l|}
\hline & Tipo & Diariamente & Semanalmente & Quinzenalmente & Mensalmente \\
\hline S & Maconha & & & & \\
\hline T & Cocaína & & & & \\
\hline U & Crack & & & & \\
\hline V & Heroína & & & & \\
\hline X & Ectasy & & & & \\
\hline Z & Outros & & & & \\
\hline
\end{tabular}




\section{PARTE NUTRICIONAL}

\section{6- Alimentação}

\section{A - Alimentação durante o primeiro ano de vida}

01- 0 adolescente foi amamentado ao peito desde o nascimento?

Sim $\square$ (1) Não $\square$ (2) Não sabe $\square$ (3) Se sim, por quanto tempo? _ _ meses 02- Com que idade o adolescente parou de mamar na mamadeira? meses / anos

03- Qual o tipo de leite mais freqüentemente utilizado na mamadeira durante o primeiro ano de vida? $\square$ Leite integral: Saquinho $\square(1) \quad \square$ Fórmulas infantis (4) $\quad \square$ Outros (5)
Longa vida $\square(2)$
Pó $\quad \square(3)$

04- Com que idade o adolescente começou a comer os mesmos alimentos da família? meses/anos

\section{B - Alimentação atual}

05-Costuma comer a gordura que enxerga na carne?

$\square \operatorname{Sim}(1) \quad \square$ Não(2) $\square$ Não come carne(3)

06-Costuma comer a pele da galinha? $\square \operatorname{Sim}(1) \quad \square$ Não(2) $\quad \square$ Não come galinha(3)

07- Qual o tipo de gordura é utilizada com mais freqüência no preparo de carne frita ou assada que 0 adolescente come? (ler as alternativas)
$\square$ manteiga (1)
$\square$ óleos vegetais (soja, milho, etc.) (6)
$\square$ gordura vegetal hidrogenada (2)
$\square$ utiliza somente o suco da própria carne (7)
$\square$ banha de porco (3)
$\square$ microondas ou grelha (8)
$\square$ margarina comum (4)
$\square$ nunca come carne frita ou assada (9)
$\square$ margarina light (com menos gordura) ou polinsaturada (5)

08- Com que freqüência o adolescente consome os alimentos citados abaixo?

a. Refrigerante:
$\square$ todos os dias(1)
$\square 1$ a 3x/sem(2)
$\square 4$ a $6 x / \operatorname{sem}(3)$
$\square$ menos que $1 \mathrm{x} / \mathrm{sem}(4)$

b. Salgados (coxinha, kibe, pastel, croissant...):

$\square$ todos os dias(1) $\quad \square 1$ a $3 x / \operatorname{sem}(2) \quad \square 4$ a $6 x / \operatorname{sem}(3) \quad \square$ menos que 1 x/sem(4)

c. Salgadinhos (Fandangos, batatinha,...):

$\square$ todos os dias(1) $\quad \square 1$ a $3 x / \operatorname{sem}(2) \quad \square 4$ a 6 x/sem(3) $\quad \square$ menos que 1 x/sem(4)

d. Lanches (hamburguer, cachorro-quente,...):

$\square$ todos os dias(1) $\quad \square 1$ a 3x/sem(2) $\quad \square 4$ a 6 x/sem(3) $\quad \square$ menos que 1 x/sem(4) 
e. Balas e chicletes:

$\square$ todos os dias(1) $\square 1$ a 3x/sem(2) $\square 4$ a 6 x/sem(3) $\square$ menos que 1 x/sem(4)

f. Doces em geral (chocolate, sorvete, pudim , doce de leite, bolacha recheada, ...):

$\square$ todos os dias(1) $\square 1$ a $3 x / \operatorname{sem}(2) \quad \square 4$ a $6 x / \operatorname{sem}(3) \quad \square$ menos que 1 x/sem(4)

09- a. Doces específicos (sorvete, doce de leite, pudim, arroz doce, manjar):

$\square$ todos os dias(1) $\square 1$ a 3x/sem(2) $\square 4$ a 6 x/sem(3) $\square$ menos que 1 x/sem(4)

b. Leite:

$\square$ todos os dias(1) $\square 1$ a 3x/sem(2) $\square 4$ a $6 x / \operatorname{sem}(3) \quad \square$ menos que 1 x/sem(4)

c. logurte:

$\square$ todos os dias(1) $\square 1$ a 3x/sem(2) $\square 4$ a 6 x/sem(3) $\quad \square$ menos que 1 x/sem(4)

d. Queijo:

$\square$ todos os dias(1) $\quad \square 1$ a $3 x / \operatorname{sem}(2) \quad \square 4$ a $6 x / \operatorname{sem}(3) \quad \square$ menos que 1 x/sem(4)

10- a) Com que freqüência você faz lanches fora de casa (Mc Donald's, Pizzarias, Trailer's ...)?

$\square$ todos os dias(1) $\square 1$ a $3 \mathrm{x} / \operatorname{sem}(2) \quad \square 4$ a $6 \mathrm{x} / \operatorname{sem}(3) \quad \square$ menos que $1 \mathrm{x} / \operatorname{sem}(4)$

b) Com que freqüência você come lanches em casa pedido por telefone (Pizzas, Sanduíches, Esfihas...)?

$\square$ todos os dias(1) $\square 1$ a 3x/sem(2) $\square 4$ a 6 x/sem(3) $\square$ menos que 1 x/sem(4)

c) Com que freqüência você come frituras?

$\square$ todos os dia(1) $\quad \square 1$ a 3x/sem(2) $\quad \square 4$ a $6 x / \operatorname{sem}(3) \quad \square$ menos que 1 x/sem(4)

11- Em qual lugar você costuma comer em companhia dos seus amigos?
$\square$ Lanchonete(1)
$\square$ Na sua casa (3)
$\square$ Escola (5)
$\square$ Restaurante (7)
$\square$ Mc Donald's (2)
$\square$ Na casa do amigo (4)
$\square$ Pizzaria (6)
$\square$ Outros (8) 


\title{
APÊNDICE D - Registro alimentar
}

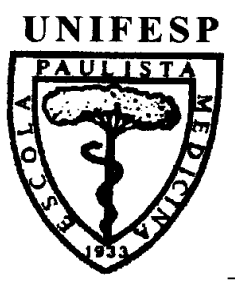

\author{
Universidade Federal de São Paulo \\ Disciplina de Nutrologia \\ Departamento de Pediatria
}

№

\section{Projeto ECCHOS}

\section{Registro Alimentar de 4 dias}

Nome:

Série: ( )

Como Fazer:

Anotar o que comer e beber durante 4 dias ( 3 dias de semana e 1 final de semana)

Atividades Necessárias:

1) Marcar o horário que recebeu o alimento;

2) Marcar o local, se comeu em casa, escola ou outro;

3) Marcar se comeu com a família, amigo ou sozinho;

4) Marcar o tipo da refeição (café da manhã, lanche, almoço e jantar);

5) Marcar a quantidade de alimento que comeu, o que ficou no prato não deverá ser marcado;

- Frutas, pães, bolachas, doces consistentes (quantas fatias, pedaços ou unidades);

- Arroz, macarrão, saladas, legumes, purês, carne picada ou moída, doce mole e outros (quantas colheres de sopa ou escumadeiras);

- Feijão, sopas (quantas conchas ou colher de sopa);

6) Marcar o tipo de preparação (frito, cozido, assado ou ensopado), tipo de molho usado;

7) Marcar qual o pedaço de frango que consumiu (peito, coxa, asa, sobrecoxa), se foi com ou sem pele. 
Nome:

Série:

Dia /2002 SEG（）TER（） QUA（）QUI（）SEX（）SAB（）DOM（）

\begin{tabular}{|c|c|c|c|c|c|}
\hline Refeição & Horário & Local & Companhia & Alimento & $\begin{array}{l}\text { Quantidade } \\
\text { (medidas caseiras) }\end{array}$ \\
\hline & & & & & \\
\hline & & & & & \\
\hline & & & & & \\
\hline & & & & & \\
\hline & & & & & \\
\hline & & & & & \\
\hline & & & & & \\
\hline & & & & & \\
\hline & & & & & \\
\hline & & & & & \\
\hline & & & & & \\
\hline & & & & & \\
\hline & & & & & \\
\hline & & & & & \\
\hline & & & & & \\
\hline & & & & & \\
\hline & & & & & \\
\hline & & & & & \\
\hline & & & & & \\
\hline & & & & & \\
\hline & & & & & \\
\hline & & & & & \\
\hline & & & & & \\
\hline & & & & & \\
\hline & & & & & \\
\hline & & & & & \\
\hline & & & & & \\
\hline & & & & & \\
\hline & & & & & \\
\hline & & & & & \\
\hline & & & & & \\
\hline & & & & & \\
\hline & & & & & \\
\hline & & & & & \\
\hline
\end{tabular}




\section{APÊNDICE E - Ficha odontológica}

\section{IDENTIFICAÇÃO DO PACIENTE}

Data:

$n^{\circ}$ ficha:

Nome:

Nascimento:

Endereço: $n^{\circ}$ ficha ECCCHOOS:

Telefone:

Cep:

1. CPO-D
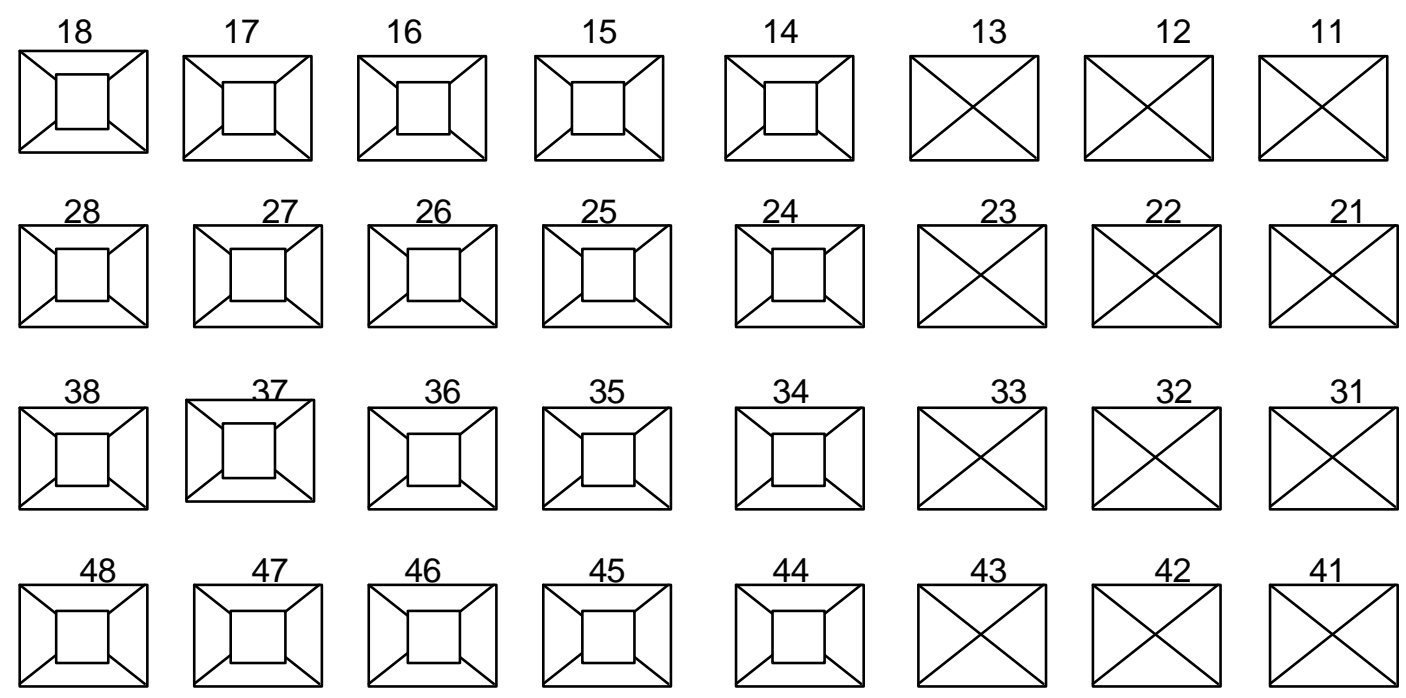

\section{OBSERVAÇÕES:}

\section{HÁBITOS DE HIGIENE BUCAL:}

- Quantas vezes ao dia realiza higiene bucal?

\section{IDA AO CIRURGIÃO-DENTISTA:}

- Quando foi a sua última visita ao cirurgião-dentista? 


\section{APÊNDICE F-Análise descritiva das variáveis sociodemográficas}

Apêndice F.1 - Valores descritivos do CPO-D em função da idade dos adolescentes

\begin{tabular}{cccccccccc}
\hline $\begin{array}{l}\text { Idade } \\
\text { (em anos) }\end{array}$ & $\mathbf{n}$ & $\%$ & Media & $\begin{array}{l}\text { Desvio } \\
\text { Padrão }\end{array}$ & Mínimo & Q1 & Mediana & Q3 & Máximo \\
\hline 15 & 32 & 13,91 & 5,00 & 4,58 & 0 & 1,00 & 5,00 & 7,00 & 17 \\
16 & 80 & 34,78 & 4,85 & 4,08 & 0 & 1,00 & 5,00 & 7,00 & 18 \\
17 & 75 & 32,61 & 7,23 & 4,72 & 0 & 4,00 & 7,00 & 10,00 & 19 \\
$18-19$ & 43 & 18,70 & 5,98 & 5,09 & 0 & 2,00 & 5,00 & 8,00 & 20 \\
Total & 230 & 100,00 & & & & & & & \\
\hline
\end{tabular}

Apêndice F.2 - Valores descritivos do CPO-D em função do sexo

\begin{tabular}{lccccccccc}
\hline Sexo & $\mathbf{n}$ & $\%$ & Media & $\begin{array}{c}\text { Desvio } \\
\text { Padrão }\end{array}$ & Mínimo & Q1 & Mediana & Q3 & Máximo \\
\hline Feminino & 104 & 45,22 & 5,35 & 4,34 & 0 & 2,00 & 5,00 & 8,00 & 18 \\
Masculino & 126 & 54,78 & 6,28 & 4,87 & 0 & 2,00 & 6,00 & 9,00 & 20 \\
Total & 230 & 100,00 & & & & & & & \\
\hline
\end{tabular}

Apêndice F.3 - Valores descritivos do CPO-D em função da idade da mãe

\begin{tabular}{cccccccccc}
\hline $\begin{array}{c}\text { Idade mãe } \\
\text { (anos) }\end{array}$ & $\mathbf{n}$ & $\%$ & Media & $\begin{array}{c}\text { Desvio } \\
\text { Padrão }\end{array}$ & Mínimo & Q1 & Mediana & Q3 & Máximo \\
\hline 30 A 35 & 11 & 4,78 & 5,45 & 5,11 & 0 & 1,00 & 5,00 & 7,00 & 19 \\
36 A 40 & 52 & 22,61 & 5,50 & 4,8 & 0 & 2,00 & 5,00 & 8,00 & 20 \\
41 a 45 & 65 & 28,26 & 5,31 & 3,95 & 0 & 2,00 & 5,00 & 7,00 & 18 \\
46 a 50 & 61 & 26,52 & 6,36 & 4,97 & 0 & 2,00 & 5,00 & 9,50 & 18 \\
51 a 60 & 39 & 16,96 & 6,10 & 4,55 & 0 & 2,00 & 5,00 & 9,00 & 17 \\
NR & 2 & 0,87 & 15,00 & 5,66 & 11 & $*$ & 15,00 & $*$ & 19 \\
Total & 230 & 100,00 & & & & & & &
\end{tabular}


Apêndice F.4 - Valores descritivos do CPO-D em função do nível da escolaridade da mãe

\begin{tabular}{cccccccccc}
\hline Escolaridade Mãe & $\mathrm{n}$ & $\%$ & Media & $\begin{array}{c}\text { Desvio } \\
\text { Padrão }\end{array}$ & Mínimo & Q1 & Mediana & Q3 & Máximo \\
\hline $\begin{array}{c}\text { Fundamental } \\
\text { incompleto }\end{array}$ & 23 & 10,00 & 7,96 & 4,98 & 0 & 5,00 & 7,00 & 10,00 & 20 \\
$\begin{array}{c}\text { Fundamental } \\
\text { completo }\end{array}$ & 38 & 16,52 & 5,32 & 4,16 & 0 & 2,00 & 5,00 & 7,25 & 17 \\
médio incompleto & 19 & 8,26 & 6,05 & 5,48 & 0 & 2,00 & 5,00 & 8,00 & 19 \\
médio completo & 84 & 36,52 & 5,85 & 4,58 & 0 & 2,00 & 5,00 & 9,00 & 18 \\
superior incompleto & 22 & 9,57 & 5,59 & 4,53 & 0 & 1,00 & 5,50 & 9,00 & 17 \\
superior completo & 41 & 17,83 & 4,95 & 4,54 & 0 & 1,00 & 4,00 & 7,00 & 17 \\
NR & 3 & 1,30 & 10,00 & 7,81 & 5 & 5,00 & 6,00 & 19,00 & 19 \\
Total & 230 & 100,00 & & & & & & & \\
\hline
\end{tabular}

Apêndice F.5 - Valores descritivos do CPO-D em função da idade do pai

\begin{tabular}{cccccccccc}
\hline $\begin{array}{c}\text { Idade Pai } \\
\text { (anos) }\end{array}$ & $\mathbf{n}$ & $\%$ & Media & $\begin{array}{c}\text { Desvio } \\
\text { Padrão }\end{array}$ & Mínimo & Q1 & Mediana & Q3 & Máximo \\
\hline 36 a 40 & 33 & 14,35 & 5,42 & 4,09 & 0 & 2,00 & 5,00 & 7,00 & 17 \\
41 a 45 & 53 & 23,04 & 4,89 & 4,43 & 0 & 1,00 & 4,00 & 7,00 & 20 \\
46 a 50 & 70 & 30,43 & 5,37 & 4,37 & 0 & 1,00 & 6,00 & 8,00 & 19 \\
51 a 70 & 58 & 25,22 & 7,48 & 5,23 & 0 & 4,00 & 7,00 & 11,00 & 19 \\
NR & 16 & 6,96 & 6,19 & 4,39 & 0 & 1,75 & 5,50 & 9,75 & 14 \\
Total & 230 & 100,00 & & & & & & & \\
\hline
\end{tabular}

Apêndice F.6 - Valores descritivos do CPO-D em função da renda familiar em número de salários mínimos

\begin{tabular}{ccrccccccc}
\hline $\begin{array}{c}\text { Renda familiar } \\
\text { (salário mínimo) }\end{array}$ & $\mathrm{n}$ & $\%$ & Media & $\begin{array}{c}\text { Desvio } \\
\text { Padrão }\end{array}$ & Mínimo & Q1 & Mediana & Q3 & Máximo \\
\hline 0 a 5 SM & 56 & 24,35 & 6,84 & 5,03 & 0 & 3,25 & 6,00 & 9,00 & 20 \\
6 a 11 SM & 81 & 35,22 & 5,16 & 4,22 & 0 & 2,00 & 5,00 & 7,50 & 19 \\
12 a 17 SM & 54 & 23,48 & 5,89 & 4,73 & 0 & 2,00 & 5,00 & 9,00 & 18 \\
18 a 23 SM & 17 & 7,39 & 5,24 & 3,40 & 0 & 2,00 & 5,00 & 8,00 & 11 \\
24 a + & 17 & 7,39 & 7,47 & 5,61 & 0 & 3,00 & 6,00 & 12,50 & 17 \\
NR & 5 & 2,17 & 2,40 & 3,78 & 0 & 0,00 & 1,00 & 5,50 & 9 \\
Total & 230 & 100,00 & & & & & & & \\
\hline
\end{tabular}




\section{APÊNDICE G - Variáveis fisiológicas}

Apêndice G.1 - Valores descritivos do CPO-D em função do estado nutricional

\begin{tabular}{cccccccccc}
\hline $\begin{array}{c}\text { Estado } \\
\text { nutricional }\end{array}$ & $\mathbf{n}$ & $\%$ & Media & $\begin{array}{c}\text { Desvio } \\
\text { Padrão }\end{array}$ & Mínimo & Q1 & Mediana & Q3 & Máximo \\
\hline Eutrófico & 148 & 64,34 & 5,70 & 4,60 & 0 & 2,00 & 5,00 & 8,00 & 20 \\
Sobrepeso & 39 & 16,96 & 6,90 & 5,10 & 0 & 2,00 & 7,00 & 10,00 & 19 \\
obeso & 43 & 18,70 & 5,30 & 4,50 & 0 & 1,00 & 7,00 & 9,00 & 18 \\
Total & 230 & 100,00 & & & & & & & \\
\hline
\end{tabular}

Apêndice G.2 - Valores descritivos do CPO-D em função do colesterol total

\begin{tabular}{|c|c|c|c|c|c|c|c|c|c|}
\hline Colesterol total & $n$ & $\%$ & Media & $\begin{array}{l}\text { Desvio } \\
\text { Padrão }\end{array}$ & Mínimo & Q1 & Mediana & Q3 & Máximo \\
\hline$\leq 200 \mathrm{mg} / \mathrm{dl}$ & 205 & 89,13 & 5,75 & 4,45 & 0 & 2,00 & 5,00 & 8,00 & 20 \\
\hline $\begin{array}{c}>200 \mathrm{mg} / \mathrm{dl} \\
\text { Total }\end{array}$ & $\begin{array}{c}25 \\
230 \\
\end{array}$ & $\begin{array}{c}10,87 \\
100,00\end{array}$ & 6,76 & 6,08 & 0 & 2,00 & 6,00 & 9,00 & 19 \\
\hline
\end{tabular}

Apêndice G.3 - Valores descritivos do CPO-D em função do colesterol HDL

\begin{tabular}{|c|c|c|c|c|c|c|c|c|c|}
\hline Colesterol HDL & $\mathbf{n}$ & $\%$ & Media & $\begin{array}{l}\text { Desvio } \\
\text { Padrão }\end{array}$ & Mínimo & Q1 & Mediana & Q3 & Máximo \\
\hline$\geq 35 \mathrm{mg} / \mathrm{dl}$ & 207 & 90,00 & 5,92 & 4,64 & 0 & 2,00 & 5,00 & 8,00 & 20 \\
\hline $\begin{array}{c}<35 \mathrm{mg} / \mathrm{dl} \\
\text { Total }\end{array}$ & $\begin{array}{r}23 \\
230 \\
\end{array}$ & $\begin{array}{c}10,00 \\
100,00\end{array}$ & 5,30 & 4,80 & 0 & 0 & 5,00 & 9,00 & 15 \\
\hline
\end{tabular}

Apêndice G.4 - Valores descritivos do CPO-D em função do colesterol LDL

\begin{tabular}{|c|c|c|c|c|c|c|c|c|c|}
\hline Colesterol LDL & $n$ & $\%$ & Media & $\begin{array}{l}\text { Desvio } \\
\text { Padrão }\end{array}$ & Mínimo & Q1 & Mediana & Q3 & Máximo \\
\hline$\leq 130 \mathrm{mg} / \mathrm{dl}$ & 210 & 91,30 & 5,73 & 4,45 & 0 & 2,00 & 5,00 & 8,00 & 20 \\
\hline $\begin{array}{c}>130 \mathrm{mg} / \mathrm{dl} \\
\text { Total }\end{array}$ & $\begin{array}{c}20 \\
230\end{array}$ & $\begin{array}{c}8,70 \\
100,00\end{array}$ & 7,20 & 6,35 & 0 & 2,50 & 5,50 & 10,00 & 19 \\
\hline
\end{tabular}


Apêndice G.5 - Valores descritivos do CPO-D em função da dislipidemia

\begin{tabular}{cccccccccc}
\hline Dislipidemia & $\mathbf{n}$ & $\%$ & Media & $\begin{array}{c}\text { Desvio } \\
\text { Padrão }\end{array}$ & Mínimo & Q1 & Mediana & Q3 & Máximo \\
\hline presente & 50 & 21,74 & 5,94 & 5,41 & 0 & 1,00 & 5,00 & 9,00 & 19 \\
ausente & 180 & 78,26 & 5,83 & 4,43 & 0 & 2,00 & 5,00 & 8,00 & 20 \\
Total & 230 & 100,00 & & & & & & & \\
\hline
\end{tabular}




\section{APÊNDICE H - Variáveis dietéticas}

Apêndice H.1 - Valores descritivos do CPO-D em função do consumo de carboidratos

\begin{tabular}{|c|c|c|c|c|c|c|c|c|c|}
\hline $\begin{array}{l}\text { Consumo de } \\
\text { carboidratos }\end{array}$ & $n$ & $\%$ & Media & $\begin{array}{l}\text { Desvio } \\
\text { Padrão }\end{array}$ & Mínimo & Q1 & Mediana & Q3 & Máximo \\
\hline $\begin{array}{l}>60 \% \text { em relação } \\
\text { às calorias totais }\end{array}$ & 45 & 19,56 & 6,87 & 5,97 & 0 & 2,00 & 5,00 & 11,00 & 20 \\
\hline $\begin{array}{l}\leq 60 \% \text { em relação } \\
\text { à calorias totais }\end{array}$ & 172 & 74,79 & 5,51 & 4,26 & 0 & 2,00 & 5,00 & 8,00 & 19 \\
\hline $\begin{array}{c}\text { NR } \\
\text { Total }\end{array}$ & $\begin{array}{c}13 \\
230 \\
\end{array}$ & $\begin{array}{c}5,65 \\
100,00\end{array}$ & 6,92 & 4,03 & 0 & 5,00 & 7,00 & 8,00 & 17 \\
\hline
\end{tabular}

Apêndice H.2 - Valores descritivos do CPO-D em função da média do consumo de lipídeos

\begin{tabular}{cccccccccc}
\hline $\begin{array}{c}\text { Consumo de } \\
\text { Lipideos }\end{array}$ & $\mathbf{n}$ & $\%$ & Media & $\begin{array}{c}\text { Desvio } \\
\text { Padrão }\end{array}$ & Mínimo & Q1 & Mediana & Q3 & Máximo \\
\hline alterado & 120 & 52,17 & 5,63 & 3,97 & 0 & 2,00 & 5,00 & 8,00 & 18 \\
limítrofe/normal & 97 & 42,17 & 6,00 & 5,46 & 0 & 1,00 & 5,00 & 9,00 & 20 \\
NR & 13 & 5,66 & 6,92 & 4,03 & 0 & 4,50 & 7,00 & 8,50 & 17 \\
Total & 230 & 100,00 & & & & & & & \\
\hline
\end{tabular}

Apêndice H.3 - Valores descritivos do CPO-D em função da média do consumo diário de calorias segundo peso, estatura, sexo e idade

\begin{tabular}{|c|c|c|c|c|c|c|c|c|c|}
\hline $\begin{array}{l}\text { Consumo de } \\
\text { calorias segundo } \\
\text { peso, estatura, } \\
\text { sexo e idade }\end{array}$ & $n$ & $\%$ & Media & $\begin{array}{l}\text { Desvio } \\
\text { Padrão }\end{array}$ & Mínimo & Q1 & Mediana & Q3 & Máximo \\
\hline Consome acima & 136 & 59,13 & 5,77 & 4,59 & 0 & 2,00 & 5,00 & 8,75 & 19 \\
\hline Normal & 81 & 35,22 & 5,84 & 4,87 & 0 & 2,00 & 5,00 & 9,00 & 20 \\
\hline $\begin{array}{l}\text { NR } \\
\text { Total }\end{array}$ & $\begin{array}{c}13 \\
230\end{array}$ & $\begin{array}{r}5,65 \\
100,00\end{array}$ & 6,92 & 4,03 & 0 & 4,50 & 7,00 & 8,50 & 17 \\
\hline
\end{tabular}


Apêndice H.4 - Valores descritivos do CPO-D em função da média do número de refeições que continham alimentos com sacarose

\begin{tabular}{cccccccccc}
\hline $\begin{array}{c}\text { refeição } \\
\text { sacarose }\end{array}$ & $\mathbf{n}$ & $\%$ & Media & $\begin{array}{c}\text { Desvio } \\
\text { Padrão }\end{array}$ & Mínimo & Q1 & Mediana & Q3 & Máximo \\
\hline$\leq 3,3$ refeições & 118 & 51,30 & 6,42 & 4,86 & 0 & 2,00 & 6,00 & 9,00 & 20 \\
$>3,3$ refeições & 100 & 43,48 & 5,01 & 4,31 & 0 & 1,00 & 4,50 & 7,00 & 19 \\
NR & 12 & 5,22 & 7,33 & 4,31 & 0 & 4,50 & 7,50 & 9,50 & 17 \\
Total & 230 & 100,00 & & & & & & & \\
\hline
\end{tabular}

Apêndice H.5 - Valores descritivos do CPO-D em função da média do consumo diário de refrigerante normal

\begin{tabular}{cccccccccc}
\hline $\begin{array}{c}\text { refrigerante } \\
\text { normal }\end{array}$ & $\mathbf{n}$ & $\%$ & Media & $\begin{array}{c}\text { Desvio } \\
\text { Padrão }\end{array}$ & Mínimo & Q1 & Mediana & Q3 & Máximo \\
\hline$<0,3$ & 76 & 33,04 & 5,62 & 4,62 & 0 & 2,00 & 5,00 & 8,00 & 19 \\
$\geq 0,3$ & 142 & 61,74 & 5,86 & 4,70 & 0 & 2,00 & 5,00 & 9,00 & 20 \\
NR & 12 & 5,22 & 7,33 & 4,13 & 0 & 4,50 & 7,50 & 9,50 & 17 \\
Total & 230 & 100,00 & & & & & & & \\
\hline
\end{tabular}

Apêndice H.6 - Valores descritivos do CPO-D em função da média do consumo diário de refrigerante diet/ light

\begin{tabular}{cccccccccc}
\hline $\begin{array}{c}\text { Refrigerante } \\
\text { diet/light }\end{array}$ & $\mathbf{n}$ & $\%$ & Media & $\begin{array}{c}\text { Desvio } \\
\text { Padrão }\end{array}$ & Mínimo & Q1 & Mediana & Q3 & Máximo \\
\hline Não consome & 192 & 83,48 & 5,67 & 4,57 & 0 & 2,00 & 5,00 & 8,00 & 20 \\
Consome & 26 & 11,30 & 6,58 & 5,35 & 0 & 2,00 & 6,50 & 10,00 & 18 \\
NR & 12 & 5,22 & 7,33 & 4,31 & 0 & 4,25 & 7,50 & 9,50 & 17 \\
Total & 230 & 100,00 & & & & & & & \\
\hline
\end{tabular}

Apêndice H.7 - Valores descritivos do CPO-D em função da média do consumo diário de salgadinhos

\begin{tabular}{cccccccccc}
\hline Salgadinhos & $\mathbf{n}$ & $\%$ & Media & $\begin{array}{c}\text { Desvio } \\
\text { Padrão }\end{array}$ & Mínimo & Q1 & Mediana & Q3 & Máximo \\
\hline Não consome & 180 & 78,26 & 5,71 & 4,60 & 0 & 2,00 & 5,00 & 8,50 & 20 \\
Consome & 38 & 16,52 & 6,11 & 5,00 & 0 & 2,00 & 5,50 & 8,00 & 19 \\
NR & 12 & 5,22 & 7,33 & 4,31 & 0 & 4,50 & 7,50 & 9,50 & 17 \\
Total & 230 & 100,00 & & & & & & & \\
\hline
\end{tabular}


Apêndice H.8 - Valores descritivos do CPO-D em função do número médio de refeições realizadas por dia

\begin{tabular}{|c|c|c|c|c|c|c|c|c|c|}
\hline $\begin{array}{c}\text { Número médio } \\
\text { de refeições } \\
\text { por dia }\end{array}$ & $\mathbf{n}$ & $\%$ & Media & $\begin{array}{l}\text { Desvio } \\
\text { Padrão }\end{array}$ & Mínimo & Q1 & Mediana & Q3 & Máximo \\
\hline $1 \mid-3$ & 12 & 5,22 & 6,75 & 6,02 & 0 & 2,00 & 5,50 & 9,75 & 19 \\
\hline $3 \mid-5$ & 97 & 42,17 & 5,73 & 4,60 & 0 & 2,00 & 5,00 & 8,50 & 20 \\
\hline $5 \mid-6$ & 48 & 20,87 & 5,63 & 4,72 & 0 & 1,00 & 5,50 & 7,75 & 17 \\
\hline$\geq 6$ & 60 & 26,06 & 5,83 & 4,53 & 0 & 2,00 & 5,00 & 8,75 & 19 \\
\hline $\begin{array}{c}\text { NR } \\
\text { Total }\end{array}$ & $\begin{array}{c}13 \\
230 \\
\end{array}$ & $\begin{array}{c}5,65 \\
100,00 \\
\end{array}$ & 6,92 & 4,39 & 0 & 4,00 & 7,00 & 9,50 & 17 \\
\hline
\end{tabular}




\section{APÊNDICE I - Variáveis dos hábitos alimentares}

Apêndice I.1 - Valores descritivos do CPO-D em função da freqüência do consumo semanal de refrigerantes

\begin{tabular}{|c|c|c|c|c|c|c|c|c|c|}
\hline $\begin{array}{c}\text { Consumo de } \\
\text { refrigerante (em } \\
\text { vezes) } \\
\end{array}$ & $\mathbf{n}$ & $\%$ & Media & $\begin{array}{l}\text { Desvio } \\
\text { Padrão }\end{array}$ & Mínimo & Q1 & Mediana & Q3 & Máximo \\
\hline 1 & 39 & 16,96 & 5,36 & 5,04 & 0 & 1,00 & 4,00 & 8,00 & 18 \\
\hline 2 a 3 & 111 & 48,26 & 5,87 & 4,58 & 0 & 2,00 & 6,00 & 9,00 & 19 \\
\hline 4 a 6 & 37 & 16,09 & 5,35 & 4,53 & 0 & 1,00 & 5,00 & 9,00 & 17 \\
\hline Todos os dias & 40 & 17,39 & 6,70 & 4,74 & 0 & 4,00 & 5,50 & 9,00 & 20 \\
\hline $\begin{array}{l}\text { NR } \\
\text { Total }\end{array}$ & $\begin{array}{c}3 \\
230\end{array}$ & $\begin{array}{c}1,30 \\
100,00\end{array}$ & 7,00 & 1,73 & 5 & 5,00 & 8,00 & 8,00 & 18 \\
\hline
\end{tabular}

Apêndice 1.2 - Valores descritivos do CPO-D em função da freqüência do consumo semanal de salgados

\begin{tabular}{|c|c|c|c|c|c|c|c|c|c|}
\hline $\begin{array}{c}\text { Consumo de } \\
\text { salgados (em } \\
\text { vezes) } \\
\end{array}$ & $\mathbf{n}$ & $\%$ & Media & $\begin{array}{l}\text { Desvio } \\
\text { Padrão }\end{array}$ & Mínimo & Q1 & Mediana & Q3 & Máximo \\
\hline 1 & 60 & 26,09 & 5,77 & 5,19 & 0 & 1,00 & 5,00 & 7,75 & 20 \\
\hline 2 a 3 & 123 & 53,48 & 5,23 & 4,18 & 0 & 2,00 & 5,00 & 8,00 & 19 \\
\hline 4 a 6 & 35 & 15,22 & 6,29 & 4,85 & 0 & 2,00 & 6,00 & 10,00 & 19 \\
\hline Todos os dias & 11 & 4,78 & 8,45 & 5,77 & 1 & 4,00 & 7,00 & 15,00 & 18 \\
\hline $\begin{array}{l}\text { NR } \\
\text { Total }\end{array}$ & $\begin{array}{c}1 \\
230\end{array}$ & $\begin{array}{c}0,43 \\
100,00\end{array}$ & 8,00 & * & 8 & * & 8,00 & * & 8 \\
\hline
\end{tabular}

Apêndice 1.3 - Valores descritivos do CPO-D em função da freqüência do consumo semanal de salgadinhos

\begin{tabular}{|c|c|c|c|c|c|c|c|c|c|}
\hline $\begin{array}{c}\text { Consumo de } \\
\text { salgadinhos (em } \\
\text { vezes) }\end{array}$ & $n$ & $\%$ & Media & $\begin{array}{l}\text { Desvio } \\
\text { Padrão }\end{array}$ & Mínimo & Q1 & Mediana & Q3 & Máximo \\
\hline NR & 5 & 2,17 & 7,20 & 6,61 & 0 & 1,50 & 6,00 & 13,50 & 17 \\
\hline 2 & 65 & 28,26 & 6,43 & 4,34 & 0 & 3,50 & 6,00 & 9.50 & 18 \\
\hline 3 & 7 & 3,05 & 8,14 & 5,34 & 2 & 5,00 & 8,00 & 9,00 & 19 \\
\hline $\begin{array}{c}4 \\
\text { Total }\end{array}$ & $\begin{array}{l}153 \\
230\end{array}$ & $\begin{array}{c}66,52 \\
100,00\end{array}$ & 5,46 & 4,67 & 0 & 1,00 & 5,00 & 8,00 & 20 \\
\hline
\end{tabular}


Apêndice 1.4 - Valores descritivos do CPO-D em função da freqüência do consumo semanal de lanches

\begin{tabular}{|c|c|c|c|c|c|c|c|c|c|}
\hline $\begin{array}{l}\text { Consumo de } \\
\text { lanches (em } \\
\text { vezes) }\end{array}$ & $\mathrm{n}$ & $\%$ & Media & $\begin{array}{l}\text { Desvio } \\
\text { Padrão }\end{array}$ & Mínimo & Q1 & Mediana & Q3 & Máximo \\
\hline 1 & 72 & 31,30 & 6,81 & 5,05 & 0 & 4,00 & 5,50 & 9,75 & 20 \\
\hline 2 a 3 & 124 & 53,91 & 5,17 & 4,18 & 0 & 1,25 & 5,00 & 8,00 & 19 \\
\hline 4 a 6 & 27 & 11,74 & 6,19 & 5,35 & 0 & 1,00 & 5,00 & 10,00 & 17 \\
\hline $\begin{array}{c}\text { Todos os dias } \\
\text { Total }\end{array}$ & $\begin{array}{c}7 \\
230\end{array}$ & $\begin{array}{c}3,04 \\
100,00\end{array}$ & 7,00 & 4,24 & 1 & 3,00 & 8,00 & 9,00 & 14 \\
\hline
\end{tabular}

Apêndice 1.5 - Valores descritivos do CPO-D em função da freqüência semanal do consumo de doces

\begin{tabular}{crrrrrrrrrr}
\hline $\begin{array}{c}\text { Consumo de } \\
\text { doces (em } \\
\text { vezes) }\end{array}$ & $\mathbf{n}$ & $\%$ & Media & $\begin{array}{c}\text { Desvio } \\
\text { Padrão }\end{array}$ & & & & & &
\end{tabular}

Apêndice 1.6 - Valores descritivos do CPO-D em função da freqüência semanal do consumo de balas

\begin{tabular}{|c|c|c|c|c|c|c|c|c|c|}
\hline $\begin{array}{c}\text { Consumo de } \\
\text { balas (em } \\
\text { vezes) }\end{array}$ & $n$ & $\%$ & Media & $\begin{array}{l}\text { Desvio } \\
\text { Padrão }\end{array}$ & Mínimo & Q1 & Mediana & Q3 & Máximo \\
\hline 1 & 22 & 9,57 & 5,05 & 5,31 & 0 & 0,75 & 4,00 & 7,25 & 20 \\
\hline 2 a 3 & 54 & 23,48 & 5,89 & 4,83 & 0 & 1,00 & 5,00 & 9,25 & 18 \\
\hline 4 a 6 & 47 & 20,43 & 6,09 & 4,57 & 0 & 2,00 & 5,00 & 9,00 & 18 \\
\hline 7 & 106 & 46,09 & 5,92 & 4,52 & 0 & 2,00 & 6,00 & 8,00 & 197 \\
\hline $\begin{array}{l}\text { NR } \\
\text { Total }\end{array}$ & $\begin{array}{c}1 \\
230 \\
\end{array}$ & $\begin{array}{c}0,43 \\
100,00\end{array}$ & 5,00 & * & 5 & * & 5,00 & * & 5 \\
\hline
\end{tabular}


Apêndice 1.7 - Valores descritivos do CPO-D em função da freqüência semanal do consumo de queijo

\begin{tabular}{|c|c|c|c|c|c|c|c|c|c|}
\hline $\begin{array}{c}\text { Consumo de } \\
\text { queijo (em } \\
\text { vezes) } \\
\end{array}$ & $\mathbf{n}$ & $\%$ & Media & $\begin{array}{l}\text { Desvio } \\
\text { Padrão }\end{array}$ & Mínimo & Q1 & Mediana & Q3 & Máximo \\
\hline 1 & 75 & 32,61 & 6,91 & 5,13 & 0 & 4,00 & 6,00 & 10,00 & 20 \\
\hline 2 a 3 & 91 & 39,57 & 5,18 & 5,26 & 0 & 1,00 & 5,00 & 8,00 & 18 \\
\hline 4 a 6 & 29 & 12,61 & 5,17 & 4,93 & 0 & 1,00 & 5,00 & 7,00 & 17 \\
\hline 7 & 29 & 12,61 & 5,69 & 4,09 & 1 & 3,00 & 5,00 & 7,00 & 19 \\
\hline $\begin{array}{c}\text { NR } \\
\text { Total }\end{array}$ & $\begin{array}{c}6 \\
230\end{array}$ & $\begin{array}{r}2,61 \\
100,00\end{array}$ & 7,17 & 3,82 & 1 & 3,25 & 9,00 & 9,50 & 11 \\
\hline
\end{tabular}




\section{APÊNDICE $\mathbf{J}$ - Variáveis comportamentais}

Apêndice J.1 - Valores descritivos do CPO-D em função do número de horas que assiste televisão por dia

\begin{tabular}{|c|c|c|c|c|c|c|c|c|c|}
\hline $\begin{array}{c}\text { Número de } \\
\text { horas que } \\
\text { assiste televisão } \\
\text { por dia } \\
\end{array}$ & $\mathrm{n}$ & $\%$ & Media & $\begin{array}{l}\text { Desvio } \\
\text { Padrão }\end{array}$ & Mínimo & Q1 & Mediana & Q3 & Máximo \\
\hline$<4$ horas & 187 & 81.30 & 5.99 & 4.74 & 0 & 2.00 & 5.00 & 9.00 & 20 \\
\hline $\begin{array}{c}\geq 4 \text { horas } \\
\text { Total }\end{array}$ & $\begin{array}{r}43 \\
230 \\
\end{array}$ & $\begin{array}{c}18.70 \\
100,00\end{array}$ & 5.26 & 4.23 & 0 & 1.00 & 5.00 & 7.00 & 16 \\
\hline
\end{tabular}

Apêndice J.2 - Valores descritivos do CPO-D em função do tempo transcorrido desde última visita ao dentista

\begin{tabular}{|c|c|c|c|c|c|c|c|c|c|}
\hline $\begin{array}{l}\text { Tempo desde } \\
\text { última visita } \\
\text { ao dentista }\end{array}$ & $\mathrm{n}$ & $\%$ & Media & $\begin{array}{l}\text { Desvio } \\
\text { Padrão }\end{array}$ & Mínimo & $\overline{Q 1}$ & Mediana & $\overline{Q 3}$ & Máximo \\
\hline$\leq 12$ meses & 120 & 52,17 & 6,82 & 4,90 & 0 & 3,00 & 6,50 & 7,50 & 19 \\
\hline $12 \mid-24$ meses & 45 & 19,57 & 5,53 & 4,30 & 0 & 2,00 & 5,00 & 8,00 & 18 \\
\hline$\geq$ que 24 meses & 62 & 26,96 & 4,32 & 4,10 & 0 & 1,00 & 4,00 & 6,00 & 20 \\
\hline $\begin{array}{c}\text { Nunca foi } \\
\text { Total }\end{array}$ & $\begin{array}{c}3 \\
230\end{array}$ & $\begin{array}{c}1,30 \\
100,00\end{array}$ & 4,00 & 2,70 & 1 & 1,00 & 5,00 & 6,00 & 6 \\
\hline
\end{tabular}

Apêndice J.3 - Valores descritivos do CPO-D em função do número de vezes que higieniza os dentes

\begin{tabular}{|c|c|c|c|c|c|c|c|c|c|}
\hline $\begin{array}{c}\text { Número de } \\
\text { vezes que } \\
\text { escova os dentes }\end{array}$ & $n$ & $\%$ & Media & $\begin{array}{l}\text { Desvio } \\
\text { Padrão }\end{array}$ & Mínimo & Q1 & Mediana & Q3 & Máximo \\
\hline $1 \mathrm{vez}$ & 16 & 6,52 & 10,60 & 5,82 & 0 & 7,00 & 10,00 & 17.00 & 18 \\
\hline 2 vezes & 70 & 30,43 & 5,37 & 4,40 & 0 & 2,00 & 5,00 & 9,00 & 20 \\
\hline $\begin{array}{c}\geq 3 \text { vezes } \\
\text { Total }\end{array}$ & $\begin{array}{l}144 \\
230\end{array}$ & $\begin{array}{c}62,61 \\
100,00\end{array}$ & 5,63 & 4,39 & 0 & 2,00 & 5,00 & 8,00 & 19 \\
\hline
\end{tabular}




\section{ANEXO A - PARECER DO COMITÊ DE ÉTICA EM PESQUISA - USP}

\section{Faculdade de Odontologia Universidade desão Paulo}

\author{
PARECER $n^{\circ}$ 205/02 \\ Protocolo 213/02
}

Com base em parecer de relator, o Comitê de Ética em Pesquisa, APROVOU o protocolo de pesquisa "Avaliação das condiçōes bucais de adolescentes obesos, eutróficos e de baixa estatura da Cidade de Săo Paulo", de responsabilidade da pesquisadora Cristina Giovannetti Del Conte Zardetto.

Tendo em vista a legislaçăo vigente, devem ser encaminhados a este Comitê relatórios referentes ao andamento da pesquisa em 16 de abril de 2003 e em 16 de outubro de 2003. Ao término da pesquisa, cópia do trabalho deve ser encaminhada a este CEP.

São Paulo, 16 de outubro de 2002

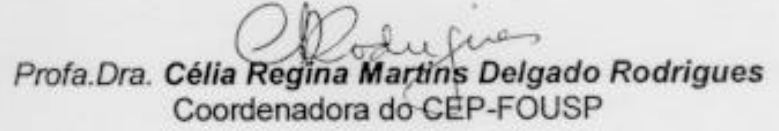

Av. Prof. Lineu Prestes, 2227 - Cidade Universitária "Armando de Salles Oliveira" CEP 05508-900 Săo Paulo - SP Diretoria Telefax (011) 38140062 - $30917817 / 60$ 


\section{ANEXO B - PARECER DO COMITÊ DE ÉTICA EM PESQUISA - UNIFESP - EPM}

IImo(a). Sr(a).

Pesquisador(a): EDSON TITO ROSETTI

Disciplina/Departamento: Nutrição e Metabolismo/Pediatria

Ref: Projeto de Pesquisa

Apoproteinas A-I e lipoproteina (a) em escolares obesos e não obesos, como fatores de risco para aterosclerose

O Comitê de Ética em Pesquisa da Universidade Federal de São Paulo/Hospital São Paulo ANALISOU e APROVOU o projeto acima.

Conforme resoluçăo $196 / 96$ do Conselho Nacional de Saúde säo deveres do pesquisador:

1. Comunicar toda e qualquer alteração do projeto e do termo de consentimento. Nestas circunstâncias a incłusăo de pacientes deve ser temporariamente interrompida até a resposta do Comitê, após análise das mudanças propostas. 2. Comunicar imediatamente ao Comitê qualquer evento adverso ocorrido durante 0 desenvolvimento do estudo.

3. Os dados individuais de todas as etapas da pesquisa devem ser mantidos em local seguro por 5 anos para possivel auditoria dos órgăos competentes.

4. Apresentar primeiro relatório parcial em 03/04/02

Atenciosamente,

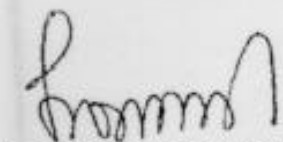

Prof. Dr. José Osmar Medina Pestana

Coordenador do Comitê de Ética em Pesquisa da Universidade Federal de São Paulo/Hospital São Paulo 